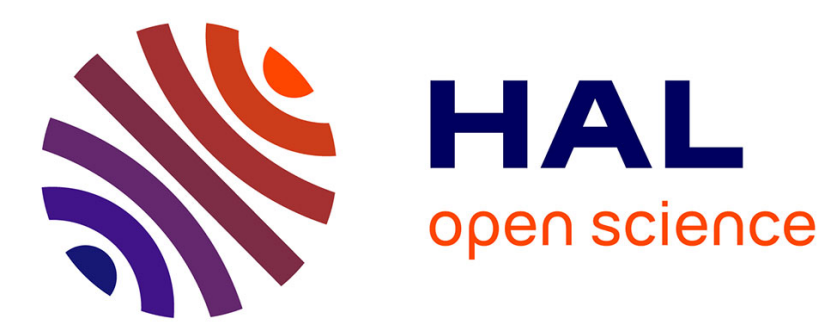

\title{
Pentafluorophenylphosphonic Acid as a New Building Block for Molecular Crystal Fabrication
}

Sylvain G Dutremez, Xavier Dumail, Sonia Mallet-Ladeira, Arie van Der Lee, Dominique Granier, Nathalie Masquelez, Jean-Sébastien Filhol

\section{- To cite this version:}

Sylvain G Dutremez, Xavier Dumail, Sonia Mallet-Ladeira, Arie van Der Lee, Dominique Granier, et al.. Pentafluorophenylphosphonic Acid as a New Building Block for Molecular Crystal Fabrication. Crystal Growth \& Design, 2021, 21 (4), pp.2028-2045. 10.1021/acs.cgd.0c01402 . hal-03193269

\section{HAL Id: hal-03193269 https://hal.science/hal-03193269}

Submitted on 8 Apr 2021

HAL is a multi-disciplinary open access archive for the deposit and dissemination of scientific research documents, whether they are published or not. The documents may come from teaching and research institutions in France or abroad, or from public or private research centers.
L'archive ouverte pluridisciplinaire HAL, est destinée au dépôt et à la diffusion de documents scientifiques de niveau recherche, publiés ou non, émanant des établissements d'enseignement et de recherche français ou étrangers, des laboratoires publics ou privés. 


\section{Pentafluorophenylphosphonic Acid as a New Building Block for Molecular Crystal Fabrication}

Sylvain G. Dutremez, ${ }^{*} \dagger$ Xavier Dumail,${ }^{\dagger}$ Sonia Mallet-Ladeira,${ }^{\ddagger}$ Arie van der Lee, ${ }^{\S}$ Dominique Granier, ${ }^{\|}$Nathalie Masquelez, ${ }^{\S}$ and Jean-Sébastien Filhol ${ }^{\perp}$

* Corresponding author. E-mail: dutremez@univ-montp2.fr; Fax: +33-4-67-14-38-52; Tel: +33-4-67-14-42-23; orcid.org/0000-0003-0765-3779.

$\dagger$ Institut Charles Gerhardt, UMR 5253 CNRS-ENSCM-UM, Equipe CMOS, Université de Montpellier, Bât. 17, CC 1701, Place Eugène Bataillon, 34095 Montpellier Cedex 5, France.

* Institut de Chimie de Toulouse (FR 2599), Université Paul Sabatier, 118 route de Narbonne, 31062 Toulouse Cedex 9, France.

§ Institut Européen des Membranes, UMR 5635 CNRS-ENSCM-UM, Université de Montpellier, Case Courrier 047, Place Eugène Bataillon, 34095 Montpellier Cedex 5, France.

"| Institut Charles Gerhardt, UMR 5253 CNRS-ENSCM-UM, Réseau Rayons X et Gamma, Université de Montpellier, Bât. 15, CC 0005, Place Eugène Bataillon, 34095 Montpellier Cedex 5, France.

$\perp$ Institut Charles Gerhardt, UMR 5253 CNRS-ENSCM-UM, Equipe CTMM, Université de Montpellier, Bât. 15, CC 1501, Place Eugène Bataillon, 34095 Montpellier Cedex 5, France. 
ABSTRACT: Molecular crystals have been prepared from pentafluorophenylphosphonic acid (4). These include $2 \mathrm{C}_{6} \mathrm{~F}_{5} \mathrm{PO}_{3} \mathrm{H}_{2} \cdot \mathrm{H}_{2} \mathrm{O} \quad\left(\mathbf{4 . 4 . \mathrm { H } _ { 2 } \mathrm { O } ) ,} \quad\left[\left(\mathrm{C}_{6} \mathrm{~F}_{5} \mathrm{PO}_{3} \mathrm{H}^{-}\right)\left(\mathrm{H}_{3} \mathrm{O}^{+}\right)\right] \cdot \mathrm{C}_{6} \mathrm{~F}_{5} \mathrm{PO}_{3} \mathrm{H}_{2}\right.$ $\left(4.4^{-} . \mathrm{H}_{3} \mathrm{O}^{+}\right), \quad\left[\left(\mathrm{C}_{6} \mathrm{~F}_{5} \mathrm{PO}_{3} \mathrm{H}^{-}\right)\left(\mathrm{NH}_{4}^{+}\right)\right] \cdot \mathrm{C}_{6} \mathrm{~F}_{5} \mathrm{PO}_{3} \mathrm{H}_{2} \quad\left(\mathbf{4 . 4} \mathbf{N}^{-} . \mathrm{NH}_{4}^{+}\right), \quad\left[\left(\mathrm{C}_{6} \mathrm{~F}_{5} \mathrm{PO}_{3} \mathrm{H}^{-}\right)\left(\mathrm{Me}_{2} \mathrm{NH}_{2}^{+}\right)\right]$ $\left(4^{-} . \mathrm{DMA}^{+}\right)$ $\left[\left(\mathrm{C}_{6} \mathrm{~F}_{5} \mathrm{PO}_{3} \mathrm{H}^{-}\right)\left(\mathrm{Me}_{2} \mathrm{NH}_{2}{ }^{+}\right)\right] \cdot \mathrm{H}_{2} \mathrm{O}$

$\left(4^{-}\right.$.DMA $\left.{ }^{+} . \mathrm{H}_{2} \mathrm{O}\right)$, $\left[\left(\mathrm{C}_{6} \mathrm{~F}_{5} \mathrm{PO}_{3} \mathrm{H}^{-}\right)\left(\mathrm{Me}_{2} \mathrm{NH}_{2}^{+}\right)\right] \cdot \mathrm{C}_{6} \mathrm{~F}_{5} \mathrm{PO}_{3} \mathrm{H}_{2} \quad\left(\mathbf{4 . 4}^{-} . \mathrm{DMA}^{+}\right), \quad\left[\left(\mathrm{C}_{6} \mathrm{~F}_{5} \mathrm{PO}_{3} \mathrm{H}^{-}\right)\left(\mathrm{Me}_{2} \mathrm{NH}_{2}^{+}\right)_{0.5}\left(\mathrm{NH}_{4}^{+}\right)_{0.5}\right]$ $\left(\mathbf{4}^{-} . \mathrm{DMA}^{+} . \mathrm{NH}_{4}{ }^{+}\right)$, and $\left[\left(\mathrm{C}_{6} \mathrm{~F}_{5} \mathrm{PO}_{3} \mathrm{H}^{-}\right)\left({ }^{+} \mathrm{H}_{3} \mathrm{NCH}_{2} \mathrm{CO}_{2} \mathrm{H}\right)\right] \quad\left(\mathbf{4}^{-} \cdot \mathbf{G l y}^{+}\right)$, where $\mathrm{DMA}^{+}=$ dimethylammonium and $\mathrm{Gly}^{+}=$glycinium. All of the assemblies incorporate an ammonium cation, a water molecule, or a hydronium ion in their structure, and these included species act as adhesive agents. They interact via $\mathrm{O} / \mathrm{N}-\mathrm{H} \cdots \mathrm{O}$ hydrogen bonds and $\mathrm{C}-\mathrm{H} \cdots \mathrm{O}$ contacts with $\mathrm{PO}_{3} \mathrm{H}_{2}$ or $\mathrm{PO}_{3} \mathrm{H}^{-}$moieties located in polar sheets, forcing the building blocks to assemble with a 2D layered arrangement. The robustness of this arrangement is reminiscent of that observed in metal arylphosphonates and guanidinium sulfonates, yet the architectures described herein differ significantly from the latter by two aspects, the lack of puckering of the layers and the absence of void spaces to accommodate solvent molecules. Interestingly, however, just like in guanidinium sulfonates, two structural types have been recognized depending on the size of the included species, a single-layer stacking motif and a bilayer stacking motif. Even though hydrogen bonding is the prevailing interaction in these systems, the use of perfluoroaryl groups is also central, as these moieties bring about weak C-F $\cdots \pi, \pi \cdots \pi, \mathrm{C}-\mathrm{F} \cdots \mathrm{F}-\mathrm{C}, \mathrm{C}-\mathrm{F} \cdots \mathrm{H}-\mathrm{C}$, and $\mathrm{O} / \mathrm{N}-\mathrm{H} \cdots \mathrm{F}-\mathrm{C}$ interactions that help increasing the cohesion of the non-polar regions. As a result, new architectures are created that differ in some cases significantly from those prepared from phenylphosphonic acid. But the weakness of perfluoroaryl-based interactions is also their strength, as these interactions are sufficiently flexible to allow changes in the organization of the aromatic groups in response to changes (ionization) occurring in the polar

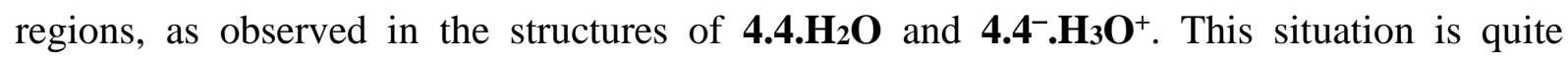
unusual and may be regarded as some kind of acidity-modulated polymorphism. The work presented here broadens the knowledge on molecular crystal formation with arylphosphonic acids, a research area largely dominated by carboxylic and sulfonic acids. Also, the computational evaluation of 4.4. $\mathrm{H}_{2} \mathrm{O}$ and $\mathbf{4 . 4}^{-} \cdot \mathrm{H}_{3} \mathrm{O}^{+}$described in this report suggests that this family of fluorinated compounds may show interesting prospects as molecular semiconductors, a research area that is currently receiving increased attention. 


\section{INTRODUCTION}

Metal phosphonates are an important class of materials with applications in fields as diverse as oxidation catalysis, magnetism, corrosion protection, surface modification of implants, nuclear waste treatment, and photoluminescence. ${ }^{1}$ These hybrid materials exhibit a wide range of architectures going from discrete species to clusters and extended networks. In this category of compounds, metal arylphosphonates occupy a special place due to the fact that a large number of them have a 2D layered arrangement in the solid state. Owing to this structural peculiarity, metal arylphosphonates are amenable to intercalation type reactions, exhibit ion exchange properties, can be used as heterogeneous acid catalysts, and show good prospects as proton conductors. ${ }^{1}$ Yet, despite the large body of literature available on these latter materials, only a limited number of papers have been published concerning the use of phenylphosphonic acid in crystal engineering studies. ${ }^{2-17}$ Even more surprising, just one report could be found concerning crystallographic characterization of fluorinated arylphosphonic acids, ${ }^{18}$ in sharp contrast with the fact that fluorine-containing molecules are now emerging as important building blocks for molecular assembly fabrication. ${ }^{19} \mathrm{We}$ wish to continue this theme here and report on the synthesis of molecular crystals ${ }^{20}$ derived from pentafluorophenylphosphonic acid (4) (Scheme 1). A related study was published a few years ago by Desiraju and co-workers on fluorobenzoic acids. ${ }^{21}$

The ultimate goal of this work was to graft diacid $\mathbf{4}$ onto metal oxide surfaces ${ }^{22,23}$ and then establish if these modified surfaces could bind substrates via arene-perfluoroarene, anion- $\pi$, and lone pair- $\pi$ interactions. ${ }^{24-38}$ Prior to doing that, however, we set about studying the crystallization of $\mathbf{4}$ with guests susceptible of giving host-guest complexes assembled by such interactions. Numerous attempts have been made, but regrettably, such assemblies could not be obtained. In particular, we have found that $\mathbf{4}$ did not form multi-component crystals with benzene, carbon tetrachloride, halides, and oxo anions. Instead, assemblies organized by hydrogen bonding were isolated that include $2 \quad \mathrm{C}_{6} \mathrm{~F}_{5} \mathrm{PO}_{3} \mathrm{H}_{2} \cdot \mathrm{H}_{2} \mathrm{O} \quad\left(\right.$ 4.4. $\mathrm{H}_{2} \mathrm{O}$ ), $\left[\left(\mathrm{C}_{6} \mathrm{~F}_{5} \mathrm{PO}_{3} \mathrm{H}^{-}\right)\left(\mathrm{H}_{3} \mathrm{O}^{+}\right)\right] \cdot \mathrm{C}_{6} \mathrm{~F}_{5} \mathrm{PO}_{3} \mathrm{H}_{2} \quad\left(\mathbf{4 . 4}^{-} . \mathrm{H}_{3} \mathrm{O}^{+}\right), \quad\left[\left(\mathrm{C}_{6} \mathrm{~F}_{5} \mathrm{PO}_{3} \mathrm{H}^{-}\right)\left(\mathrm{NH}_{4}^{+}\right)\right] \cdot \mathrm{C}_{6} \mathrm{~F}_{5} \mathrm{PO}_{3} \mathrm{H}_{2}$ $\left(\mathbf{4 . 4}^{-} . \mathrm{NH}_{4}^{+}\right), \quad\left[\left(\mathrm{C}_{6} \mathrm{~F}_{5} \mathrm{PO}_{3} \mathrm{H}^{-}\right)\left(\mathrm{Me}_{2} \mathrm{NH}_{2}^{+}\right)\right] \quad\left(\mathbf{4}^{-} . \mathrm{DMA}^{+}\right), \quad\left[\left(\mathrm{C}_{6} \mathrm{~F}_{5} \mathrm{PO}_{3} \mathrm{H}^{-}\right)\left(\mathrm{Me}_{2} \mathrm{NH}_{2}^{+}\right)\right] \cdot \mathrm{H}_{2} \mathrm{O}$ $\left(4^{-} . \mathrm{DMA}^{+} . \mathrm{H}_{2} \mathrm{O}\right), \quad\left[\left(\mathrm{C}_{6} \mathrm{~F}_{5} \mathrm{PO}_{3} \mathrm{H}^{-}\right)\left(\mathrm{Me}_{2} \mathrm{NH}_{2}^{+}\right)\right] \cdot \mathrm{C}_{6} \mathrm{~F}_{5} \mathrm{PO}_{3} \mathrm{H}_{2} \quad\left(\mathbf{4 . 4}^{-}\right.$. DMA $\left.{ }^{+}\right), \quad$ and $\left[\left(\mathrm{C}_{6} \mathrm{~F}_{5} \mathrm{PO}_{3} \mathrm{H}^{-}\right)\left(\mathrm{Me}_{2} \mathrm{NH}_{2}^{+}\right)_{0.5}\left(\mathrm{NH}_{4}^{+}\right)_{0.5}\right] \quad\left(\mathbf{4}^{-} . \mathbf{D M A}^{+} . \mathbf{N H}_{4}^{+}\right)$. Also, crystallization of $\mathbf{4}$ in the presence of glycine gave the salt $\left[\left(\mathrm{C}_{6} \mathrm{~F}_{5} \mathrm{PO}_{3} \mathrm{H}^{-}\right)\left({ }^{+} \mathrm{H}_{3} \mathrm{NCH}_{2} \mathrm{CO}_{2} \mathrm{H}\right)\right]\left(\mathbf{4}^{-} . \mathbf{G l y}^{+}\right)$that shows protonation of glycine instead of the awaited $\mathrm{COO}^{-} \ldots \mathrm{C}_{6} \mathrm{~F}_{5}$ interaction. All of the molecular 
crystals incorporate an ammonium cation, a water molecule, or a hydronium ion in their structure. Isolation of the hydronium-containing structure $\mathbf{4 . 4}^{-} . \mathrm{H}_{3} \mathrm{O}^{+}$was totally unexpected due to the existence of the neutral form 4.4. $\mathrm{H}_{2} \mathrm{O}$, yet computational evaluation of these two polymorphs at the DFT-D3 level provides energy and molecular orbital arguments that substantiate the validity of $\mathbf{4 . 4}^{-} \cdot \mathbf{H}_{3} \mathbf{O}^{+}$. This situation may be regarded as some kind of aciditymodulated polymorphism. As regards the ammonium cations present in $\mathbf{4 . 4}^{-}$. $\mathbf{N H}_{4}{ }^{+} \mathbf{4}^{-} . \mathbf{G l y}^{+}$, they originate from the salt or the guest molecule utilized in the co-crystallization experiment, or from decomposition of the $N, N$-dimethylformamide (DMF) solvent. Importantly, these included species act as adhesive agents, as they interact with the $\mathrm{PO}_{3}$ groups and create polar sheets, forcing the building blocks to assemble with a 2D layered arrangement. The robustness of this arrangement is reminiscent of that observed in metal arylphosphonates and guanidinium sulfonates, the main difference with the latter being the lack of puckering of the layers. $^{20,39-43}$ Interestingly, just like in guanidinium sulfonates, two structural types have been recognized: the first type consists of a single-layer stacking motif made of an alternation of polar and non-polar regions along the stacking direction. In this case, aryl groups protruding from a polar layer alternatively point upward or downward that layer and interdigitate with aromatic moieties from surrounding layers. The second structural type is bilayer stacking. In this case, all of the pentafluorophenyl groups protruding from a polar layer point in the same direction and do not interdigitate with neighboring aromatic moieties. As a result, two consecutive polar regions are separated from one another by two successive layers of $\mathrm{C}_{6} \mathrm{~F}_{5}$ groups, instead of just one in the single-layer stacking motif.

Even though hydrogen bonding is the prevailing interaction in these systems, the use of perfluoroaryl groups is clearly central, as these moieties bring about weak C-F $\cdots \pi, \pi \cdots \pi$, CF $\cdots$ F-C, C-F $\cdots$ H-C, and $\mathrm{O} / \mathrm{N}-\mathrm{H} \cdots \mathrm{F}-\mathrm{C}$ interactions that help increasing the cohesion of the nonpolar regions. As a result, new architectures are created that differ in some cases significantly from those prepared from phenylphosphonic acid. Also, compact structures are obtained that show no or prohibitively small void spaces to accommodate solvent molecules, in sharp contrast with guanidinium sulfonates. ${ }^{44-46}$ But the weakness of perfluoroaryl-based interactions is also their strength, as these interactions are sufficiently flexible to allow changes in the organization of the aromatic groups in response to changes (ionization) occurring in the polar regions, as observed in the structures of 4.4. $\mathrm{H}_{2} \mathrm{O}$ and $\mathbf{4 . 4}^{-} . \mathrm{H}_{3} \mathrm{O}^{+}$. This attribute is linked with the ability of the perfluoroaryl moieties to absorb part of the negative 
charge of the ionized phosphonate groups and to interact more strongly with the perfluoroaryl groups of the neutral phosphonic acid molecules.

The work presented here broadens the knowledge on molecular crystal formation with arylphosphonic acids, a research area largely dominated by carboxylic and sulfonic acids. In addition, the structural similarities that exist between derivatives of $\mathbf{4}$ and metal arylphosphonates suggest that the former materials may be worthy of further study in regard to proton conduction and ion exchange applications. Proton conductivity investigations of 4.4. $\mathrm{H}_{2} \mathrm{O}$ and $\mathbf{4 . 4}^{-} . \mathrm{H}_{3} \mathrm{O}^{+}$are currently underway and will be the focus of a separate report. ${ }^{47} \mathrm{In}$ connection with ion exchange applications, the exposed results set the ground for further studies aimed at assessing to which extent the use of other kinds of organic templates or metal cations modifies the architectures of the derivatives of $\mathbf{4}$, and if the use of biologically relevant amines is suitable for the preparation of multi-component assemblies of pharmaceutical significance. ${ }^{15,16,48,49}$ Last, the computational evaluation of 4.4.H2O and 4.4- . $_{3} \mathrm{O}^{+}$reported in this work suggests that this family of fluorinated compounds and their derivatives may show interesting prospects as molecular semiconductors, a research area that is currently receiving increased attention. ${ }^{50-52}$ 


\section{EXPERIMENTAL SECTION}

Characterization Methods. Solution ${ }^{1} \mathrm{H},{ }^{13} \mathrm{C},{ }^{19} \mathrm{~F},{ }^{29} \mathrm{Si}$, and ${ }^{31} \mathrm{P}$ NMR spectra were obtained on Bruker instruments of the following types: Avance DPX 200, AC 250, and Avance DRX 400. Chemical shifts were referenced as follows: ${ }^{1} \mathrm{H}$ (protio impurities of the NMR solvents), ${ }^{13} \mathrm{C}$ (NMR solvents), ${ }^{19} \mathrm{~F}\left(\mathrm{CFCl}_{3}\right),{ }^{29} \mathrm{Si}\left(\mathrm{Me}_{4} \mathrm{Si}\right),{ }^{31} \mathrm{P}\left(85 \% \mathrm{H}_{3} \mathrm{PO}_{4}\right)$. Solutionstate infrared spectra were recorded in the transmission mode on a Perkin Elmer 1600 Series FT-IR spectrometer with a $4 \mathrm{~cm}^{-1}$ resolution. Solid-state infrared spectra were recorded with a $4 \mathrm{~cm}^{-1}$ resolution on a PerkinElmer Spectrum Two FT-IR spectrometer equipped with a diamond crystal Attenuated Total Reflectance (ATR) unit. Electron impact (EI) mass spectra were obtained on a JEOL JMS-DX300 instrument and fast atom bombardment (FAB) spectra on a JEOL JMS-SX102 A machine. Coupled TGA-DSC experiments were conducted under a nitrogen flow $\left(100 \mathrm{~mL} \mathrm{~min}^{-1}\right)$ on a TA Instruments SDT-Q600 Simultaneous TGA / DSC apparatus, with a heating rate of $5 \mathrm{~K} / \mathrm{min}$. X-ray powder patterns were recorded on a PANalytical X'pert MPD-Pro diffractometer in the Bragg-Brentano $\theta-\theta$ reflection geometry with Ni-filtered $\mathrm{Cu} \mathrm{K \alpha}$ radiation $(\lambda=1.5418 \AA)$. Measurements were performed at room temperature in the $3-60^{\circ} 2 \theta$ range, using a step size of $0.033^{\circ}$ and a counting time per step of 240 s. Elemental analysis of $\mathbf{3}$ was carried out at the Service Central de Microanalyse of the Centre National de la Recherche Scientifique (CNRS), Vernaison, France, and that of $\mathbf{4}$ was performed in-house using an Elementar Vario Micro Cube apparatus.

Materials. The chemicals used in this study were obtained from the following commercial sources: magnesium turnings (Alfa Aesar), bromopentafluorobenzene (Alfa Aesar), diethyl chlorophosphite (Alfa Aesar), 30\% w/w solution of hydrogen peroxide in water (Fluka), iodotrimethylsilane (Alfa Aesar), magnesium sulfate (VWR), Celite ${ }^{\circledR}$ (SigmaAldrich), ammonium nitrate (Sigma-Aldrich), ammonium chloride (Alfa Aesar), glycine (Alfa Aesar). Solvents were purchased from the following suppliers: diethyl ether (Sigma-Aldrich), n-pentane (Carlo Erba), acetone (Sigma-Aldrich), dichloromethane (Carlo Erba), carbon tetrachloride (VWR), benzene (Alfa Aesar), methanol (Carlo Erba), N,N-dimethylformamide (Carlo Erba), 37\% w/w hydrochloric acid solution (VWR). Prior to use, diethyl ether was distilled over sodium-benzophenone ketyl. 
Synthesis. $\mathrm{C}_{6} \mathrm{~F}_{5} \mathrm{P}\left(\mathrm{OC}_{2} \mathrm{H}_{5}\right)_{2}(\mathrm{1})$. A 500 -mL flask equipped with a magnetic stir bar and a dropping funnel is charged with a $5.0 \mathrm{~g}$ portion of magnesium $(206 \mathrm{mmol})$. The setup is placed under an inert atmosphere of argon. The magnesium turnings are covered with $50 \mathrm{~mL}$ of dry diethyl ether. The dropping funnel is charged with a $25 \mathrm{~mL}$ portion of bromopentafluorobenzene $(201 \mathrm{mmol})$ via a syringe. A few drops of bromopentafluorobenzene are added to the flask to initiate the formation of the magnesium derivative. The bromopentafluorobenzene left in the funnel is diluted with $200 \mathrm{~mL}$ of anhydrous diethyl ether. This solution is added dropwise to the flask at such a pace that a gentle reflux is maintained. When the addition is complete, the reaction mixture is refluxed for $30 \mathrm{~min}$, and then it is allowed to reach room temperature with stirring.

In a second 500-mL flask, a solution containing $27 \mathrm{~mL}$ of diethyl chlorophosphite (188 mmol) in $150 \mathrm{~mL}$ of anhydrous diethyl ether is prepared. The pentafluorophenylmagnesium bromide solution is added dropwise via a canula to the diethyl chlorophosphite solution while keeping the temperature at $-60{ }^{\circ} \mathrm{C}$. The reaction mixture is stirred at $-60{ }^{\circ} \mathrm{C}$ for $2 \mathrm{~h}$, then at room temperature overnight. The solvent is removed in vacuo, resulting in the formation of a gelatinous solid. $n$-Pentane is added to the solid to precipitate the magnesium salts. The salts are removed by filtration through Celite ${ }^{\circledR}$, and then the solvent is removed in vacuo. This procedure is repeated a second time so as to ensure removal of the maximum amount of salts. The crude product is purified by vacuum distillation $\left(50-55{ }^{\circ} \mathrm{C}, 0.01\right.$ mbar). The target compound is isolated as a colorless liquid in $63 \%$ yield. NMR $\left({ }^{1} \mathrm{H},{ }^{31} \mathrm{P}\left\{{ }^{1} \mathrm{H}\right\}\right)$ and IR data for $\mathbf{1}$ can be found elsewhere. ${ }^{53}{ }^{19} \mathrm{~F}$ NMR $(376.5$ $\left.\mathrm{MHz}, \mathrm{CDCl}_{3}, \mathrm{ppm}\right): \delta-161.1$ (m, 2F; meta), -151.0 (t, ${ }^{3} J_{\mathrm{FF}}=20.3 \mathrm{~Hz}, 1 \mathrm{~F}$; para), -135.1 (m, 2F; ortho). ${ }^{13} \mathrm{C}$ NMR (100.6 MHz, $\left.\mathrm{CDCl}_{3}, \mathrm{ppm}\right): \delta 16.9\left(\mathrm{~d},{ }^{3} J_{\mathrm{PC}}=6 \mathrm{~Hz} ; \mathrm{CH}_{3}\right), 64.4\left(\mathrm{~d},{ }^{2} J_{\mathrm{PC}}=\right.$ $\left.15.4 \mathrm{~Hz} ; \mathrm{CH}_{2}\right), 115.3\left(\mathrm{dm},{ }^{1} J_{\mathrm{PC}}=55.7 \mathrm{~Hz}\right.$; ipso), $137.6\left(\mathrm{dm},{ }^{1} J_{\mathrm{CF}}=254 \mathrm{~Hz}\right.$; meta), $142.6(\mathrm{dm}$, ${ }^{1} J_{\mathrm{CF}}=256 \mathrm{~Hz}$; para), $147.1\left(\mathrm{dm},{ }^{1} J_{\mathrm{CF}}=249 \mathrm{~Hz}\right.$; ortho $)$ EI+ MS $(70 \mathrm{eV}) \mathrm{m} / z(\%): 288(17)$ $[M]^{+}, 243(38)\left[M-\mathrm{OCH}_{2} \mathrm{CH}_{3}\right]^{+}, 168(31)\left[\mathrm{C}_{6} \mathrm{~F}_{5} \mathrm{H}\right]^{+}, 121(11)\left[\mathrm{P}\left(\mathrm{OCH}_{2} \mathrm{CH}_{3}\right)_{2}\right]^{+}$.

$\mathrm{C}_{6} \mathrm{~F}_{5} \mathrm{P}(\mathrm{O})\left(\mathrm{OC}_{2} \mathrm{H}_{5}\right)_{2}(2)$. A 500 -mL flask equipped with a magnetic stir bar is charged with a $24.906 \mathrm{~g}$ portion of phosphonite $\mathbf{1}(86.5 \mathrm{mmol})$. Compound $\mathbf{1}$ is diluted with $200 \mathrm{~mL}$ of acetone. An $8 \mathrm{~mL}$ portion of hydrogen peroxide solution is added dropwise to the acetone solution while cooling the mixture with an ice bath. After addition is complete, stirring is continued overnight. Acetone is removed on a rotary evaporator. The remaining liquid is transferred into a separatory funnel. Water is added so as to increase the volume of the aqueous layer, and then the product is extracted with dichloromethane $(3 \times 50 \mathrm{~mL})$. The 
organic layers are combined and dried over magnesium sulfate. After removal of the drying agent and evaporation of the dichloromethane, the product is purified by vacuum distillation $\left(78-82{ }^{\circ} \mathrm{C}, 0.1 \mathrm{mbar}\right)$. Yield $=50 \%$. NMR $\left({ }^{1} \mathrm{H},{ }^{19} \mathrm{~F},{ }^{31} \mathrm{P}\left\{{ }^{1} \mathrm{H}\right\}\right)$, IR, and MS data for 2 have been reported previously. ${ }^{54,55}{ }^{13} \mathrm{C} \mathrm{NMR}\left(100.6 \mathrm{MHz}, \mathrm{CDCl}_{3}, \mathrm{ppm}\right): \delta 16.6\left(\mathrm{~d},{ }^{3} \mathrm{~J}_{\mathrm{PC}}=7 \mathrm{~Hz} ; \mathrm{CH}_{3}\right)$, $64.1\left(\mathrm{~d},{ }^{2} J_{\mathrm{PC}}=6 \mathrm{~Hz} ; \mathrm{CH}_{2}\right), 105.0\left(\mathrm{dm},{ }^{1} J_{\mathrm{PC}}=185 \mathrm{~Hz}\right.$; ipso), 138.1 (dm, ${ }^{1} J_{\mathrm{CF}} \approx 253 \mathrm{~Hz}$; meta), $144.4\left(\mathrm{dm},{ }^{1} J_{\mathrm{CF}} \approx 260 \mathrm{~Hz}\right.$; para), $147.8\left(\mathrm{dm},{ }^{1} J_{\mathrm{CF}} \approx 256 \mathrm{~Hz}\right.$; ortho).

$\mathrm{C}_{6} \mathrm{~F}_{5} \mathrm{P}(\mathrm{O})\left(\mathrm{OSiMe}_{3}\right)_{2}(3)$. A $250-\mathrm{mL}$ flask equipped with a magnetic stir bar is charged with a $5.353 \mathrm{~g}$ portion of phosphonate $2(17.6 \mathrm{mmol})$. Compound 2 is diluted with $100 \mathrm{~mL}$ of anhydrous dichloromethane. A $6 \mathrm{~mL}$ portion $(35 \mathrm{mmol}$ ) of iodotrimethylsilane (purity $=83 \%$ ) is added dropwise to the dichloromethane solution while cooling the mixture with an ice bath. Stirring near $0{ }^{\circ} \mathrm{C}$ is continued for 2 hours, and then the mixture is allowed to come to room temperature overnight. The volatiles are removed in vacuo with heating to $70{ }^{\circ} \mathrm{C}$, giving an oily brown solid. Yield $=86 \%$. ${ }^{1} \mathrm{H}$ NMR $\left(200.1 \mathrm{MHz}, \mathrm{CDCl}_{3}, \mathrm{ppm}\right): \delta 0.37\left(\mathrm{~s}, 18 \mathrm{H} ; \mathrm{CH}_{3}\right)$. ${ }^{19} \mathrm{~F}$ NMR (235.4 MHz, $\left.\mathrm{CDCl}_{3}, \mathrm{ppm}\right): \delta-160.7$ (m, 2F; meta), -148.2 (broad, 1F; para), -132.1 (m, 2F; ortho). ${ }^{13} \mathrm{C}$ NMR (100.6 MHz, $\left.\mathrm{CDCl}_{3}, \mathrm{ppm}\right): \delta 1.1\left(\mathrm{~s} ; \mathrm{CH}_{3}\right), 107.7\left(\mathrm{dm},{ }^{1} J_{\mathrm{PC}}=\right.$ $193 \mathrm{~Hz}$; ipso), 137.9 (dm, ${ }^{1} J_{\mathrm{CF}} \approx 254 \mathrm{~Hz}$; meta), 143.7 (dm, ${ }^{1} J_{\mathrm{CF}} \approx 259 \mathrm{~Hz}$; para), 147.2 (dm, ${ }^{1} J_{\mathrm{CF}} \approx 254 \mathrm{~Hz}$; ortho). ${ }^{31} \mathrm{P}\left(81.0 \mathrm{MHz}, \mathrm{CDCl}_{3}, \mathrm{ppm}\right): \delta-15.4(\mathrm{~m}) .{ }^{29} \mathrm{Si}\left(39.8 \mathrm{MHz}, \mathrm{CDCl}_{3}\right.$, ppm): $\delta+25.2(\mathrm{~s})$. IR $\left(\mathrm{CCl}_{4}, \mathrm{~cm}^{-1}\right): \tilde{v} 1255\left(\mathrm{~s}, \delta_{\mathrm{s}}\left(\mathrm{CH}_{3}\right)\right), 1228(\mathrm{~m}, \mathrm{v}(\mathrm{P}=\mathrm{O})), 1057(\mathrm{~s}, v(\mathrm{P}-\mathrm{O}-$ $\mathrm{Si})$ ). EI+ MS (70 eV) m/z (\%): $465(8)\left[M+\mathrm{Si}\left(\mathrm{CH}_{3}\right)_{3}\right]^{+}, 393(4)[M+\mathrm{H}]^{+}, 377(100)\left[M-\mathrm{CH}_{3}\right]^{+}$, 305 (13) $\left[M-\mathrm{CH}_{3}-\mathrm{Si}\left(\mathrm{CH}_{3}\right)_{3}+\mathrm{H}\right]^{+}, 73$ (92) $\left[\mathrm{Si}\left(\mathrm{CH}_{3}\right)_{3}\right]^{+}$. Anal. Calcd for $\mathrm{C}_{12} \mathrm{H}_{18} \mathrm{~F}_{5} \mathrm{O}_{3} \mathrm{PSi}_{2}$ (392.41): C, 36.73; H, 4.62; F, 24.21; P, 7.89. Found: C, 34.85; H, 4.32; F, 22.53; P, 8.05.

$\mathrm{C}_{6} \mathrm{~F}_{5} \mathrm{P}(\mathrm{O})(\mathrm{OH})_{2}(4)$. A 250 -mL flask equipped with a magnetic stir bar is charged with an $8.64 \mathrm{~g}$ portion of trimethylsilyl ester $3(22.0 \mathrm{mmol})$. Compound $\mathbf{3}$ is solubilized in $125 \mathrm{~mL}$ of dichloromethane. A $10 \mathrm{~mL}$ portion of water $(556 \mathrm{mmol})$ is added to the dichloromethane solution. The mixture is refluxed for $1 \mathrm{~h}$. Water is added so as to increase the volume of the aqueous layer, then this layer is separated from the organic phase. The aqueous layer is washed several times with dichloromethane. Phosphonic acid 4 is extracted by washing the aqueous phase with several portions of diethyl ether. Subsequently, the aqueous layer is saturated with sodium chloride and washed three more times with diethyl ether. The ether fractions are combined and dried over magnesium sulfate. A yellowish powder is recovered after removal of the drying agent and evaporation of the solvent. A white solid is obtained upon washing the yellowish powder with dichloromethane and drying in vacuo. Yield $=70 \%$. The X-ray powder pattern of the solid matches that of 4.4.H2O. DSC: $54.1-71.6{ }^{\circ} \mathrm{C}$ 
(endotherm, loss of water), $178{ }^{\circ} \mathrm{C}$ (endotherm, triple point). Literature melting point: 141$142{ }^{\circ} \mathrm{C} .{ }^{56,57}$ The ${ }^{1} \mathrm{H},{ }^{13} \mathrm{C}\left\{{ }^{19} \mathrm{~F}\right\},{ }^{19} \mathrm{~F}$, and ${ }^{31} \mathrm{P}$ NMR data of 4 in DMSO- $d_{6}$ can be found in ref. ${ }^{18}$ IR (ATR, cm $\left.{ }^{-1}\right): \tilde{v} 3250$ (v br, v(O-H) H2O $_{2}, 2788$ (v br, v(O-H) $1234(\mathrm{~m}, \mathrm{v}(\mathrm{P}=\mathrm{O})), 1027$ (s, v(P-OH)), 963 (vs, v(P-OH)). FAB+ MS (GT) m/z (\%): 993 (1) $[4 M+\mathrm{H}]^{+}, 745(5)[3 M+\mathrm{H}]^{+}, 497(33)[2 M+\mathrm{H}]^{+}, 249(100)[M+\mathrm{H}]^{+}$. Anal. Calcd for $\mathrm{C}_{6} \mathrm{H}_{2} \mathrm{~F}_{5} \mathrm{O}_{3} \mathrm{P} \cdot 0.5 \mathrm{H}_{2} \mathrm{O}$ (257.05): C, 28.04; H, 1.18; O, 21.78. Found: C, 27.82; H, 0.90; O, 21.52 .

Crystallization Experiments. 4.4. $\mathrm{H}_{2} \mathrm{O}$. About $50 \mathrm{mg}$ of acid 4 were dissolved in a 8$\mathrm{mL}$ portion of diethyl ether, and a $4-\mathrm{mL}$ portion of $\mathrm{CCl}_{4}$ was added to the solution. The mixture was allowed to evaporate slowly to dryness, giving colorless crystals. X-ray

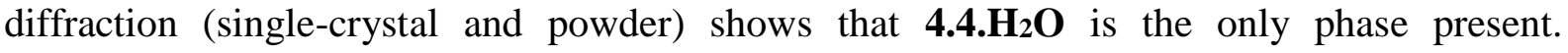
Alternatively, single crystals with the same lattice constants can be obtained upon crystallization of $\mathbf{4}$ from a 2:1 v/v mixture of diethyl ether and benzene.

4.4 $4^{-} \mathrm{H}_{3} \mathrm{O}^{+}$. Compound 4 was dissolved in a few milliliters of a concentrated hydrochloric acid solution. The clear solution was allowed to evaporate slowly to dryness, giving colorless crystals. X-ray diffraction (single-crystal and powder) indicates that a mixture of $\mathbf{4 . 4}^{-} . \mathrm{H}_{3} \mathrm{O}^{+}$and $\mathbf{4 . 4 .} \mathrm{H}_{2} \mathrm{O}$ is present.

4.4- $\mathrm{NH}_{4}^{+}$. Equimolar amounts of 4 and ammonium nitrate were dissolved in methanol. The resulting solution was allowed to evaporate slowly to dryness, giving colorless crystals.

4- $^{-} \mathbf{M A A}^{+}$. Compound 4 was dissolved in DMF. The solution was allowed to evaporate slowly to dryness, giving colorless crystals. X-ray crystallography shows that the crystals contain dimethylammonium cations due to decomposition of the solvent.

4- $^{-} \mathrm{DMA}^{+} . \mathrm{H}_{2} \boldsymbol{O}$. Compound 4 was dissolved in DMF. The solution was allowed to evaporate slowly to dryness, giving colorless crystals. X-ray crystallography shows that the structure contains dimethylammonium cations and water molecules.

4.4- DMA $^{+}$. Compound 4 was dissolved in DMF, and then a few drops of a concentrated hydrochloric acid solution were added. The mixture was allowed to evaporate slowly to dryness, giving colorless crystals.

$4^{-} . \mathrm{DMA}^{+} . \mathrm{NH}_{4}^{+}$. Equimolar amounts of $\mathbf{4}$ and ammonium chloride were dissolved in DMF. The resulting solution was allowed to evaporate slowly to dryness, giving colorless crystals. 
4-Gly+. Equimolar amounts of 4 and glycine were dissolved in water. The resulting solution was allowed to evaporate to dryness, giving colorless crystals.

Single-Crystal X-ray Diffraction. X-ray diffraction data were collected at low temperature (100(2) or 180(2) K) on a Bruker-AXS APEX II QUAZAR diffractometer equipped with a $30 \mathrm{~W}$ air-cooled microfocus source (for $\mathbf{4 . 4}^{-} . \mathbf{D M A}^{+}, \mathbf{4}^{-} . \mathbf{G l y}^{+}, \mathbf{4}^{-} . \mathbf{D M A}^{+} . \mathbf{H}_{2} \mathbf{O}$, 4.4- . $_{3} \mathrm{O}^{+}$, and $\mathbf{4 . 4}^{-} . \mathrm{NH}_{4}{ }^{+}$), or an Oxford Diffraction GEMINI EOS instrument (for 4-.DMA $^{+} . \mathbf{N H}_{4}{ }^{+}, \mathbf{4}^{-}$.DMA ${ }^{+}$, and 4.4.H $\left.\mathbf{2}\right)$. The Mo K $\alpha$ radiation $(\lambda=0.71073 \AA)$ was used in each experiment. The structures were solved by direct methods using SHELXS-97 ${ }^{58}$ or SIR92, ${ }^{59}$ and refinement was carried out by the least-squares method on $F^{2}$ with use of the SHELXL program. ${ }^{60}$ All non-hydrogen atoms were refined with anisotropic displacement parameters. Hydrogens bonded to carbon atoms were refined isotropically at calculated positions using the riding model. All $\mathrm{N}$-bound and $\mathrm{O}$-bound $\mathrm{H}$ atoms were located in difference Fourier maps. O-H distances for $\mathrm{H}_{3} \mathrm{O}^{+}$in $\mathbf{4 . 4}^{-} . \mathrm{H}_{3} \mathrm{O}^{+}$and water molecules in 4.4. $\mathrm{H}_{2} \mathrm{O}$ were restrained to $0.85(2) \AA$ with free $U_{\text {iso }}(\mathrm{H})$ values. Likewise, O-H distances of hydroxyl groups were restrained to $0.84(2) \AA$ in $\mathbf{4}^{-}$.DMA ${ }^{+}$and $\mathbf{4}^{-}$. $\mathbf{G l y}^{+}$, and N-H distances were restrained to $0.91(1) \AA$ in $\mathbf{4}^{-}$. $\mathbf{G l y}{ }^{+}$. For some hydrogen-bonded systems, the SADI instruction was used to make $\mathrm{O}-\mathrm{H}$ or $\mathrm{N}-\mathrm{H}$ distances approximately equal within a certain standard deviation. For $\mathbf{4}^{-}$. $\mathbf{D M A}^{+}$, a model was found in which the two independent pentafluorophenyl groups are disordered over two positions with occupancy factors close to 0.5. Similarity restraints on bond lengths and angles as well as on displacement parameters were used to model these disorders. For 4.4. $\mathbf{H}_{2} \mathrm{O}$, the crystal investigated was twinned, and the twin law $(100,0 \overline{1} 0,1 / 20 \overline{1})$ was determined by the TwinRotMat software implemented in PLATON. ${ }^{61}$ The two domains found were refined to a volume ratio of 30:70. Crystallographic parameters and basic information pertaining to data collection and structure refinement are summarized in Table 1. Structure drawings were done with OLEX2. ${ }^{62}$

Calculation Method. Computation of very soft materials with a cohesive energy mostly dominated by van der Waals forces, at finite temperature, is still a great challenge. It requires the use of a functional that includes dispersion contributions, and the utilization of zero-point energy and finite temperature corrections by means of a statistical physics approach. 
A 148-atom unit cell, $\mathrm{C}_{48} \mathrm{H}_{24} \mathrm{O}_{28} \mathrm{~F}_{40} \mathrm{P}_{8}$, and a 222-atom unit cell, $\mathrm{C}_{72} \mathrm{H}_{26} \mathrm{O}_{42} \mathrm{~F}_{60} \mathrm{P}_{12}$, were used to compute the structures of 4.4. $\mathrm{H}_{2} \mathrm{O}$ and $\mathbf{4 . 4}^{-} . \mathrm{H}_{3} \mathrm{O}^{+}$, respectively. Periodic electronic structure calculations were performed using density functional theory (DFT) within the PBE+D3 generalized gradient approximation. ${ }^{63}$ Projected augmented wave (PAW) pseudopotentials ${ }^{64,65}$ were utilized as implemented in the VASP code. ${ }^{66,67} \Gamma$-Centered $(3 \times 3 \times$ $2)$ and $(3 \times 2 \times 2) k$-point meshes with the high $k$-point density in the direction of the smallest unit cell parameter were employed respectively for the 4.4. $\mathrm{H}_{2} \mathrm{O}$ and $\mathbf{4 . 4}^{-} \cdot \mathbf{H}_{3} \mathrm{O}^{+}$polymorphs. The structures were computed using a $550 \mathrm{eV}$ cut-off (to account for the more electronegative oxygen and fluorine atoms and to properly describe electronic polarization) with optimization of the positions of all or just a part of the atoms present in the unit cell, with or without optimization of the lattice constants. For all of the calculations, the residual forces on optimized atoms were lower than $0.01 \mathrm{eV}^{-1}$. Vibrations were computed using finite displacements of $0.01 \AA$ to derive the dynamic matrix that was diagonalized to extract vibrational frequencies. Finite-temperature corrections and zero-point energies were calculated from phonons using a physical-statistical approach, and these data were used to obtain enthalpic and entropic vibrational contributions. 


\section{RESULTS}

Synthesis. Pentafluorophenylphosphonic acid (4) was synthesized as shown in Scheme 1. In a first step, pentafluorophenylmagnesium bromide is allowed to react with diethyl chlorophosphite in anhydrous diethyl ether to produce diethyl pentafluorophenylphosphonite $\mathbf{1}$. In a second step, phosphonite $\mathbf{1}$ is transformed into phosphonate $\mathbf{2}$ by oxidation with $\mathrm{H}_{2} \mathrm{O}_{2}$. Dealkylation of phosphonate $\mathbf{2}$ is next achieved by reaction with two equivalents of iodotrimethylsilane to generate bistrimethylsilyl ester $\mathbf{3}$. In a last step, hydrolysis of $\mathbf{3}$ gives smoothly phosphonic acid $\mathbf{4}$. The synthesis of phosphonite $\mathbf{1}$ is inspired from previous work by Namestnikov and colleagues. ${ }^{53}$ Phosphonate 2 is also a known compound that has been prepared in the past via a photochemical modification of the Arbuzov reaction using (EtO) $)_{3} \mathrm{P}$ and $\mathrm{C}_{6} \mathrm{~F}_{5} \mathrm{I}^{54}$ Alternatively, a two-step process can be used to make 2 that involves photochemical reaction between $(\mathrm{EtO})_{2} \mathrm{POP}(\mathrm{OEt})_{2}$ and $\mathrm{C}_{6} \mathrm{~F}_{5} \mathrm{I}$ to produce $\mathbf{1}$, followed by oxidation of $\mathbf{1}$ with $\mathrm{Me}_{3} \mathrm{COOH} .{ }^{55}$ As regards diacid 4, this compound can be obtained by hydrolysis of tetrafluoro(pentafluorophenyl)phosphorane. ${ }^{56}$ In addition, mechanistic studies show that 4 forms when solutions of $\mathrm{C}_{6} \mathrm{~F}_{5} \mathrm{PF}_{2}$ or $\mathrm{C}_{6} \mathrm{~F}_{5} \mathrm{P}\left(\mathrm{OCH}_{3}\right)_{2}$ are treated with $\mathrm{HSO}_{3} \mathrm{~F}$, followed by hydrolysis. ${ }^{57}$ Last, quite recently, an alternative strategy to prepare 4 was reported by a German group. ${ }^{18}$ The procedure involves the synthesis of bis(diethylamino)pentafluorophenylphosphane by the reaction between $\mathrm{C}_{6} \mathrm{~F}_{5} \mathrm{MgBr}$ and $\mathrm{ClP}\left(\mathrm{NEt}_{2}\right)_{2}$, followed by hydrolysis of $\mathrm{C}_{6} \mathrm{~F}_{5} \mathrm{P}\left(\mathrm{NEt}_{2}\right)_{2}$ with aqueous $\mathrm{HCl}$ to produce the corresponding phosphinic acid. In the last step, mild oxidation of the phosphinic acid with DMSO and catalytic quantities of iodine in methyl tert-butyl ether (MTBE) affords 4. Interestingly, in our hands, we have found that $\mathbf{4}$ crystallizes with half a mole of water per mole of acid, as proven by coupled TGA-DSC, infrared, and elemental analyses. Furthermore, the X-ray powder pattern of the as-synthesized material matches that of 4.4. $\mathbf{H}_{2} \mathrm{O}$ (vide infra). 
<smiles>CCOP(Cl)OCC</smiles><smiles>CCOP(OCC)c1c(F)c(F)c(F)c(F)c1F</smiles>

1<smiles>O=P(O)(O)c1c(F)c(F)c(F)c(F)c1F</smiles>

4<smiles>CCOP(=O)(OCC)c1c(F)c(F)c(F)c(F)c1F</smiles>

2 $\mathrm{Me}_{3} \mathrm{Sil}$ $\downarrow$

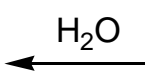<smiles>COP(=O)(OC)c1c(F)c(F)c(F)c(F)c1F</smiles>

3

Scheme 1. Synthesis of pentafluorophenylphosphonic acid (4).

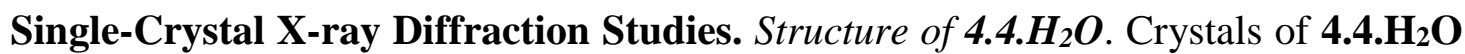
resulted from attempts to prepare inclusion compounds showing intermolecular $\mathrm{C}-\mathrm{Cl} \cdots \pi_{\mathrm{F}}$ and $\pi_{\mathrm{F}} \cdots \pi_{\mathrm{H}}$ contacts, ${ }^{24-27,35-38}$ by crystallization of $\mathbf{4}$ in the presence of $\mathrm{CCl}_{4}$ and benzene. X-ray diffraction reveals that the awaited assemblies did not form; instead, crystals with 2 $\mathrm{C}_{6} \mathrm{~F}_{5} \mathrm{PO}_{3} \mathrm{H}_{2}, \mathrm{H}_{2} \mathrm{O}$ as a formula moiety were obtained. This compound crystallizes in the triclinic space group $P \overline{1}$ with $Z=4$ (Table 1). There are four $\mathrm{C}_{6} \mathrm{~F}_{5} \mathrm{PO}_{3} \mathrm{H}_{2}$ molecules in the asymmetric unit and two water molecules. All of the components occupy general positions. Variable-temperature XRD measurements indicate that no phase transition occurs in the range $100-298 \mathrm{~K}$. 
Table 1. Crystal data and experimental details of data collection and refinement for phosphonic acid 4 and its derivatives.

\begin{tabular}{|c|c|c|c|c|c|c|c|c|}
\hline & 4.4. $\mathrm{H}_{2} \mathrm{O}$ & $4.4^{-} . \mathrm{H}_{3} \mathrm{O}^{+}$ & $4.4^{-} \cdot \mathrm{NH}_{4}{ }^{+}$ & $4^{-} . \mathrm{DMA}^{+}$ & $4^{-} . \mathrm{DMA}^{+} . \mathrm{H}_{2} \mathrm{O}$ & 4.4-. DMA $^{+}$ & $4^{-} . \mathrm{DMA}^{+} \cdot \mathrm{NH}_{4}{ }^{+}$ & $4^{-} . \mathrm{Gly}^{+}$ \\
\hline Formula sum & $\mathrm{C}_{12} \mathrm{H}_{6} \mathrm{~F}_{10} \mathrm{O}_{7} \mathrm{P}_{2}$ & $\mathrm{C}_{12} \mathrm{H}_{6} \mathrm{~F}_{10} \mathrm{O}_{7} \mathrm{P}_{2}$ & $\mathrm{C}_{12} \mathrm{H}_{7} \mathrm{~F}_{10} \mathrm{NO}_{6} \mathrm{P}_{2}$ & $\mathrm{C}_{8} \mathrm{H}_{9} \mathrm{~F}_{5} \mathrm{NO}_{3} \mathrm{P}$ & $\mathrm{C}_{8} \mathrm{H}_{11} \mathrm{~F}_{5} \mathrm{NO}_{4} \mathrm{P}$ & $\mathrm{C}_{14} \mathrm{H}_{11} \mathrm{~F}_{10} \mathrm{NO}_{6} \mathrm{P}_{2}$ & $\mathrm{C}_{7} \mathrm{H}_{7} \mathrm{~F}_{5} \mathrm{NO}_{3} \mathrm{P}$ & $\mathrm{C}_{8} \mathrm{H}_{7} \mathrm{~F}_{5} \mathrm{NO}_{5} \mathrm{P}$ \\
\hline Formula moiety & $\begin{array}{l}2 \mathrm{C}_{6} \mathrm{H}_{2} \mathrm{~F}_{5} \mathrm{O}_{3} \mathrm{P} \\
\mathrm{H}_{2} \mathrm{O}\end{array}$ & $\begin{array}{l}\mathrm{C}_{6} \mathrm{H}_{2} \mathrm{~F}_{5} \mathrm{O}_{3} \mathrm{P} \\
\mathrm{C}_{6} \mathrm{HF}_{5} \mathrm{O}_{3} \mathrm{P}, \mathrm{H}_{3} \mathrm{O}\end{array}$ & $\begin{array}{l}\mathrm{C}_{6} \mathrm{H}_{2} \mathrm{~F}_{5} \mathrm{O}_{3} \mathrm{P}, \\
\mathrm{C}_{6} \mathrm{HF}_{5} \mathrm{O}_{3} \mathrm{P}, \mathrm{H}_{4} \mathrm{~N}\end{array}$ & $\begin{array}{l}\mathrm{C}_{6} \mathrm{HF}_{5} \mathrm{O}_{3} \mathrm{P} \\
\mathrm{C}_{2} \mathrm{H}_{8} \mathrm{~N}\end{array}$ & $\begin{array}{l}\mathrm{C}_{6} \mathrm{HF}_{5} \mathrm{O}_{3} \mathrm{P}, \\
\mathrm{C}_{2} \mathrm{H}_{8} \mathrm{~N}, \mathrm{H}_{2} \mathrm{O}\end{array}$ & $\begin{array}{l}\mathrm{C}_{6} \mathrm{H}_{2} \mathrm{~F}_{5} \mathrm{O}_{3} \mathrm{P} \\
\mathrm{C}_{6} \mathrm{HF}_{5} \mathrm{O}_{3} \mathrm{P} \\
\mathrm{C}_{2} \mathrm{H}_{8} \mathrm{~N}\end{array}$ & $\begin{array}{l}\mathrm{C}_{6} \mathrm{HF}_{5} \mathrm{O}_{3} \mathrm{P}, 0.5 \\
\mathrm{C}_{2} \mathrm{H}_{8} \mathrm{~N}, 0.5 \mathrm{H}_{4} \mathrm{~N}\end{array}$ & $\begin{array}{l}\mathrm{C}_{6} \mathrm{HF}_{5} \mathrm{O}_{3} \mathrm{P} \\
\mathrm{C}_{2} \mathrm{H}_{6} \mathrm{NO}_{2}\end{array}$ \\
\hline $\begin{array}{l}\text { FW } \\
\text { Cryst color and } \\
\text { habit }\end{array}$ & $\begin{array}{l}514.11 \\
\text { colorless block }\end{array}$ & $\begin{array}{l}514.11 \\
\text { colorless stick }\end{array}$ & $\begin{array}{l}513.13 \\
\text { colorless needle }\end{array}$ & $\begin{array}{l}293.13 \\
\text { colorless block }\end{array}$ & $\begin{array}{l}311.15 \\
\text { colorless needle }\end{array}$ & $\begin{array}{l}541.18 \\
\text { colorless plate }\end{array}$ & $\begin{array}{l}279.11 \\
\text { colorless plate }\end{array}$ & $\begin{array}{l}323.12 \\
\text { colorless needle }\end{array}$ \\
\hline Cryst size $\left(\mathrm{mm}^{3}\right)$ & $\begin{array}{l}0.60 \times 0.50 \times \\
0.08\end{array}$ & $\begin{array}{l}0.20 \times 0.04 \times \\
0.04\end{array}$ & $\begin{array}{l}0.30 \times 0.04 \times \\
0.04\end{array}$ & $\begin{array}{l}0.20 \times 0.18 \times \\
0.16\end{array}$ & $\begin{array}{l}0.16 \times 0.02 \times \\
0.02\end{array}$ & $\begin{array}{l}0.16 \times 0.12 \times \\
0.04\end{array}$ & $\begin{array}{l}0.22 \times 0.18 \times \\
0.16\end{array}$ & $\begin{array}{l}0.08 \times 0.04 \times \\
0.02\end{array}$ \\
\hline Cryst system & triclinic & triclinic & triclinic & triclinic & orthorhombic & triclinic & monoclinic & monoclinic \\
\hline Space group & $P \overline{1}$ (No. 2) & $P \overline{1}$ (No. 2) & $P \overline{1}$ (No. 2) & $P \overline{1}$ (No. 2) & $P 2_{1} 2_{1} 2_{1}$ (No. 19) & $P \overline{1}$ (No. 2) & $C 2 / c$ (No. 15) & $P 2_{1}$ (No. 4) \\
\hline$a(\AA)$ & $9.5620(6)$ & $9.5498(9)$ & $6.2262(11)$ & $9.4823(3)$ & $4.7982(4)$ & $7.5369(4)$ & $19.0062(3)$ & $13.8013(10)$ \\
\hline$b(\AA)$ & $10.4839(6)$ & $15.7343(13)$ & $7.9166(15)$ & $10.5287(4)$ & $13.3696(11)$ & $7.7477(4)$ & $14.2003(2)$ & $4.8796(3)$ \\
\hline$c(\AA)$ & $16.8957(13)$ & $18.8613(16)$ & $17.480(3)$ & $11.8909(5)$ & $18.3914(15)$ & $18.7900(12)$ & $7.52600(10)$ & $17.0431(12)$ \\
\hline$\alpha\left(^{\circ}\right)$ & $85.308(5)$ & $112.232(3)$ & $87.040(6)$ & $90.295(3)$ & 90 & $85.025(3)$ & 90 & 90 \\
\hline$\beta\left(^{\circ}\right)$ & $81.885(6)$ & $91.645(3)$ & $83.550(6)$ & $92.806(3)$ & 90 & $85.276(3)$ & $91.2130(10)$ & $101.874(4)$ \\
\hline$\gamma\left(\left(^{\circ}\right)\right.$ & $89.935(4)$ & $103.024(3)$ & $83.599(5)$ & $95.155(3)$ & 90 & $61.828(3)$ & 90 & 90 \\
\hline$V\left(\AA^{3}\right)$ & 1671.07(19) & $2535.4(4)$ & $850.1(3)$ & $1180.87(8)$ & 1179.81(17) & $962.52(10)$ & $2030.77(5)$ & $1123.21(13)$ \\
\hline$Z$ & 4 & 6 & 2 & 4 & 4 & 2 & 8 & 4 \\
\hline$T(\mathrm{~K})$ & $193(2)$ & $100(2)$ & $100(2)$ & $180(2)$ & $100(2)$ & $180(2)$ & $100(2)$ & $180(2)$ \\
\hline
\end{tabular}




\begin{tabular}{|c|c|c|c|c|c|c|c|c|}
\hline$\rho_{\text {calcd }}\left(\mathrm{g} \mathrm{cm}^{-3}\right)$ & 2.043 & 2.02 & 2.005 & 1.649 & 1.752 & 1.867 & 1.826 & 1.911 \\
\hline$F(000)$ & 1016 & 1524 & 508 & 592 & 632 & 540 & 1120 & 648 \\
\hline$\mu\left(\mathrm{mm}^{-1}\right)$ & 0.408 & 0.403 & 0.398 & 0.299 & 0.311 & 0.357 & 0.343 & 0.337 \\
\hline$T_{\min }, T_{\max }$ & $0.86587,1.00000$ & $0.6987,0.7463$ & $0.6612,0.7461$ & $0.94463,1.00000$ & $0.6922,0.7461$ & $0.6977,0.7463$ & $0.93040,1.00000$ & $0.6921,0.7461$ \\
\hline$\theta$ range $\left(^{\circ}\right)$ & $2.979-29.588$ & $1.176-32.202$ & $1.173-25.35$ & $3.032-27.484$ & $2.215-30.533$ & $1.089-27.876$ & $2.869-27.877$ & $1.221-33.867$ \\
\hline \multirow[t]{3}{*}{ Index ranges } & $-13 \leq h \leq 12$ & $-14 \leq h \leq 14$ & $-7 \leq h \leq 7$ & $-12 \leq h \leq 12$ & $-6 \leq h \leq 6$ & $-9 \leq h \leq 9$ & $-24 \leq h \leq 24$ & $-21 \leq h \leq 21$ \\
\hline & $-14 \leq k \leq 14$ & $-23 \leq k \leq 23$ & $-9 \leq k \leq 9$ & $-13 \leq k \leq 13$ & $-19 \leq k \leq 19$ & $-10 \leq k \leq 10$ & $-18 \leq k \leq 18$ & $-7 \leq k \leq 7$ \\
\hline & $-22 \leq l \leq 23$ & $-28 \leq l \leq 28$ & $-21 \leq l \leq 21$ & $-15 \leq l \leq 15$ & $-26 \leq l \leq 26$ & $-24 \leq l \leq 24$ & $-9 \leq l \leq 9$ & $-26 \leq l \leq 26$ \\
\hline Data collected & 103215 & 99906 & 17962 & 40212 & 52102 & 34568 & 34397 & 27352 \\
\hline Unique data, $R_{\text {int }}$ & $68754,0.0390$ & $17748,0.0769$ & $3128,0.0493$ & $5405,0.041$ & $3607,0.0512$ & $4589,0.0439$ & $2425,0.0234$ & $8661,0.0336$ \\
\hline$<\sigma(I) / I\rangle^{a}$ & 0.0385 & 0.0689 & 0.0323 & 0.0276 & 0.0222 & 0.0266 & 0.0096 & 0.056 \\
\hline Obsd data $(I>$ & 50823 & 10945 & 2750 & 4213 & 3344 & 3732 & 2285 & 6316 \\
\hline \multicolumn{9}{|l|}{$2 \sigma(I))$} \\
\hline $\begin{array}{l}\text { L.S. params, } \\
\text { restraints }\end{array}$ & 600,26 & 910,4 & 301,15 & 539,730 & 192,0 & 315,4 & 172,1 & 391,11 \\
\hline $\begin{array}{l}R,^{b} R_{\mathrm{w}}^{c} \text { (obsd } \\
\text { reflns) }\end{array}$ & $0.046,0.1216$ & $0.0487,0.0992$ & $0.0804,0.2036$ & $0.0378,0.0882$ & $0.0262,0.0654$ & $0.0355,0.0804$ & $0.0249,0.0661$ & $0.0415,0.0834$ \\
\hline$R,{ }^{b} R_{\mathrm{w}}^{c}$ (all reflns) & $0.0641,0.138$ & $0.1022,0.1243$ & $0.0886,0.2076$ & $0.0564,0.0969$ & $0.0309,0.0679$ & $0.0477,0.0874$ & $0.0266,0.0673$ & $0.0707,0.0948$ \\
\hline \multirow[t]{3}{*}{$w^{d}$} & {$\left[\sigma^{2}\left(F_{\mathrm{o}}^{2}\right)+\right.$} & {$\left[\sigma^{2}\left(F_{\mathrm{o}}^{2}\right)+\right.$} & {$\left[\sigma^{2}\left(F_{\mathrm{o}}^{2}\right)+\right.$} & {$\left[\sigma^{2}\left(F_{\mathrm{o}}^{2}\right)+\right.$} & {$\left[\sigma^{2}\left(F_{\mathrm{o}}^{2}\right)+\right.$} & {$\left[\sigma^{2}\left(F_{\mathrm{o}}^{2}\right)+\right.$} & {$\left[\sigma^{2}\left(F_{\mathrm{o}}^{2}\right)+\right.$} & {$\left[\sigma^{2}\left(F_{\mathrm{o}}^{2}\right)+\right.$} \\
\hline & $(0.0597 P)^{2}+$ & $(0.0413 P)^{2}+$ & $(0.0425 P)^{2}+$ & $(0.0448 P)^{2}+$ & $(0.0333 P)^{2}+$ & $(0.0301 P)^{2}+$ & $(0.0319 P)^{2}+$ & $(0.0412 P)^{2}+$ \\
\hline & $1.4906 P]^{-1}$ & $1.8587 P]^{-1}$ & $11.8512 P]^{-1}$ & $0.4162 P]^{-1}$ & $0.3080 P]^{-1}$ & $0.7962 P]^{-1}$ & $2.3968 P]^{-1}$ & $0.1567 P]^{-1}$ \\
\hline Max shift/esd & 0.003 & 0.016 & 0 & 0.001 & 0.006 & 0.001 & 0.001 & 0.001 \\
\hline$S$ & 1.043 & 1.017 & 1.167 & 1.030 & 1.094 & 1.07 & 1.05 & 1.024 \\
\hline
\end{tabular}




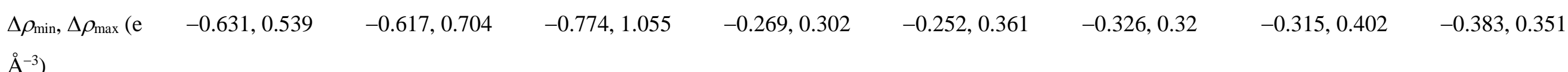

${ }^{a}<\sigma(I) / I>$ is the mean ratio of the experimental intensity standard deviation over the intensity for all reflections. ${ }^{b} R=\Sigma\left\|F_{\mathrm{o}}|-| F_{\mathrm{c}}\right\| / \Sigma\left|F_{\mathrm{o}}\right| .{ }^{c} R_{w}=\left[\Sigma\left(w\left(F_{\mathrm{o}}{ }^{2}-\right.\right.\right.$ $\left.\left.\left.F_{\mathrm{c}}^{2}\right)^{2}\right) / \Sigma\left(w\left(F_{\mathrm{o}}^{2}\right)^{2}\right)\right]^{1 / 2} \cdot{ }^{d} P=\left[F_{\mathrm{o}}^{2}+2 F_{\mathrm{c}}^{2}\right] / 3$. 
When viewing the structure down the $a$-axis, a bilayer stacking motif is evident (Figure 1). In this motif, each polar region made of $\mathrm{PO}_{3} \mathrm{H}_{3}$ groups and water molecules is separated from the next polar region by two non-interpenetrated layers of $\mathrm{C}_{6} \mathrm{~F}_{5}$ fragments. This stacking motif is reminiscent of that found in lipid bilayers. Also, a similar 2D arrangement has been reported recently for cadmium benzylphosphonate and several fluorinated derivatives. ${ }^{68}$ Water molecules are essential to ensure cohesion of the assembly. As can be seen from Figure 1, facing sheets of $\mathrm{PO}_{3} \mathrm{H}_{2}$ groups in the polar region are separated by one sheet of water molecules. Hydrogen-bonding interactions are observed between $\mathrm{PO}_{3} \mathrm{H}_{2}$ groups and water molecules (see Table S1 in the Supporting Information), but no interaction is detected between $\mathrm{PO}_{3} \mathrm{H}_{2}$ groups from facing layers. In the $a$-direction, $\mathrm{C}_{6} \mathrm{~F}_{5} \mathrm{PO}_{3} \mathrm{H}_{2}$ units arrange in columns due to $\mathrm{P}-\mathrm{OH} \cdots \mathrm{O}=\mathrm{P}$ hydrogen-bonding interactions (Table $\mathrm{S} 1$ ), and these columns are connected with one another by rows of water molecules along $b$. Two types of hydrogen-bond networks involving water molecules are found, $\mathrm{P}-\mathrm{OH} \cdots \mathrm{H}_{2} \mathrm{O} \cdots \mathrm{HO}-\mathrm{P}$ and $\mathrm{P}=\mathrm{O} \cdots \mathrm{HOH} \cdots \mathrm{O}=\mathrm{P}$ networks. The separation distance between water molecules along $a$ alternates between 4.794(4) and 4.801(4) $\AA$. The spacing between these molecules along $b$ is either 5.247(7) or 5.270(7) A. Thus, water molecules are isolated and show no interaction with their neighbors (no H-bonded water chains are noticed). The separation distance between mean $\mathrm{PO}_{3} \mathrm{H}_{2}$ planes from facing layers in the polar region is $4.056 \AA$, and the separation distances between the two mean $\mathrm{PO}_{3} \mathrm{H}_{2}$ planes and the mean water plane are about half of that

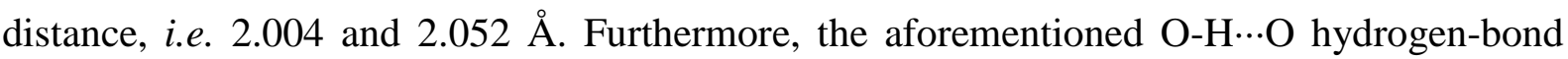
networks are supplemented by $\mathrm{C}-\mathrm{F} \cdots \mathrm{H}-\mathrm{O}$ interactions and $\mathrm{C}_{6} \mathrm{~F}_{5} \cdots \mathrm{C}_{6} \mathrm{~F}_{5}$ interactions. The geometrical parameters of the C-F...H-O interactions (Table S1) are in line with values previously reported for organics. ${ }^{26}$ Concerning $\mathrm{C}_{6} \mathrm{~F}_{5} \cdots \mathrm{C}_{6} \mathrm{~F}_{5}$ interactions, these interactions are

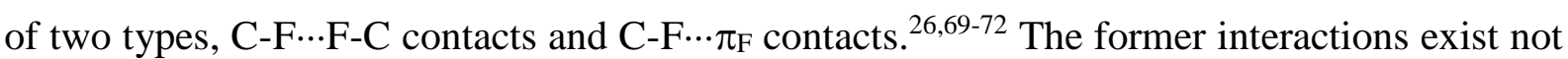
only between $\mathrm{C}_{6} \mathrm{~F}_{5}$ fragments located in the same layer, but also between $\mathrm{C}_{6} \mathrm{~F}_{5}$ fragments situated in facing layers. Type I and type II C-F...F-C interactions are both observed (Table S1). ${ }^{26,69-71}$ Interestingly, it must be pointed out that intermolecular interactions involving fluorine atoms, especially those of the F...F type, are more repulsive than attractive in nature, and this issue has been discussed in detail in two recent publications. ${ }^{73,74}$ As regards C-F $\cdots \pi_{\mathrm{F}}$ contacts, these interactions seem to be weak (Table S1). Certainly, they are much weaker than that observed in the structure of the anhydrous form of $\mathrm{C}_{6} \mathrm{~F}_{5} \mathrm{PO}_{3} \mathrm{H}_{2}$, for which a C-F... $\mathrm{Cg}$ distance of $3.279 \AA$ is measured with a C-F...Cg angle of $135.23^{\circ} .{ }^{18}$ 


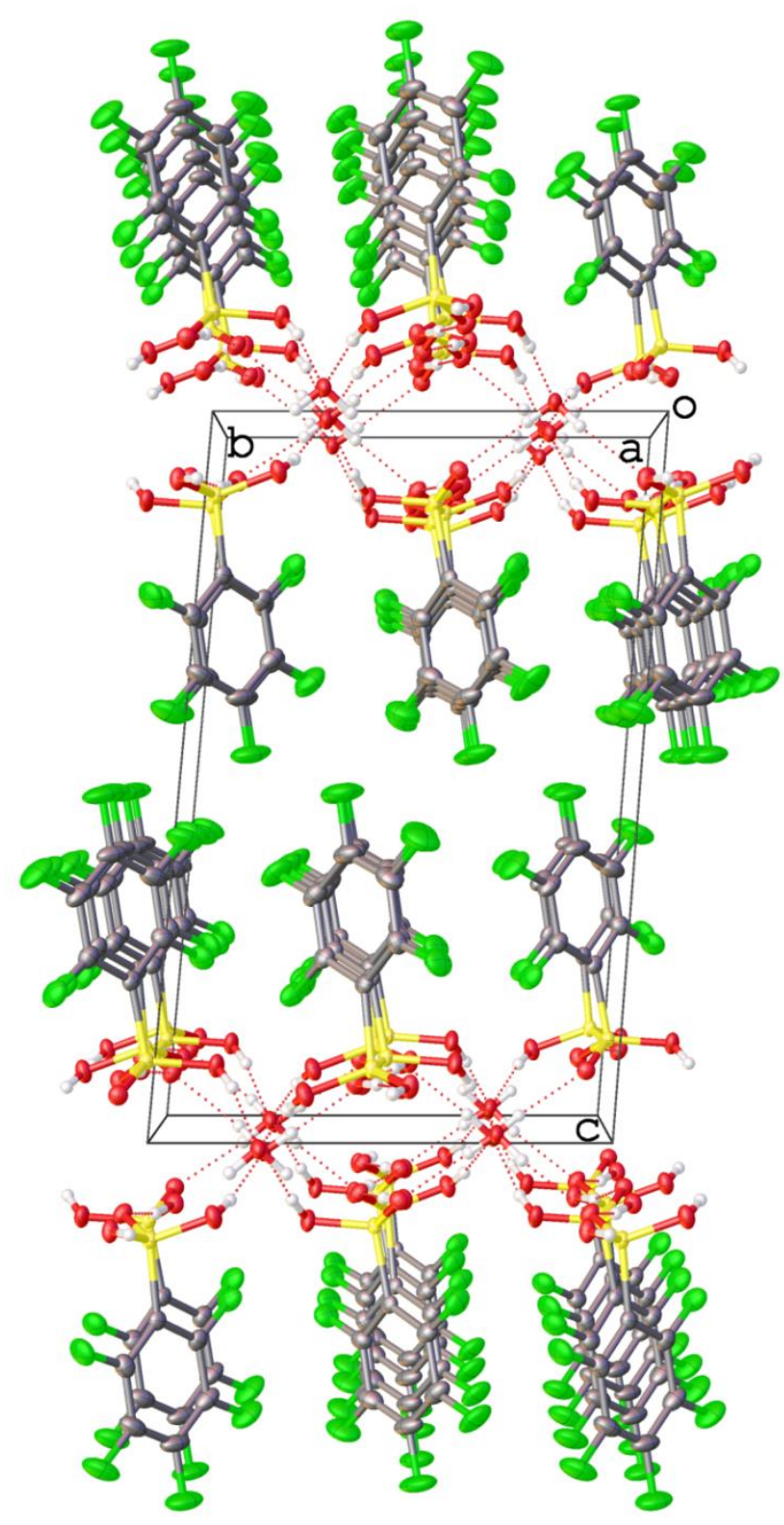

Figure 1. Unit cell of 4.4. $\mathrm{H}_{2} \mathrm{O}$ viewed along $a$ showing a bilayer stacking motif.

Serendipitous Discovery of a Polymorphic Structure of 4.4. $\mathrm{H}_{2} \mathrm{O}:$ 4.4 $^{-} \cdot \mathrm{H}_{3} \mathrm{O}^{+}$. The ability of $\mathbf{4}$ to self-assemble with chloride ions was tested by crystallization of the latter from a concentrated hydrochloric acid solution. Interestingly, single-crystal X-ray diffraction showed that the expected assembly did not form and, instead, crystals with $\mathrm{C}_{6} \mathrm{~F}_{5} \mathrm{PO}_{3} \mathrm{H}_{2}$, $\mathrm{C}_{6} \mathrm{~F}_{5} \mathrm{PO}_{3} \mathrm{H}^{-}, \mathrm{H}_{3} \mathrm{O}^{+}$as a formula moiety were obtained. The unexpected compound, $\mathbf{4 . 4}^{-} . \mathrm{H}_{3} \mathrm{O}^{+}$, crystallizes in the triclinic space group $P \overline{1}$ with $Z=6$ (Table 1). There are three $\mathrm{C}_{6} \mathrm{~F}_{5} \mathrm{PO}_{3} \mathrm{H}_{2}$ molecules in the asymmetric unit, three $\mathrm{C}_{6} \mathrm{~F}_{5} \mathrm{PO}_{3} \mathrm{H}^{-}$anions, and three hydronium cations. All 
of the components occupy general positions. Variable-temperature XRD measurements indicate that no phase transition occurs in the range 100-298 K.

4.4- . $_{3} \mathrm{O}^{+}$is a polymorph of 4.4.H2 $\mathrm{O}$ owing to protonation of the included water molecule by one phosphonic acid group. When viewing the structure down the $a$-axis (Figure 2), a bilayer stacking motif is visible that is similar to that encountered in the structure of 4.4. $\mathrm{H}_{2} \mathrm{O}$. In this motif, each polar region made of $\mathrm{PO}_{3} \mathrm{H}_{2}$ groups, $\mathrm{PO}_{3} \mathrm{H}^{-}$anions, and hydronium cations is separated from the next polar region by two non-interpenetrated layers of $\mathrm{C}_{6} \mathrm{~F}_{5}$ fragments. In the $a$-direction, $\mathrm{C}_{6} \mathrm{~F}_{5} \mathrm{PO}_{3} \mathrm{H}_{2}$ and $\mathrm{C}_{6} \mathrm{~F}_{5} \mathrm{PO}_{3} \mathrm{H}^{-}$units arrange in columns due to $\mathrm{P}-\mathrm{OH} \cdots \mathrm{O}=\mathrm{P} /{ }^{-} \mathrm{O}-\mathrm{P}$ hydrogen-bonding interactions (see Table $\mathrm{S} 2$ in the Supporting Information). Interestingly, all of the columns are not identical: one column out of three is made solely of $\mathrm{C}_{6} \mathrm{~F}_{5} \mathrm{PO}_{3} \mathrm{H}_{2}$ molecules, the next one of $\mathrm{C}_{6} \mathrm{~F}_{5} \mathrm{PO}_{3} \mathrm{H}^{-}$anions, and the third column is a mix of $\mathrm{C}_{6} \mathrm{~F}_{5} \mathrm{PO}_{3} \mathrm{H}_{2}$ and $\mathrm{C}_{6} \mathrm{~F}_{5} \mathrm{PO}_{3} \mathrm{H}^{-}$units. These three types of columns alternate along $b$. The columns are connected with one another by two types of hydrogen-bond networks, one involving exclusively phosphonate groups and one involving hydronium cations (Figure 2). Hydronium cations arrange in columns along $a$, just like water molecules do in the structure of 4.4. $\mathbf{H}_{2} \mathbf{O}$. Their spacing in this direction is either short (3.396(3) or 3.604(3) $\AA$ ), or long (6.002(3) or 6.247(3) $\AA$ ). In the $b$-direction, two types of hydronium rows are visible, one that alternates short (5.398(2) $\mathrm{A})$ and long (10.370(2) $\AA$ ) spacings, and one that has only very long spacings $(15.734(1) \AA$ ). But hydronium cations also function as glue between opposing sheets of $\mathrm{PO}_{3} \mathrm{H}_{2} / \mathrm{PO}_{3} \mathrm{H}^{-}$groups in the polar region. As can be seen from Figure 2, there is no direct hydrogen-bonding interaction between facing phosphonate groups in the polar region, but the layers are separated by and hydrogen-bonded to one sheet of hydronium cations. The separation distance between mean phosphonate planes from facing layers in the polar region is $4.385 \AA$, and the separation distances between the two mean phosphonate planes and the mean hydronium plane are about half of that distance, i.e. 2.176

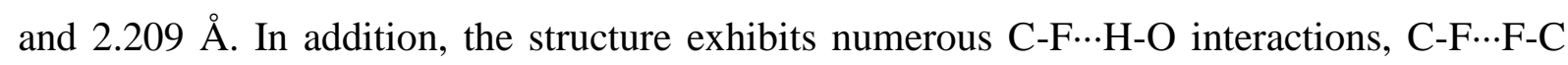

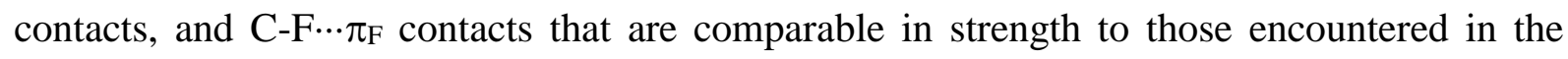
structure of 4.4.H2 $\mathrm{O}$ (Table S2). 


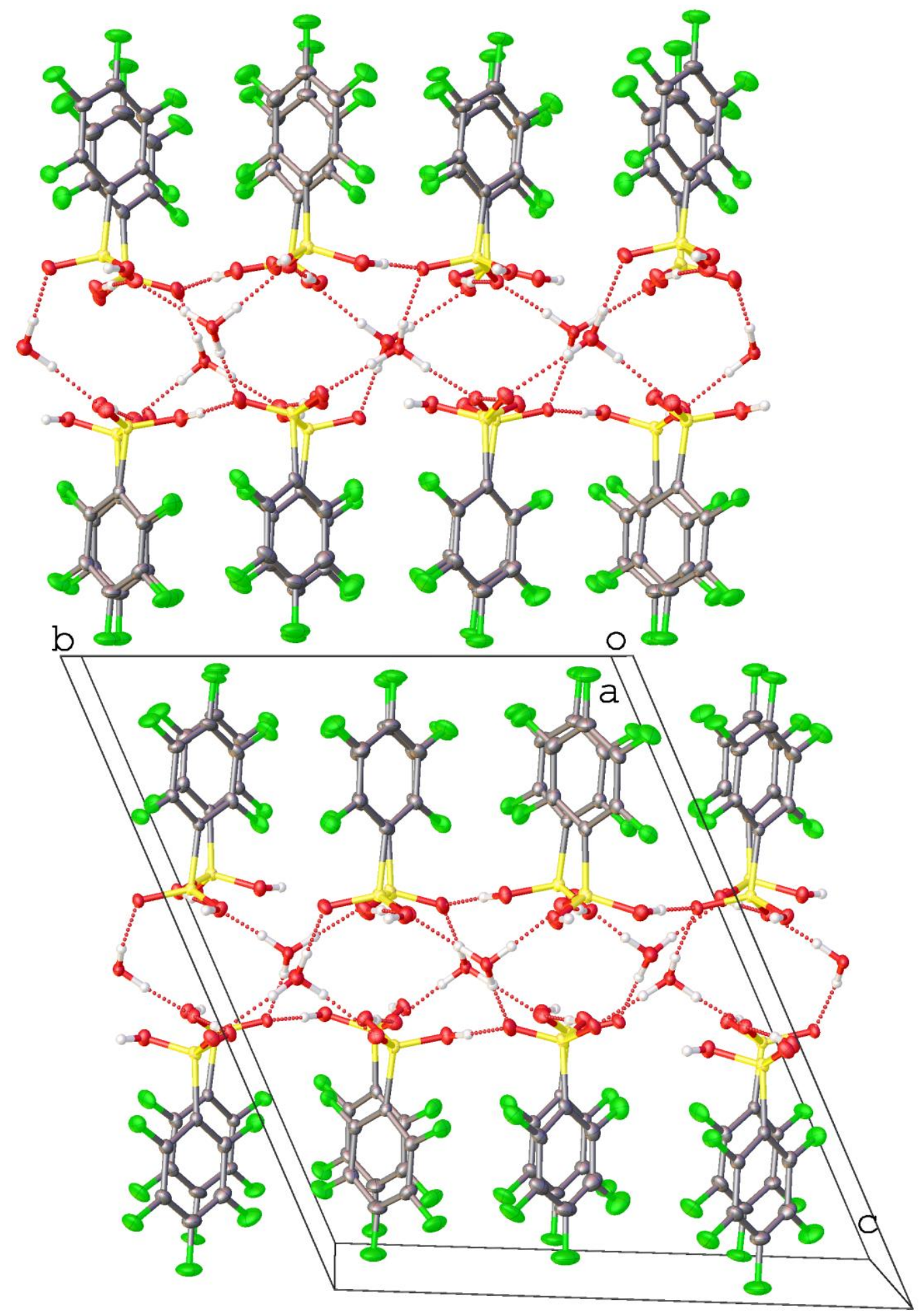

Figure 2. View along $a$ of $\mathbf{4 . 4}^{-} \cdot \mathbf{H}_{3} \mathrm{O}^{+}$showing a bilayer stacking motif.

Comparison of the Structure of 4.4. $\mathrm{H}_{2} \mathrm{O}$ with those of anhydrous 4 and $\mathrm{C}_{6} \mathrm{H}_{5} \mathrm{PO}_{3} \mathrm{H}_{2}$. Evidently, the structure of 4.4. $\mathrm{H}_{2} \mathrm{O}$ is quite different from that of anhydrous $\mathrm{C}_{6} \mathrm{~F}_{5} \mathrm{PO}_{3} \mathrm{H}_{2}$. The structure of 4.4. $\mathrm{H}_{2} \mathrm{O}$ consists of a succession of layers that are all parallel and perpendicular 
to the $c$-axis (Figure 1). The layers are made of either $\mathrm{PO}_{3} \mathrm{H}_{2}$ groups, or water molecules, or $\mathrm{C}_{6} \mathrm{~F}_{5}$ moieties. A layered A-B-A-B arrangement is evident when viewing the structure of anhydrous $\mathrm{C}_{6} \mathrm{~F}_{5} \mathrm{PO}_{3} \mathrm{H}_{2}$ along $a$, the layers piling up along $b$ (Figure 3). This time, however, each layer consists of columns of hydrogen-bonded $\mathrm{C}_{6} \mathrm{~F}_{5} \mathrm{PO}_{3} \mathrm{H}_{2}$ molecules. In each layer, the columns are all parallel and tilted with respect to the $b$-direction of the cell. In one layer out of two, the columns are tilted clockwise by $90^{\circ}$, and in the other layers the columns are tilted anticlockwise by the same amount. The main interaction that ensures cohesion between layers is $\mathrm{C}-\mathrm{F} \cdots \pi_{\mathrm{F}}$ contact (Figure 3). Clearly, the structural differences that exist between 4.4.H2O and anhydrous $\mathrm{C}_{6} \mathrm{~F}_{5} \mathrm{PO}_{3} \mathrm{H}_{2}$ is a consequence of the presence of water molecules in the former compound that keep the $\mathrm{PO}_{3} \mathrm{H}_{2}$ groups in the same plane.

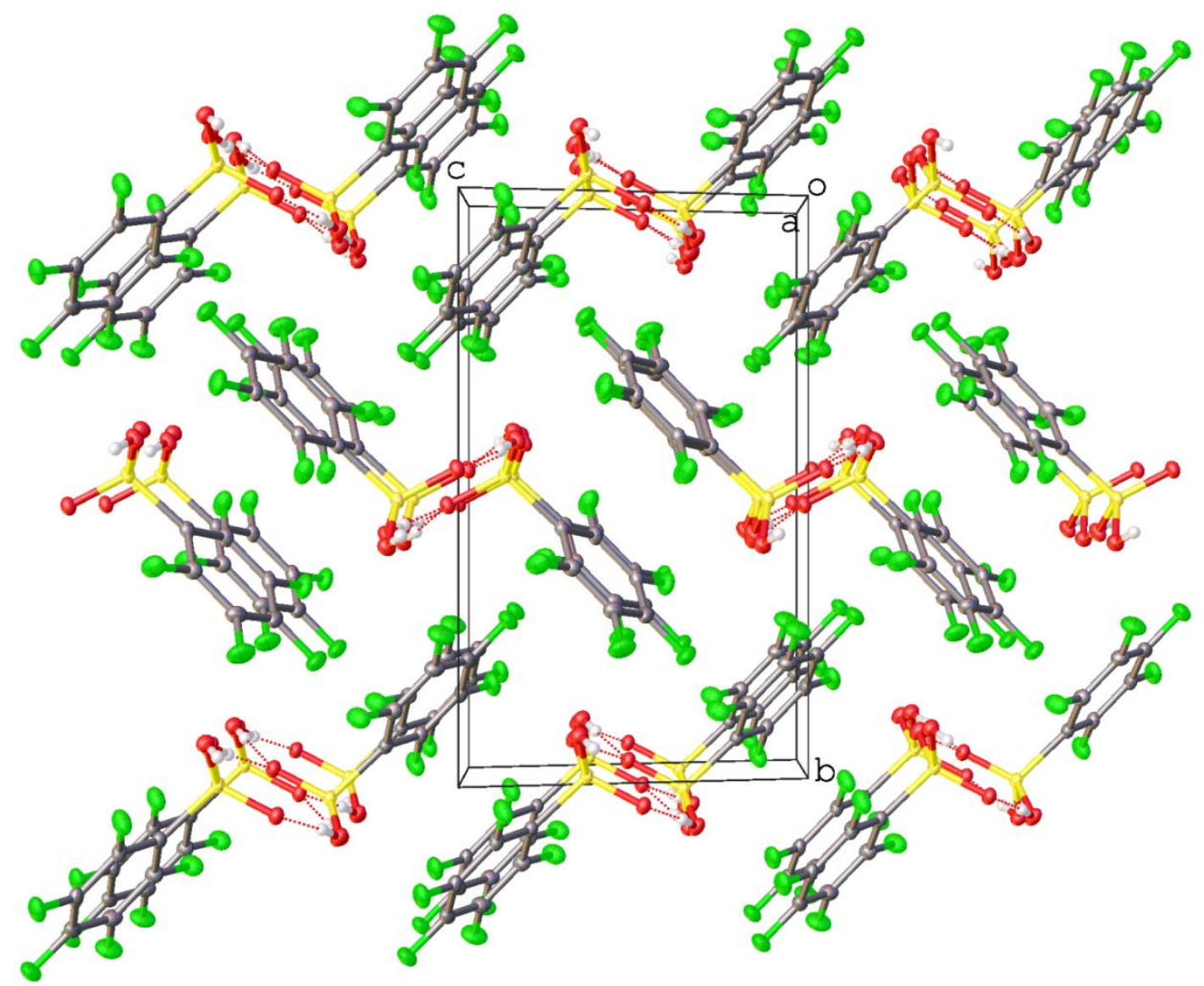

Figure 3. View of anhydrous $\mathrm{C}_{6} \mathrm{~F}_{5} \mathrm{PO}_{3} \mathrm{H}_{2}$ along $a$ showing a layered $\mathrm{A}-\mathrm{B}-\mathrm{A}-\mathrm{B}$ arrangement. ${ }^{18}$

The structure of 4.4. $\mathrm{H}_{2} \mathrm{O}$ is also quite different from that of $\mathrm{C}_{6} \mathrm{H}_{5} \mathrm{PO}_{3} \mathrm{H}_{2}$. First, unlike 4.4. $\mathrm{H}_{2} \mathrm{O}, \mathrm{C}_{6} \mathrm{H}_{5} \mathrm{PO}_{3} \mathrm{H}_{2}$ crystallizes with a single-layer stacking motif, i.e., the structure consists of a succession of polar regions made of $\mathrm{PO}_{3} \mathrm{H}_{2}$ moieties and non-polar regions made of 
phenyl groups piling up along $c$ (Figure 4). Secondly, there is no water molecule in the crystal lattice of $\mathrm{C}_{6} \mathrm{H}_{5} \mathrm{PO}_{3} \mathrm{H}_{2}$, so the polar region is quite compact. Specifically, in that region, the mean separation distance between facing phosphonate planes is $2.151 \AA$ at $183 \mathrm{~K}$ and $2.204 \AA$ at $295 \mathrm{~K}^{2,3}$ Yet, in an analogous fashion to 4.4. $\mathrm{H}_{2} \mathrm{O}$, the structure of $\mathrm{C}_{6} \mathrm{H}_{5} \mathrm{PO}_{3} \mathrm{H}_{2}$ exhibits numerous $\mathrm{C}-\mathrm{H} \cdots \pi$ interactions that ensure cohesion of the non-polar region.

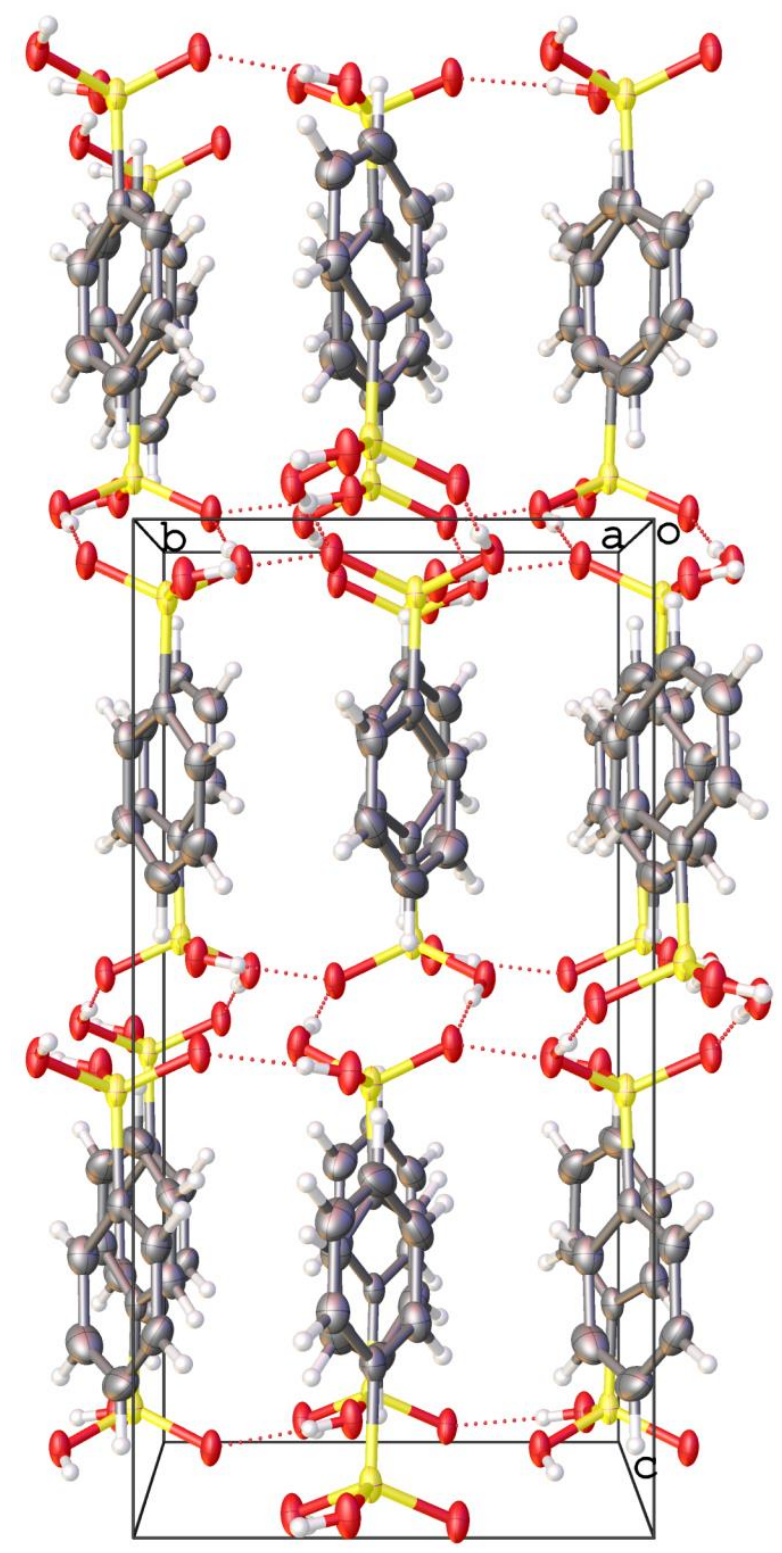

Figure 4. View along $a$ showing the single-layer stacking motif present in $\mathrm{C}_{6} \mathrm{H}_{5} \mathrm{PO}_{3} \mathrm{H}_{2}{ }^{3}$

Structure of . $^{-}{ }^{-} \mathrm{NH}_{4}{ }^{+}$. The ability of 4 to interact with nitrate ions was also tested by crystallization of the latter in the presence of ammonium nitrate. ${ }^{28,29,33}$ Crystals of $\mathbf{4 . 4}^{-} . \mathbf{N H}^{+}$ were obtained that have $\mathrm{C}_{6} \mathrm{~F}_{5} \mathrm{PO}_{3} \mathrm{H}_{2}, \mathrm{C}_{6} \mathrm{~F}_{5} \mathrm{PO}_{3} \mathrm{H}^{-}, \mathrm{NH}_{4}{ }^{+}$as an empirical formula. 4.4 $\mathbf{4}^{-} \mathbf{N H}_{4}^{+}$ 
crystallizes in the triclinic space group $P \overline{1}$ with $Z=2$ (Table 1). There is one $\mathrm{C}_{6} \mathrm{~F}_{5} \mathrm{PO}_{3} \mathrm{H}_{2}$ molecule in the asymmetric unit, one $\mathrm{C}_{6} \mathrm{~F}_{5} \mathrm{PO}_{3} \mathrm{H}^{-}$anion, and one ammonium cation. All of the components occupy general positions.

When viewing the structure down the $a$-axis (Figure 5), a bilayer stacking motif is visible that is similar to those encountered in the structures of $4.4 . \mathrm{H}_{2} \mathrm{O}$ and $\mathbf{4 . 4}^{-} \cdot \mathrm{H}_{3} \mathrm{O}^{+}$. In this motif, each polar region made of $\mathrm{PO}_{3} \mathrm{H}_{2}$ groups, $\mathrm{PO}_{3} \mathrm{H}^{-}$anions, and ammonium cations is separated from the next polar region by two non-interpenetrated layers of $\mathrm{C}_{6} \mathrm{~F}_{5}$ fragments. Organization of the building blocks in the lattice of $\mathbf{4 . 4}^{-} . \mathbf{N H}_{4}+$ is reminiscent of that found in 4.4- . $_{3} \mathrm{O}^{+}$. Similarly to $\mathbf{4 . 4}^{-} \cdot \mathrm{H}_{3} \mathrm{O}^{+}, \mathrm{C}_{6} \mathrm{~F}_{5} \mathrm{PO}_{3} \mathrm{H}_{2}$ and $\mathrm{C}_{6} \mathrm{~F}_{5} \mathrm{PO}_{3} \mathrm{H}^{-}$units arrange in columns in the $a$-direction, with one column out of two made solely of $\mathrm{C}_{6} \mathrm{~F}_{5} \mathrm{PO}_{3} \mathrm{H}_{2}$ molecules, and the next one containing only $\mathrm{C}_{6} \mathrm{~F}_{5} \mathrm{PO}_{3} \mathrm{H}^{-}$anions. These two types of columns alternate along $b$. In these columns, $\mathrm{C}_{6} \mathrm{~F}_{5} \mathrm{PO}_{3} \mathrm{H}_{2}$ molecules and $\mathrm{C}_{6} \mathrm{~F}_{5} \mathrm{PO}_{3} \mathrm{H}^{-}$anions are all parallel but do not interact with another. The separation distance between them is $6.226(1) \AA$, i.e. the length of the $a$-axis. The columns are connected with one another by two types of hydrogen-bond networks, one involving exclusively phosphonate groups and one involving ammonium cations (Figure 5). Ammonium cations arrange in columns along $a$, just like hydronium cations do in the structure of $\mathbf{4 . 4}^{-} \cdot \mathbf{H}_{3} \mathrm{O}^{+}$. Their spacing in this direction is 6.226(1) $\AA$. In the $b$ direction, the separation distance between ammonium cations is 7.917(2) $\AA$. As can be seen from Figure 5, each ammonium cation in the polar region is kept in place tightly by four hydrogen bonds with nearby oxygen atoms; three strong hydrogen bonds are detected and a weaker one (Table S3). Thus, similarly to $\mathbf{4 . 4}^{-} . \mathbf{H}_{3} \mathrm{O}^{+}$, ammonium cations serve as bridges between $\mathrm{C}_{6} \mathrm{~F}_{5} \mathrm{PO}_{3} \mathrm{H}_{2}$ and $\mathrm{C}_{6} \mathrm{~F}_{5} \mathrm{PO}_{3} \mathrm{H}^{-}$columns and keep opposing sheets of $\mathrm{PO}_{3} \mathrm{H}_{2} / \mathrm{PO}_{3} \mathrm{H}^{-}$ groups in close vicinity in the polar region. No interaction is detected between phosphonate groups from facing layers. The separation distance between mean phosphonate planes from facing layers in the polar region is $4.474 \AA$, and the separation distance between each mean phosphonate plane and the mean ammonium plane is half of that distance, i.e. $2.237 \AA$. In addition, the structure exhibits several C-F..H-O interactions, C-F $\cdots$ F-C contacts, and C$\mathrm{F} \cdots \pi_{\mathrm{F}}$ contacts that are comparable in strength to those encountered in the structures of

\section{4. $\mathrm{H}_{2} \mathrm{O}$ and 4.4 $^{-} \cdot \mathrm{H}_{3} \mathrm{O}^{+}$(Table S3).}

Two structures are known in which the ammonium benzenephosphonate entity is present. The first structure was reported in 2008 by $\mathrm{Ng}$ et al. and has $\mathrm{C}_{6} \mathrm{H}_{5} \mathrm{PO}_{3} \mathrm{H}^{-}, \mathrm{NH}_{4}^{+}$as a formula moiety. ${ }^{5}$ This compound crystallizes in the orthorhombic space group $P b c n$ with $\mathrm{Z}=$ 
8, and its 3D arrangement is a bilayer stacking motif similar to that found in $\mathbf{4 . 4 ^ { - }} \cdot \mathbf{N H}_{4}^{+}$. The second structure was reported in 2005 by an Indian team, and that structure is almost identical to that of $\mathbf{4 . 4}^{-} \mathrm{NH}_{4}^{+}{ }^{+}$. Specifically, its formula moiety is $\mathrm{C}_{6} \mathrm{H}_{5} \mathrm{PO}_{3} \mathrm{H}_{2}, \mathrm{C}_{6} \mathrm{H}_{5} \mathrm{PO}_{3} \mathrm{H}^{-}, \mathrm{NH}_{4}{ }^{+}$, it crystallizes in the triclinic space group $P \overline{1}$ with $\mathrm{Z}=2$, and its cell dimensions are close to those of $\mathbf{4 . 4}^{-} . \mathbf{N H}_{4}{ }^{+}$. Furthermore, its 3D arrangement is a bilayer stacking motif similar to that found in $\mathbf{4 . 4}^{-} \cdot \mathbf{N H}_{4}^{+}$, with layers consisting of an alternation of $\mathrm{C}_{6} \mathrm{H}_{5} \mathrm{PO}_{3} \mathrm{H}_{2}$ columns and $\mathrm{C}_{6} \mathrm{H}_{5} \mathrm{PO}_{3} \mathrm{H}^{-}$columns. Thus, in this particular case, replacement of the $\mathrm{C}_{6} \mathrm{H}_{5}$ groups by $\mathrm{C}_{6} \mathrm{~F}_{5}$ groups does not generate any significant change in the organization of the building units; this is presumably because their organization is governed by the phosphonate-phosphonate and ammonium-phosphonate hydrogen-bond networks, and not by interactions between aromatic groups. 


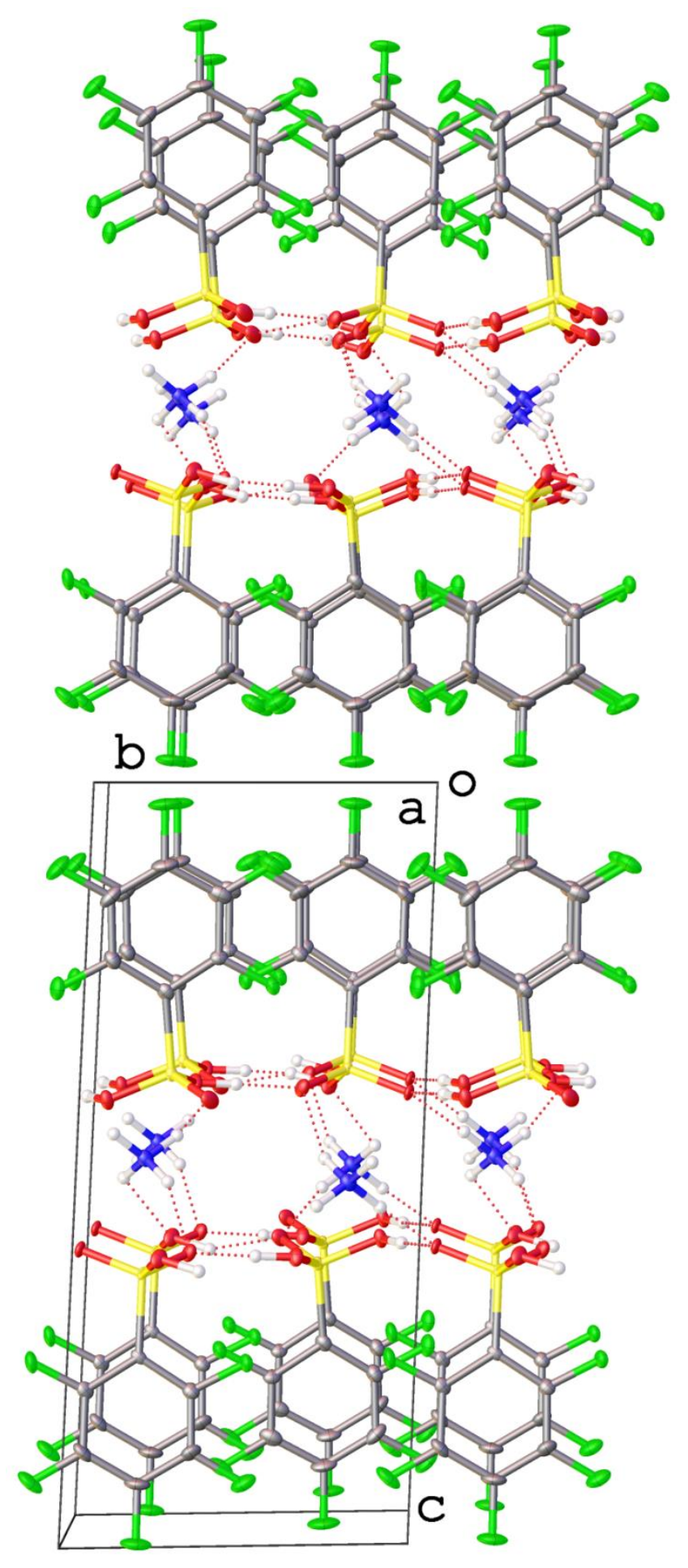

Figure 5. View along $a$ of $\mathbf{4 . 4}^{-} \cdot \mathbf{N H}_{4}^{+}$showing a bilayer stacking motif.

Structure of $\mathbf{4}^{-} . \mathbf{D M A}^{+}$. Crystals of $\mathbf{4}^{-} . \mathbf{D M A}^{+}$were obtained by crystallization of $\mathbf{4}$ from $N, N$-dimethylformamide (DMF). The formula moiety of $\mathbf{4}^{-} . \mathbf{D M A}^{+}$is $\mathrm{C}_{6} \mathrm{~F}_{5} \mathrm{PO}_{3} \mathrm{H}^{-}$, $\mathrm{C}_{2} \mathrm{H}_{8} \mathrm{~N}^{+}$. This compound crystallizes in the triclinic space group $P \overline{1}$ with $Z=4$ (Table 1 ). 
There are two pentafluorophenylphosphonate anions in the asymmetric unit and two dimethylammonium cations. All of the components occupy general positions.

The dimethylammonium cation present in the structure does not originate from the salt used during crystallization. It originates from decomposition of the solvent by the strongly acidic phosphonic acid. A similar situation has been observed previously in the synthesis of several hybrid iodoplumbates, in which hydrolysis of an amide with hydriodic acid was used to generate the organic cation incorporated in the structure. ${ }^{75}$ Interestingly, unlike the previous compounds, 4-.DMA ${ }^{+}$crystallizes with a single-layer stacking motif, i.e., the structure consists of a succession of polar regions made of $\mathrm{PO}_{3} \mathrm{H}^{-}$anions and dimethylammonium cations, separated along $b$ by interpenetrated layers of pentafluorophenyl groups (Figure 6). The latter groups are disordered over two positions in a ratio close to 50:50.

The structure of $\mathbf{4}^{-}$.DMA ${ }^{+}$is organized by numerous $\mathrm{O} / \mathrm{N}-\mathrm{H} \cdots \mathrm{O}, \mathrm{C}-\mathrm{F} \cdots \mathrm{F}-\mathrm{C}$, and $\mathrm{C}-$ $\mathrm{F} \cdots \pi$ interactions, as noticed in the previous structures. Only one C-F $\cdots \mathrm{H}-\mathrm{O}$ interaction is detected, but a large number of $\mathrm{C}-\mathrm{H} \cdots \mathrm{O}$ and $\mathrm{C}-\mathrm{F} \cdots \mathrm{H}-\mathrm{C}$ interactions involving the methyl groups of the dimethylammonium cation are observed (Table S4). Dimethylammonium cations are sandwiched between two layers of $\mathrm{PO}_{3} \mathrm{H}^{-}$groups in the polar region. Given the bulkiness of these cations, it was anticipated that the separation distance between facing $\mathrm{PO}_{3} \mathrm{H}^{-}$planes would be much larger than the distances observed in the previous structures. Interestingly, however, the opposite situation is observed, i.e., the separation distance between mean $\mathrm{PO}_{3} \mathrm{H}^{-}$planes is only $3.737 \AA$. Furthermore, the separation distances between the two mean $\mathrm{PO}_{3} \mathrm{H}^{-}$planes and the mean dimethylammonium plane are about half of that distance, i.e. 1.867 and $1.870 \AA$. Close examination of the structure of $\mathbf{4}^{-}$. DMA ${ }^{+}$reveals that this is because the methyl groups protrude in the $\mathrm{PO}_{3} \mathrm{H}^{-}$layers and occupy void spaces near the $\mathrm{C}_{6} \mathrm{~F}_{5}$ moieties. Thus, for layered materials like the ones studied here, the single-layer stacking motif is the best suited arrangement for accommodation of cations with large sizes.

One structure is known of a phenylphosphonic acid salt incorporating dimethylammonium cations. ${ }^{7}$ The latter structure is different from that of $\mathbf{4}^{-}$.DMA ${ }^{+}$: first, it is a multi-component system of empirical formula $\mathrm{C}_{2} \mathrm{H}_{8} \mathrm{~N}^{+}, \mathrm{C}_{6} \mathrm{H}_{5} \mathrm{PO}_{3} \mathrm{H}^{-}, 2 \mathrm{C}_{6} \mathrm{H}_{5} \mathrm{PO}_{3} \mathrm{H}_{2}$. Second, inspection of its packing indicates that it has a partially interpenetrated bilayer structure, with non-polar regions in which phenyl groups are not all parallel but some groups are oriented perpendicular to other groups. 


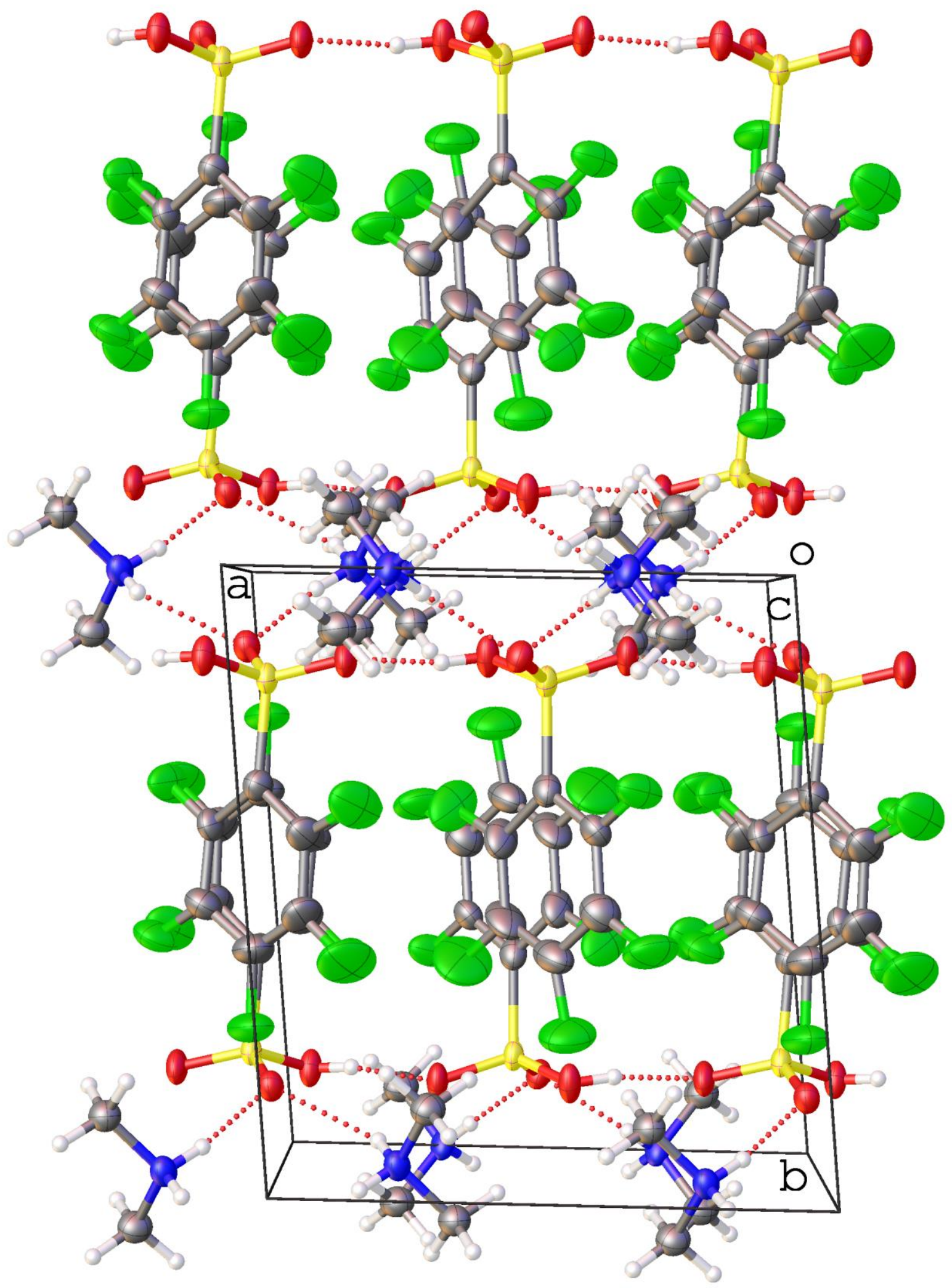

Figure 6. View along $c$ of $\mathbf{4}^{-}$.DMA ${ }^{+}$showing a single-layer stacking motif. 
Structure of $\mathbf{4}^{-} . \mathrm{DMA}^{+} . \mathrm{H}_{2} \mathrm{O}$. Crystals of $\mathbf{4}^{-} . \mathrm{DMA}^{+} . \mathrm{H}_{2} \mathrm{O}$ were obtained by crystallization of 4 from DMF. The formula moiety of $\mathbf{4}^{-} . \mathbf{D M A}^{+} . \mathrm{H}_{2} \mathrm{O}$ is $\mathrm{C}_{6} \mathrm{~F}_{5} \mathrm{PO}_{3} \mathrm{H}^{-}, \mathrm{C}_{2} \mathrm{H}_{8} \mathrm{~N}^{+}$, $\mathrm{H}_{2} \mathrm{O}$. This compound crystallizes in the orthorhombic space group $P 2{ }_{1} 2_{1} 2_{1}$ with $Z=4$ (Table 1). There is one pentafluorophenylphosphonate anion in the asymmetric unit, one dimethylammonium cation, and one water molecule. All of the components occupy general positions.

As already pointed out in the case of $\mathbf{4}^{-}$.DMA ${ }^{+}$, the dimethylammonium cation present in the structure originates from decomposition of the DMF solvent by the strongly acidic phosphonic acid. Beyond that, three major structural differences exist between $\mathbf{4}^{-}$.DMA $\mathbf{A}^{+} . \mathbf{H}_{2} \mathbf{O}$ and $\mathbf{4}^{-}$.DMA ${ }^{+}$: first, one water molecule is found in the lattice. Second, the compound crystallizes in the chiral space group $P 2{ }_{1} 2_{1} 2_{1}$ with a Flack parameter of $0.02(3)$, meaning that the structure is homochiral. Third, the pentafluorophenyl groups are not disordered.

The structure of $\mathbf{4}^{-}$.DMA ${ }^{+} . \mathbf{H}_{2} \mathbf{O}$ looks very similar to that $\mathbf{4}^{-} . \mathbf{D M A} \mathbf{A}^{+}$: it crystallizes with a single-layer stacking motif, i.e., the structure consists of a succession of polar regions made of $\mathrm{PO}_{3} \mathrm{H}^{-}$anions and dimethylammonium cations separated in the $c$-direction by interpenetrated layers of pentafluorophenyl groups (Figure 7). Interestingly, unlike Nafion ${ }^{\circledR}$, water molecules are not located in the polar regions but occupy void spaces between pentafluorophenyl groups in the non-polar regions. These molecules show no disorder, as they are at the heart of an intricate hydrogen-bond network. First, they display short O-H...F-C interactions with nearby pentafluorophenyl groups (Table S5). Second, they interact with phosphonate groups via $\mathrm{O}-\mathrm{H} \cdots \mathrm{O}$ hydrogen bonds and with dimethylammonium cations via $\mathrm{C}$ $\mathrm{H} \cdots \mathrm{O}$ contacts. Third, they are bonded to one another and form chains that run along $a$. The presence of water molecules in the non-polar regions has also an impact on $\mathrm{C}_{6} \mathrm{~F}_{5} \cdots \mathrm{C}_{6} \mathrm{~F}_{5}$ interactions: because of the increased distance between aromatic groups, fewer C-F $\cdots$ F-C, and C-F $\cdots \pi$ interactions are observed in comparison with the previous structures (Table S5). The separation distance between mean $\mathrm{PO}_{3} \mathrm{H}^{-}$planes from facing layers is quite short, $2.698 \AA$, because of the protrusion of the methyl groups of the dimethylammonium cations in the $\mathrm{PO}_{3} \mathrm{H}^{-}$layers. No interaction is detected between phosphonate groups from facing layers. 


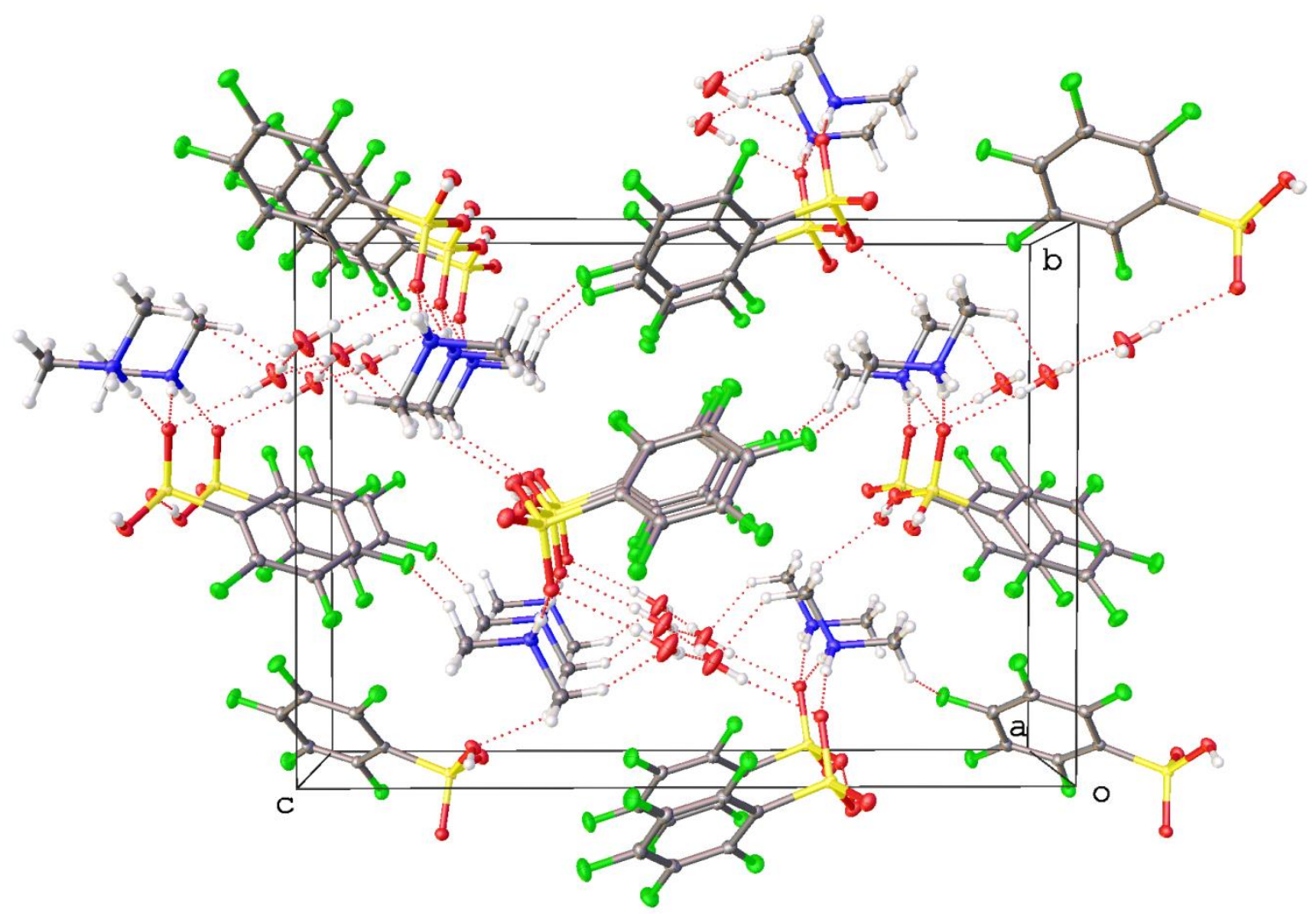

Figure 7. View along $a$ of $\mathbf{4}^{-} . \mathbf{D M A} \mathbf{A}^{+} \cdot \mathbf{H}_{2} \mathbf{O}$ showing a single-layer stacking motif.

Structure of $\mathbf{4 . 4}^{-} . \mathrm{DMA}^{+}$. Crystals of $\mathbf{4 . 4}^{-} . \mathbf{D M A}{ }^{+}$resulted from attempts to crystallize 4 from a DMF solution containing a few drops of a concentrated hydrochloric acid solution. The formula moiety of $\mathbf{4 . 4}^{-} . \mathrm{DMA}^{+}$is $\mathrm{C}_{6} \mathrm{~F}_{5} \mathrm{PO}_{3} \mathrm{H}_{2}, \mathrm{C}_{6} \mathrm{~F}_{5} \mathrm{PO}_{3} \mathrm{H}^{-}, \mathrm{C}_{2} \mathrm{H}_{8} \mathrm{~N}^{+}$. This compound crystallizes in the triclinic space group $P \overline{1}$ with $Z=2$ (Table 1). There is one pentafluorophenylphosphonic acid molecule in the asymmetric unit, one pentafluorophenylphosphonate anion, and one dimethylammonium cation. All of the components occupy general positions. Again, the dimethylammonium cation present in the structure originates from decomposition of the DMF solvent by strong acid.

As previously noticed in the structures of $\mathbf{4}^{-}$. DMA ${ }^{+}$and $\mathbf{4}^{-}$.DMA ${ }^{+} . \mathbf{H}_{2} \mathbf{O}$, a single-layer stacking motif is evident in the structure of $\mathbf{4 . 4}^{-}$.DMA ${ }^{+}$. The layers pile up along $c$ (Figure 8). Nonetheless, the stacking motif of $\mathbf{4 . 4}^{-}$. DMA ${ }^{+}$is slightly different from that found in 4-.DMA $^{+}$and $4^{-}$.DMA ${ }^{+} . \mathrm{H}_{2} \mathrm{O}$ : in $\mathbf{4}^{-} . \mathrm{DMA}^{+}$and $\mathbf{4}^{-}$.DMA ${ }^{+} . \mathrm{H}_{2} \mathrm{O}$, each phosphonate layer contains only $\mathrm{C}_{6} \mathrm{~F}_{5} \mathrm{PO}_{3} \mathrm{H}^{-}$anions, resulting in an $\mathrm{A}^{-} \mathrm{A}^{-}-\mathrm{C}^{+}-\mathrm{A}^{-} \mathrm{A}^{-}-\mathrm{C}^{+}$stacking pattern $\left(\mathrm{A}^{-} \mathrm{A}^{-}=\right.$ anionic layer made of phosphonate groups arranged in a head-to-tail fashion; $\mathrm{C}^{+}=$cationic layer). In 4.4- . $^{-} \mathrm{MA}^{+}$, one phosphonate layer out of two contains only $\mathrm{C}_{6} \mathrm{~F}_{5} \mathrm{PO}_{3} \mathrm{H}_{2}$ molecules, 
and the next one is made solely of $\mathrm{C}_{6} \mathrm{~F}_{5} \mathrm{PO}_{3} \mathrm{H}^{-}$anions, resulting in a $\mathrm{NN}-\mathrm{C}^{+}-\mathrm{A}^{-} \mathrm{A}^{-}-\mathrm{C}^{+}-\mathrm{NN}-\mathrm{C}^{+}$ arrangement $(\mathrm{NN}=$ neutral layer made of phosphonic acid molecules arranged in a head-totail fashion). Such a remarkable arrangement is not observed in the structure of the hydro counterpart $\mathrm{C}_{2} \mathrm{H}_{8} \mathrm{~N}^{+}, \mathrm{C}_{6} \mathrm{H}_{5} \mathrm{PO}_{3} \mathrm{H}^{-}, 2 \mathrm{C}_{6} \mathrm{H}_{5} \mathrm{PO}_{3} \mathrm{H}_{2} .^{7}$ The architecture of 4.4 $^{-} . \mathbf{D M A}^{+}$is assembled by numerous $\mathrm{O} / \mathrm{N}-\mathrm{H} \cdots \mathrm{O}, \mathrm{C}-\mathrm{H} \cdots \mathrm{O}, \mathrm{C}-\mathrm{F} \cdots \mathrm{H}-\mathrm{O} / \mathrm{N}$, and $\mathrm{C}-\mathrm{F} \cdots \mathrm{H}-\mathrm{C}$ hydrogen-bonding interactions (Table S6), among which quite a few involve dimethylammonium cations. Interestingly, only a limited number of C-F..F-C and C-F $\cdots \pi$ contacts are detected between aromatic rings. Certainly, the reason for this situation is not to be sought in the presence of water molecules between aromatic rings in the non-polar regions, as no water is present in 4.4-.DMA ${ }^{+}$. Close examination of the structure reveals the existence of two $\pi$-stacking interactions between fluorinated rings with geometries similar to those found in regular arenes. ${ }^{25,27}$ There is one face-to-face interaction and one parallel-displaced interaction (Table S6). This arrangement is unusual for a perfluoroarene and could just be the result of enforced proximity created by the packing of the building blocks. Nevertheless, by comparison with the $\pi \cdots \pi$ interactions found in 2,3,4,5,6-pentafluorophenol $(\mathrm{Cg} \cdots \mathrm{Cg}=4.313 \AA)^{76}$ and those found in the bis(2,3,4,5,6-pentafluorophenol) $2,3,4,5,6$-pentafluoroaniline molecular crystal $(\mathrm{Cg} \cdots \mathrm{Cg} \geq 4.246 \AA),{ }^{77,78}$ these interactions look reasonably strong. The separation distance between mean $\mathrm{PO}_{3} \mathrm{H}_{2} / \mathrm{PO}_{3} \mathrm{H}^{-}$planes from facing layers is very short, $1.774 \AA$, because of the protrusion of the methyl groups of the dimethylammonium cations in the layers. Furthermore, unlike the previous structures, hydrogen-bonding interactions are detected between $\mathrm{PO}_{3} \mathrm{H}_{2} / \mathrm{PO}_{3} \mathrm{H}^{-}$groups from facing layers. 


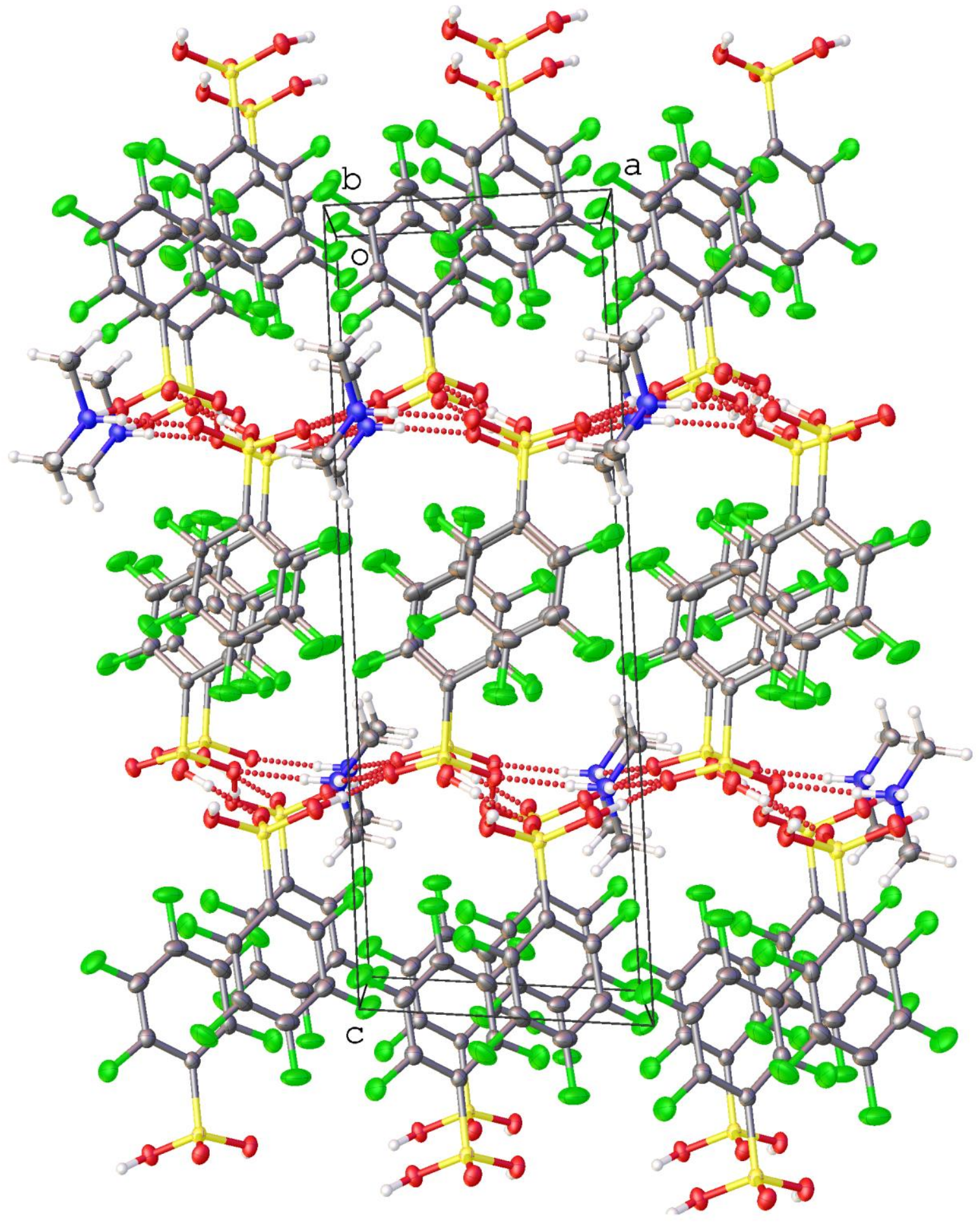

Figure 8. View along $b$ of 4.4- $^{-}$.DMA ${ }^{+}$showing a single-layer stacking motif.

Structure of $\mathbf{4}^{-} \cdot \mathbf{D M A ^ { + }} . \mathrm{NH}_{4}{ }^{+}$. Crystals of $\mathbf{4}^{-} . \mathbf{D M A}^{+} . \mathbf{N H}_{4}{ }^{+}$were obtained by crystallization of $\mathbf{4}$ from a DMF solution containing equimolar amounts of ammonium chloride. The formula moiety of $\mathbf{4}^{-}$. DMA ${ }^{+} \mathbf{N H}_{4}{ }^{+}$is $\mathrm{C}_{6} \mathrm{~F}_{5} \mathrm{PO}_{3} \mathrm{H}^{-}, 0.5 \mathrm{C}_{2} \mathrm{H}_{8} \mathrm{~N}^{+}, 0.5 \mathrm{NH}_{4}{ }^{+}$. This compound crystallizes in the monoclinic space group $C 2 / c$ with $Z=8$ (Table 1). There is one 
pentafluorophenylphosphonate anion in the asymmetric unit, one half of a dimethylammonium cation, and one half of an ammonium cation. The pentafluorophenylphosphonate anion occupies a general position, whereas the ammonium and dimethylammonium cations sit on twofold rotation axes. Dimethylammonium cations originate from decomposition of the DMF solvent by the phosphonic acid.

As can be seen in Figure 9, $\mathbf{4}^{-} . \mathbf{D M} \mathbf{A}^{+} . \mathbf{N H}_{\mathbf{4}}{ }^{+}$crystallizes with a single-layer stacking motif. The layers pile up along $a$. This situation is remarkable, as it shows that when small cations and larger ones are present at the same time in a layered system like the ones studied here, the resulting stacking motif is the one imposed by the larger cations. Yet, this assertion should be tempered, as the single-layer stacking motif observed in $\mathbf{4}^{-}$. DMA ${ }^{+} . \mathbf{N H}_{4}{ }^{+}$is slightly different from those observed up to now. Specifically, in the present case, each non-polar region does not consist of pentafluorophenylphosphonate anions pointing alternatively upwards or downwards. Instead, pentafluorophenylphosphonate ions assemble in pairs, and each pair points alternatively upwards or downwards. Consequently, large hydrophilic channels delineated by $\mathrm{NH}_{2}{ }^{+}$and $\mathrm{PO}_{3} \mathrm{H}^{-}$moieties are created in the $c$-direction that contain rows of $\mathrm{NH}_{4}{ }^{+}$cations (Figure 9). This arrangement allows for maximization of hydrogenbonding interactions between ammonium and phosphonate groups (Table S7). Interestingly, also, it is reminiscent of the arrangement found in $\mathbf{4 . 4}^{-} \cdot \mathbf{N H}_{4}{ }^{+}$, for which a bilayer stacking motif was observed (see above). So, even though the overall structure of $\mathbf{4}^{-}$. DMA ${ }^{+} . \mathbf{N H}_{4}{ }^{+}$ shows a single-layer stacking motif enforced by the large dimethylammonium cations, some bits of it recall the bilayer stacking motif observed in the structure of $\mathbf{4 . 4}^{-} . \mathbf{N H}_{\mathbf{4}}{ }^{+}$made solely of small $\mathrm{NH}_{4}{ }^{+}$cations. Unsurprisingly, no interaction is detected between phosphonate groups from facing layers because these groups are kept apart by ammonium ions. The separation distance between mean phosphonate planes from facing layers in the polar region is $4.382 \AA$, and the separation distance between each mean phosphonate plane and the mean nitrogen plane is half of that distance, i.e. $2.191 \AA$. Hydrophilic channels are surrounded by hydrophobic ones that are delineated by $\left(\mathrm{CH}_{3}\right)_{2} \mathrm{~N}$ and $\mathrm{C}_{6} \mathrm{~F}_{5}$ moieties (Figure 9). In this way, a maximum number of C-F $\cdots \mathrm{H}-\mathrm{C}$ contacts are generated (Table S7). Moreover, the channels are empty. $\mathrm{C}_{6} \mathrm{~F}_{5} \cdots \mathrm{C}_{6} \mathrm{~F}_{5}$ interactions are also present, but their contribution to the organization of the structure seems to be a lot less significant than hydrogen-bonding interactions: no $\mathrm{Cg} \cdots \mathrm{Cg}$ contact smaller than $4.0 \AA$ is noticed, and only one C-F $\cdots$ F-C and three C-F $\cdots \pi$ interactions are detected (Table S7). 


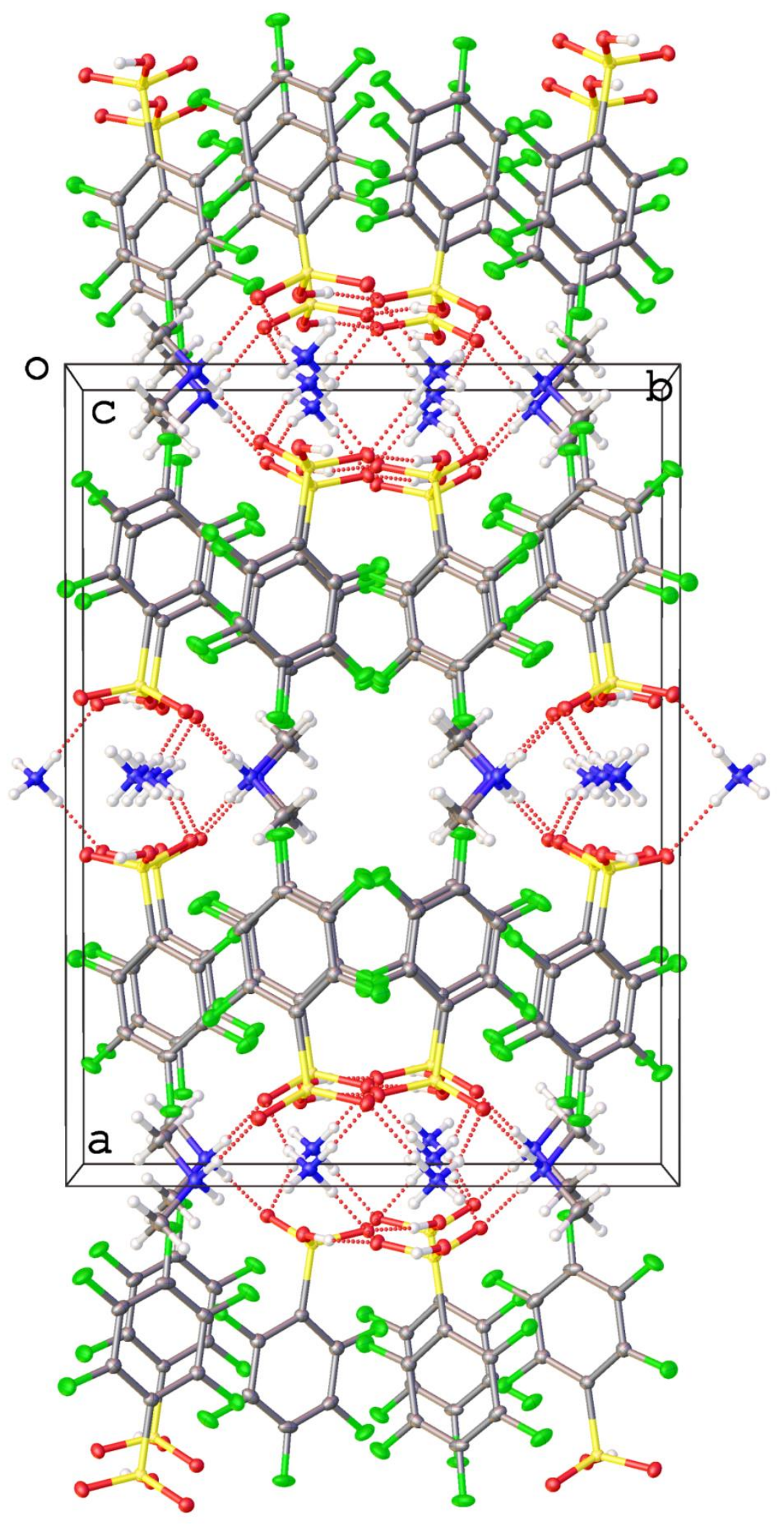

Figure 9. View along $c$ of $\mathbf{4}^{-} . \mathbf{D M A}^{+} . \mathbf{N H}_{4}{ }^{+}$showing a single-layer stacking motif.

Structure of $\mathbf{4}^{-} \cdot \mathbf{G l y}^{+}$. The goal of this crystallization experiment was to force the pentafluorophenyl moiety of $\mathbf{4}$ to interact with the carboxylate group of an amino acid. The 
amino acid that was chosen is glycine. X-ray diffraction shows that a two-component assembly does form, but, disappointingly, the sought-after interaction is not observed. Instead, protonation of the carboxylate group of the amino acid has taken place. This result is another demonstration of the strong acidic character of 4 . The formula moiety of $\mathbf{4}^{-} . \mathbf{G l y}^{+}$is $\mathrm{C}_{6} \mathrm{~F}_{5} \mathrm{PO}_{3} \mathrm{H}^{-}, \mathrm{HO}_{2} \mathrm{CCH}_{2} \mathrm{NH}_{3}{ }^{+}$. This compound crystallizes in the monoclinic space group $P 2_{1}$ with $Z=4$ (Table 1). There are two pentafluorophenylphosphonate anions in the asymmetric unit and two glycinium cations. All of the components occupy general positions.

A single-layer stacking motif was anticipated for $\mathbf{4}^{-} . \mathbf{G l y}^{+}$on the basis of the size of glycine. X-ray diffraction shows that this is true; the direction of the layers coincide with the diagonal of the $a c$ face of the cell (Figure 10). The arrangement of the layers is the same as those found in $\mathbf{4}^{-} . \mathbf{D M A}{ }^{+}$and $\mathbf{4}^{-} . \mathbf{D M A}{ }^{+} . \mathbf{H}_{2} \mathbf{O}$, i.e., each non-polar region consists of pentafluorophenylphosphonate anions pointing alternatively upwards or downwards and, also, all of the layers are identical in the stacking direction. The non-polar region shows no abnormal feature: aromatic groups interact with one another through $\mathrm{C}-\mathrm{F} \cdots \mathrm{F}-\mathrm{C}$ and $\mathrm{C}-\mathrm{F} \cdots \pi$ interactions, and the strengths of these interactions are in line with those detected in the previous structures. Furthermore, the distance between aromatic groups is $4.880 \AA$, suggesting the absence of any significant $\pi \cdots \pi$ interaction between them.

The polar region is made of phosphonate groups and glycinium ions. The assembly is held together by an intricate network of hydrogen bonds (Table S8). These interactions are supplemented by C-F $\cdots \mathrm{H}-\mathrm{O}$ and $\mathrm{C}-\mathrm{F} \cdots \mathrm{H}-\mathrm{C}$ interactions with nearby $\mathrm{C}_{6} \mathrm{~F}_{5}$ groups. As can be seen from Figure 10, phosphonate groups and glycinium ions assemble in groups of four to give $\mathrm{R}_{4}^{2}(14)$ and $\mathrm{R}_{4}{ }^{4}(12)$ hydrogen-bonded rings. These rings are connected to one another and form a strip. The width of the strip is large, $4.119 \AA$, thereby preventing interaction between phosphonate groups from facing layers.

A large body of literature is available on the preparation of self-assembled structures between glycine and a mono-, a di-, or a tricarboxylic acid. On the other hand, reports about molecular crystal formation between glycine and a phosphorus-based acid are less numerous, and only a handful of crystal structures have been published on such compounds. For instance, assemblies prepared from glycine and mono- and diphenyl phosphate have been characterized crystallographically, ${ }^{79,80}$ as well as those obtained from co-crystallization of glycine with phosphoric and phosphorous acids. ${ }^{81-86}$ Interestingly, similarly to $\mathbf{4}^{-}$. $\mathbf{G l y}^{+}$, all of these structures show a layered arrangement. 


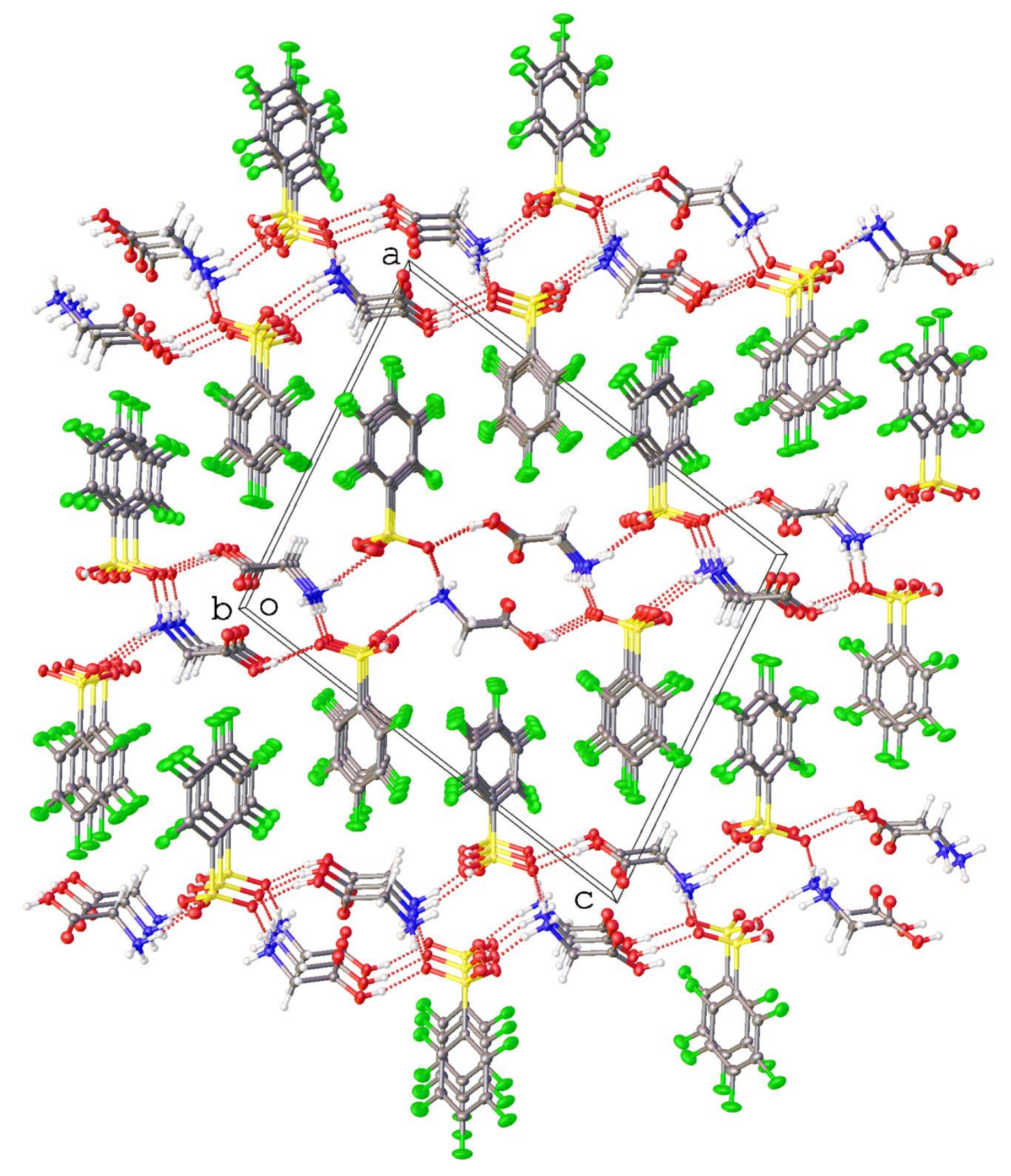

Figure 10. View along $b$ of $\mathbf{4}^{-}$.Gly ${ }^{+}$showing a single-layer stacking motif.

Another single-crystal X-ray diffraction analysis of $\mathbf{4}^{-}$. $\mathbf{G l y}^{+}$was carried out at $293 \mathrm{~K}$. At this temperature, the space group is the same as that found at $180 \mathrm{~K}$, i.e. $P 2{ }_{1}$, and the structure is indistinguishable from the low-temperature one. These results suggest the absence of a ferroelectric phase transition in the $180-293 \mathrm{~K}$ range, in contrast to the situation observed for other systems containing glycine. ${ }^{83-86}$ 


\section{Computational Evaluation of the Structures of $2 \mathrm{C}_{6} \mathrm{~F}_{5} \mathrm{PO}_{3} \mathrm{H}_{2} \cdot \mathrm{H}_{2} \mathrm{O}\left(4.4 . \mathrm{H}_{2} \mathrm{O}\right)$ and}

$\left[\left(\mathrm{C}_{6} \mathrm{~F}_{5} \mathrm{PO}_{3} \mathrm{H}^{-}\right)\left(\mathrm{H}_{3} \mathrm{O}^{+}\right)\right] \cdot \mathrm{C}_{6} \mathrm{~F}_{5} \mathrm{PO}_{3} \mathrm{H}_{2} \quad\left(\mathbf{4 . 4}^{-} . \mathrm{H}_{3} \mathrm{O}^{+}\right)$. Energy Calculations. Unlike crystal structures obtained from neutron diffraction experiments, X-ray crystal structures suffer from the large uncertainty on $\mathrm{H}$-atom positions, which is linked to the low diffracting power of the unique electron of hydrogen. Thus, evaluation of the quality of DFT calculations by direct comparison with experimental X-ray structures is not possible, as the poor positioning of $\mathrm{H}$ atoms dominates the relaxation energy. As a result, in a first step, we have optimized the positions of the $\mathrm{H}$-atoms in the experimental unit cells, while keeping the coordinates of the heavier atoms unchanged. By doing so, stabilization of the systems by up to $7.5 \mathrm{eV} /$ formula unit (f.u.), nearly $1 \mathrm{eV} / \mathrm{H}$-atom, is observed (Table 2) for $\mathbf{4 . 4}^{-} . \mathbf{H}_{3} \mathbf{O}^{+}$(hereafter called the $\mathrm{H}_{3} \mathrm{O}^{+}$form) and 4.4. $\mathrm{H}_{2} \mathrm{O}$ (hereafter called the $\mathrm{H}_{2} \mathrm{O}$ form). These calculations confirm the poor positioning of the hydrogen atoms in the experimental X-ray structures and, at the same time, allow for a more accurate picture of the hydrogen-bonding schemes to be obtained. In addition, for this partial relaxation, it is found that the energy difference between the $\mathbf{H}_{3} \mathbf{O}^{+}$ and $\mathbf{H}_{2} \mathrm{O}$ polymorphs is small, $87 \mathrm{meV} / \mathrm{f}$.u., with the $\mathbf{H}_{2} \mathrm{O}$ phase being more stable. The CIF files of the computed structures with optimized H-atom positions are provided as Supporting Information.

Table 2. Computed energy values for the $\mathrm{H}_{3} \mathrm{O}^{+}\left(\right.$4.4 $\left.^{-} \cdot \mathrm{H}_{3} \mathrm{O}^{+}\right)$and $\mathrm{H}_{2} \mathrm{O}\left(\right.$ 4.4. $\left.\mathrm{H}_{2} \mathrm{O}\right)$ forms of pentafluorophenylphosphonic acid.

\begin{tabular}{|c|c|c|c|c|c|c|c|}
\hline & $\begin{array}{l}\text { Experimental } \\
\text { structure }\end{array}$ & $\begin{array}{l}\text { H-optimized } \\
\text { experimental } \\
\text { structure }\end{array}$ & $\begin{array}{l}\text { Optimized in } \\
\text { experimental } \\
\text { unit cell }\end{array}$ & $\begin{array}{l}\text { Fully } \\
\text { optimized }\end{array}$ & $\begin{array}{l}\text { Zero-point } \\
\text { energy } \\
\text { (harmonic) }\end{array}$ & $\begin{array}{l}\text { Finite- } \\
\text { temperature } \\
\text { corrections }\end{array}$ & $\begin{array}{l}\text { Free } \\
\text { energy at } \\
300 \mathrm{~K}\end{array}$ \\
\hline $\begin{array}{l}E_{\mathrm{H} 3 \mathrm{O}+} \\
\text { (eV/f.u.) }\end{array}$ & -229.455 & -233.959 & -234.293 & -234.293 & 5.218 & -0.733 & -229.807 \\
\hline $\begin{array}{l}E_{\mathrm{H} 2 \mathrm{O}} \\
\text { (eV/f.u.) }\end{array}$ & -226.490 & -234.046 & -234.281 & -234.283 & 5.233 & -0.724 & -229.772 \\
\hline $\begin{array}{l}\Delta E \\
\text { (eV/f.u.) }\end{array}$ & -2.966 & 0.087 & -0.011 & -0.010 & -0.014 & -0.009 & -0.034 \\
\hline
\end{tabular}

Then, the overall quality of the calculations relative to the X-ray structure can be evaluated by optimization of all atom positions in the experimental unit cell, starting from the $\mathrm{H}$-optimized structure. In this approach, the energy variation comes solely from the heavier atoms that are correctly positioned by X-ray diffraction, a large relaxation implying a poor 
description of the chemical bonds by DFT (provided that complicating factors such as phase transitions ${ }^{87}$ are absent). This optimization leads to structures that are only $300 \mathrm{meV} / \mathrm{f} . \mathrm{u}$. (9 meV/atom) more stable than those derived from experiments. Furthermore, optimization of the unit cells shifts the experimental lattice parameters by less than $0.6 \%$ and leads to negligible energy changes. These findings strongly suggest that the DFT-D3 method used in this work provides a correct description of the systems under consideration and makes possible a direct comparison with the experimental results. The CIF files of the fully optimized structures are available as Supporting Information. Furthermore, it is found that the energy difference between the fully optimized $\mathrm{H}_{3} \mathrm{O}^{+}$and $\mathrm{H}_{2} \mathrm{O}$ phases is again quite small, around $10 \mathrm{meV} / \mathrm{f}$.u., but this time the $\mathbf{H}_{3} \mathbf{O}^{+}$phase is slightly more stable. With such a small energy difference, zero-point energies and finite-temperature contributions cannot be neglected and must therefore be computed.

The $\mathbf{H}_{3} \mathrm{O}^{+}$phase is further stabilized by $14 \mathrm{meV} /$ f.u. relative to the $\mathbf{H}_{2} \mathbf{O}$ phase by zero-point energy (Table 2). The main reason for this stabilization is the presence of $\mathrm{H}_{3} \mathrm{O}^{+}$ ions in the $\mathrm{H}_{3} \mathrm{O}^{+}$phase that have, on average, weaker $\mathrm{O}-\mathrm{H}$ bonds than $\mathrm{H}_{2} \mathrm{O}$ molecules in the $\mathrm{H}_{2} \mathrm{O}$ phase, thereby resulting in a lower zero-point energy contribution. Finite-temperature effects associated with enthalpic and entropic changes also stabilize the $\mathrm{H}_{3} \mathrm{O}^{+}$phase by 9 meV/f.u.; this stabilization stems from the fact that the $\mathbf{H}_{3} \mathbf{O}^{+}$phase has a slightly higher density of low-energy phonons than the $\mathbf{H}_{2} \mathrm{O}$ phase. Combination of all of these effects leads to a $34 \mathrm{meV} /$ f.u. $\left(<1 \mathrm{meV} /\right.$ atom) stabilization of the $\mathbf{H}_{3} \mathbf{O}^{+}$phase relative to the $\mathrm{H}_{2} \mathbf{O}$ phase. Clearly, the energy difference between the two phases is tiny, so it is difficult to conclude definitely which one is more stable because of the inherent uncertainties of the DFT method. However, it is evident that the two polymorphs are very close energetically, consistent with the fact that they both can be isolated experimentally, and suggesting that they may compete with each other depending on crystallization conditions.

Effect of Ionization on Phase Stability. The $\mathbf{H}_{2} \mathrm{O}$ and $\mathbf{H}_{3} \mathrm{O}^{+}$phases are polymorphs with two salient differences: i) ionization of one $\mathrm{C}_{6} \mathrm{~F}_{5} \mathrm{PO}_{3} \mathrm{H}_{2}$ molecule according to the equation $\mathrm{C}_{6} \mathrm{~F}_{5} \mathrm{PO}_{3} \mathrm{H}_{2}+\mathrm{H}_{2} \mathrm{O} \rightleftarrows \mathrm{C}_{6} \mathrm{~F}_{5} \mathrm{PO}_{3} \mathrm{H}^{-}+\mathrm{H}_{3} \mathrm{O}^{+}$; ii) the dissimilar organizations of the $\mathrm{C}_{6} \mathrm{~F}_{5}$ groups in the non-polar regions (Figure 11).

In the case of the $\mathrm{H}_{3} \mathrm{O}^{+}$phase, half of the $\mathrm{C}_{6} \mathrm{~F}_{5} \mathrm{PO}_{3} \mathrm{H}_{2}$ molecules present in the unit cell are ionized. This creates a mix of neutral $\mathrm{C}_{6} \mathrm{~F}_{5} \mathrm{PO}_{3} \mathrm{H}_{2}$ entities and negatively charged $\mathrm{C}_{6} \mathrm{~F}_{5} \mathrm{PO}_{3} \mathrm{H}^{-}$species. Ionized species are usually disfavored relative to neutral ones, as charge separation has an important energy cost. This cost can be estimated by computing the 
structure of a hypothetical ionized phase created by hydrogen transfer from half of the $\mathrm{C}_{6} \mathrm{~F}_{5} \mathrm{PO}_{3} \mathrm{H}_{2}$ entities to $\mathrm{H}_{2} \mathrm{O}$ molecules in the $\mathbf{H}_{2} \mathrm{O}$ phase, and calculating the energy of the local minimum. In this case, it is found that the ionized structure is $400 \mathrm{meV} / \mathrm{f} . \mathrm{u}$. less stable than the neutral one. Conversely, it is possible to compute the structure of a hypothetical enforced neutral phase created by $\mathrm{H}$-atom transfer from $\mathrm{H}_{3} \mathrm{O}^{+}$cations to $\mathrm{C}_{6} \mathrm{~F}_{5} \mathrm{PO}_{3} \mathrm{H}^{-}$anions in the $\mathrm{H}_{3} \mathrm{O}^{+}$phase. Under such circumstances, the neutral structure is found to be unstable and converges back to the ionized $\mathrm{H}_{3} \mathrm{O}^{+}$phase, no local minimum being reached. Thus, in the $\mathrm{H}_{3} \mathrm{O}^{+}$phase, there must be some effect that stabilizes substantially the ionized form relative to the neutral form and that compensates for the $400 \mathrm{meV} / \mathrm{f}$.u. associated with ionization. As the two polymorphs show similar H-bond networks with about four hydrogen bonds per $\mathrm{PO}_{3}$ group, it is clear that the origin of this stabilization has to be found elsewhere. Interestingly, the two polymorphs show very different arrangements of the $\mathrm{C}_{6} \mathrm{~F}_{5}$ rings that might account for this stabilization (see Figure 11).

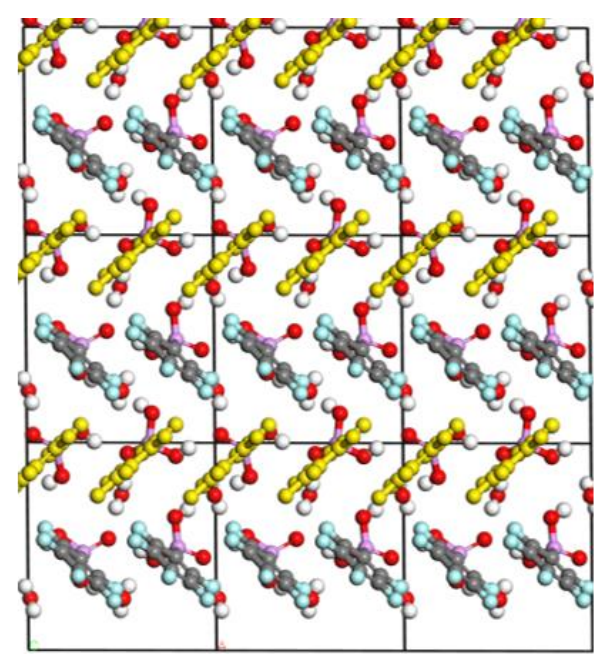

A)

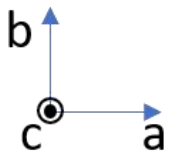

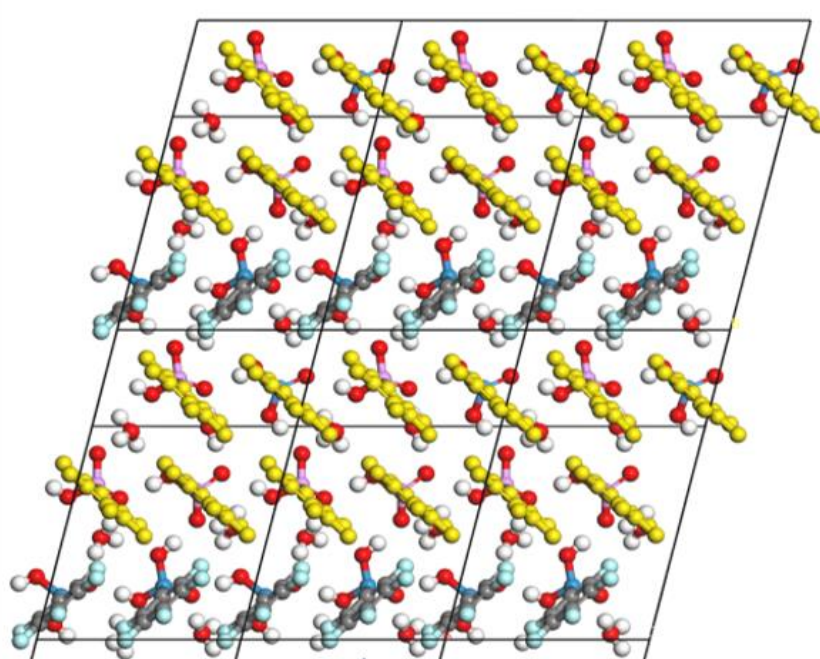

B)

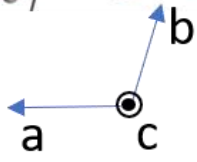

Figure 11. Organization of the $\mathrm{C}_{6} \mathrm{~F}_{5}$ moieties in the computed $\mathrm{H}_{2} \mathrm{O}$ (A) and $\mathbf{H}_{3} \mathrm{O}^{+}$(B) polymorphs. Rows of $\mathrm{C}_{6} \mathrm{~F}_{5}$ moieties with a same orientation are colored in blue or yellow.

Effect of Deprotonation on Electronic Structure. We next investigated the effect of the differing arrangements of the $\mathrm{C}_{6} \mathrm{~F}_{5}$ groups on electronic structure in the two polymorphs. To this end, we have computed the electron density variation associated with the transformation of a neutral $\mathrm{H}_{2} \mathrm{O}$ phase into an ionized $\mathrm{H}_{3} \mathrm{O}^{+}$phase in two ways, one using the experimental 
$\mathrm{H}_{2} \mathrm{O}$ phase (4.4. $\mathrm{H}_{2} \mathrm{O}$ ) as a starting point and a hypothetical ionized $\mathrm{H}_{3} \mathrm{O}^{+}$phase as the end product (Figure 12, top line), and one using a hypothetical neutral $\mathbf{H}_{2} \mathbf{O}$ phase as a starting point and the experimental ionized $\mathrm{H}_{3} \mathrm{O}^{+}$polymorph $\left(\mathbf{4 . 4}^{-} . \mathrm{H}_{3} \mathrm{O}^{+}\right.$) as the end product (Figure 12, bottom line). The hypothetical ionized $\mathrm{H}_{3} \mathrm{O}^{+}$phase used in the top transformation of Figure 12, abbreviated $\mathbf{H}_{3} \mathrm{O}^{+}$(hypo.), was created by forcing ionization of half of the $\mathrm{C}_{6} \mathrm{~F}_{5} \mathrm{PO}_{3} \mathrm{H}_{2}$ molecules present in the experimental $\mathbf{H}_{2} \mathrm{O}$ phase. The neutral $\mathbf{H}_{2} \mathrm{O}$ phase used in the bottom transformation of Figure 12, abbreviated $\mathbf{H}_{2} \mathbf{O}$ (hypo.), was obtained by forced proton transfer from $\mathrm{H}_{3} \mathrm{O}^{+}$cations to $\mathrm{C}_{6} \mathrm{~F}_{5} \mathrm{PO}_{3} \mathrm{H}^{-}$anions in the experimental $\mathrm{H}_{3} \mathrm{O}^{+}$phase. From the perspective of the $\mathrm{C}_{6} \mathrm{~F}_{5}$ rings, formation of $\mathrm{C}_{6} \mathrm{~F}_{5} \mathrm{PO}_{3} \mathrm{H}^{-}$and $\mathrm{H}_{3} \mathrm{O}^{+}$species by protonation of $\mathrm{H}_{2} \mathrm{O}$ molecules by $\mathrm{PO}_{3} \mathrm{H}_{2}$ moieties induces an overall gain in electron density for the cycles connected to $\mathrm{PO}_{3} \mathrm{H}^{-}$groups (see blue isosurfaces in Figure 12). Concomitantly, a slight electron density loss is observed for the $\mathrm{C}_{6} \mathrm{~F}_{5}$ rings connected to neutral $\mathrm{PO}_{3} \mathrm{H}_{2}$ groups upon formation of $\mathrm{H}_{3} \mathrm{O}^{+}$species: a fraction of the charge density of the neutral molecule is transferred to $\mathrm{H}_{3} \mathrm{O}^{+}$ions, probably through hydrogen bond strengthening (see yellow isosurfaces in Figure 12). With ionization, there is also an increase in electron density between aromatic rings, suggesting the formation of weak intermolecular bonds (see blue isosurfaces in Figure 12). Nevertheless, these new bonds are quite different in the two structures. For $\mathrm{H}_{3} \mathrm{O}^{+}\left(\right.$hypo.), the response to ionization is the formation of pairs of $\mathrm{C}_{6} \mathrm{~F}_{5}$ rings (red ellipse), while for the experimental $\mathrm{H}_{3} \mathrm{O}^{+}$structure, there is a strong delocalization of the electron density over several aromatic rings that generates some kind of $\pi$-conjugated polymer (red wavy line). This suggests that, in the experimental $\mathbf{H}_{3} \mathbf{O}^{+}$form, stronger intermolecular bonding interactions are created in comparison with $\mathbf{H}_{3} \mathbf{O}^{+}($hypo.).

Therefore, in $\mathbf{4 . 4}^{-} \cdot \mathrm{H}_{3} \mathrm{O}^{+}$, ionization is compensated by: i) charge delocalization over the pentafluorophenyl moieties; ii) a stabilizing electrostatic interaction between positively charged $\mathrm{C}_{6} \mathrm{~F}_{5}$ moieties of $\mathrm{C}_{6} \mathrm{~F}_{5} \mathrm{PO}_{3} \mathrm{H}_{2}$ molecules and negatively charged $\mathrm{C}_{6} \mathrm{~F}_{5}$ moieties of $\mathrm{C}_{6} \mathrm{~F}_{5} \mathrm{PO}_{3} \mathrm{H}^{-}$ions; iii) stronger interactions between the aromatic rings of $\mathrm{C}_{6} \mathrm{~F}_{5} \mathrm{PO}_{3} \mathrm{H}^{-}$and $\mathrm{C}_{6} \mathrm{~F}_{5} \mathrm{PO}_{3} \mathrm{H}_{2}$ species by intermolecular weak bond formation. As seen in Figure 12, charge transfer and electrostatic interactions are also observed in $\mathbf{H}_{3} \mathrm{O}^{+}(\mathbf{h y p o .})$ upon forced ionization of the experimental $\mathbf{H}_{2} \mathrm{O}$ phase, but electron delocalization and intermolecular bond formation are far more limited. In this case, formation of a $\mathrm{C}_{6} \mathrm{~F}_{5}-\mathrm{C}_{6} \mathrm{~F}_{5}$ dimer is observed, instead of a network. 


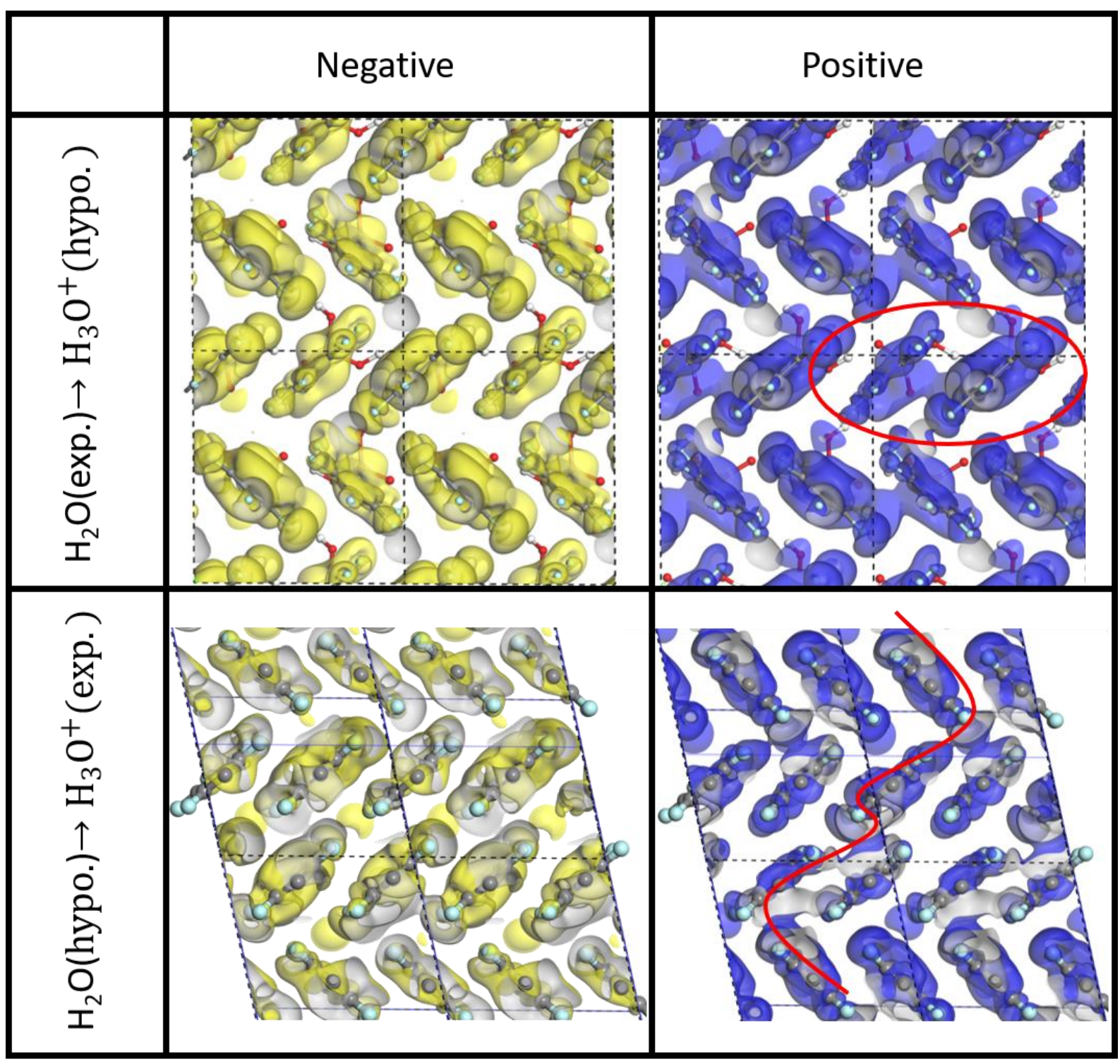

Figure 12. Charge density variation upon ionization of half of the $\mathrm{C}_{6} \mathrm{~F}_{5} \mathrm{PO}_{3} \mathrm{H}_{2}$ entities into $\mathrm{C}_{6} \mathrm{~F}_{5} \mathrm{PO}_{3} \mathrm{H}^{-}$and $\mathrm{H}_{3} \mathrm{O}^{+}$. Top line: transformation of the experimental $\mathbf{H}_{2} \mathbf{O}$ phase into $\mathrm{H}_{3} \mathrm{O}^{+}$(hypo.). Bottom line: ionization of $\mathrm{H}_{2} \mathrm{O}$ (hypo.) into the experimental $\mathrm{H}_{3} \mathrm{O}^{+}$phase. Left column: yellow isosurfaces show the localization of electron deficient areas. Right column: blue isosurfaces reproduce an increase in electron density. Ionization induces the formation of intermolecular bonds that generate either a dimer (red ellipse) or a polymer (red wavy line).

The increased interaction between $\mathrm{C}_{6} \mathrm{~F}_{5} \mathrm{PO}_{3} \mathrm{H}^{-}$and $\mathrm{C}_{6} \mathrm{~F}_{5} \mathrm{PO}_{3} \mathrm{H}_{2}$ fragments can be rationalized using the computed molecular orbital diagram for the free species shown in Scheme 2. Aromatic ring stacking is controlled mainly by the interaction between associated frontier orbitals with the correct local symmetry. The relevant orbitals for $\mathrm{C}_{6} \mathrm{~F}_{5} \mathrm{PO}_{3} \mathrm{H}_{2}$ are the 
LUMO and HOMO-1 (as the HOMO is associated with the oxygen lone pair), and those for $\mathrm{C}_{6} \mathrm{~F}_{5} \mathrm{PO}_{3} \mathrm{H}^{-}$are the LUMO and HOMO-4 (as the HOMO to HOMO-3 orbitals are associated with the oxygen lone pairs and the $\mathrm{P}^{=-} \mathrm{O}$ bonds). Upon formation of $\mathrm{C}_{6} \mathrm{~F}_{5} \mathrm{PO}_{3} \mathrm{H}^{-}$by ionization, the electron-enriched species sees a shift of its molecular orbitals to higher energies because of stronger electron-electron repulsion. Therefore, the HOMO-4 of $\mathrm{C}_{6} \mathrm{~F}_{5} \mathrm{PO}_{3} \mathrm{H}^{-}$and the LUMO of $\mathrm{C}_{6} \mathrm{~F}_{5} \mathrm{PO}_{3} \mathrm{H}_{2}$ become energetically closer and can interact strongly, the latter orbital having the correct local symmetry to interact with the HOMO-4 of $\mathrm{C}_{6} \mathrm{~F}_{5} \mathrm{PO}_{3} \mathrm{H}^{-}$. In $\mathrm{H}_{3} \mathrm{O}^{+}$(hypo.), only dimers are created, which is not sufficient to compensate for the energy penalty associated with ionization. In the experimental $\mathrm{H}_{3} \mathrm{O}^{+}$polymorph, the arrangement of the $\mathrm{C}_{6} \mathrm{~F}_{5}$ groups is conducive to the formation of a pseudo- $1 \mathrm{D} \pi$-connected system that takes advantage of charge delocalization over the neutral molecules and benefits from intermolecular bond strengthening between aromatic moieties, thereby compensating for the energy cost caused by ionization. As the widths of bands pertaining to molecular orbitals are directly linked to orbital overlaps in crystal structures, delocalization in the two polymorphs was investigated by looking at their density of states (DOS). The band at the top of the conduction band and the one at the bottom of the valence band for both polymorphs are associated mainly with the $\pi$ and $\pi^{*}$ carbon-dominated molecular orbitals of the aromatic moiety (see Figure S9). The two bands for the $\mathbf{H}_{3} \mathbf{O}^{+}$form show larger widths (by about 100 $\mathrm{meV}$ ) than those of the $\mathbf{H}_{2} \mathbf{O}$ form. This suggests a stronger overlap between the orbitals of the molecules in the $\mathbf{H}_{3} \mathrm{O}^{+}$polymorph and a more efficient delocalization. This greater overlap can also be checked by computing the Fukui functions ( $\mathrm{f}+$ and $\mathrm{f}-$ ). ${ }^{88,89}$ Consistently, the computed Fukui functions (Figure S10) show that the $\mathbf{H}_{3} \mathbf{O}^{+}$phase has more delocalized electrons and holes than the $\mathbf{H}_{2} \mathbf{O}$ form. This is indicative of the existence of quite different electronic mobilities: the $\mathbf{H}_{2} \mathbf{O}$ polymorph tends to form more localized electrons or holes, while the $\mathbf{H}_{3} \mathrm{O}^{+}$polymorph exhibits more delocalized ones. As the last occupied and first empty bands of the $\mathrm{H}_{3} \mathrm{O}^{+}$phase have larger widths, this induces a reduction of the band gap, i.e. $3.10 \mathrm{eV}$ for the $\mathbf{H}_{3} \mathrm{O}^{+}$form and $3.21 \mathrm{eV}$ for the $\mathbf{H}_{2} \mathbf{O}$ form. 


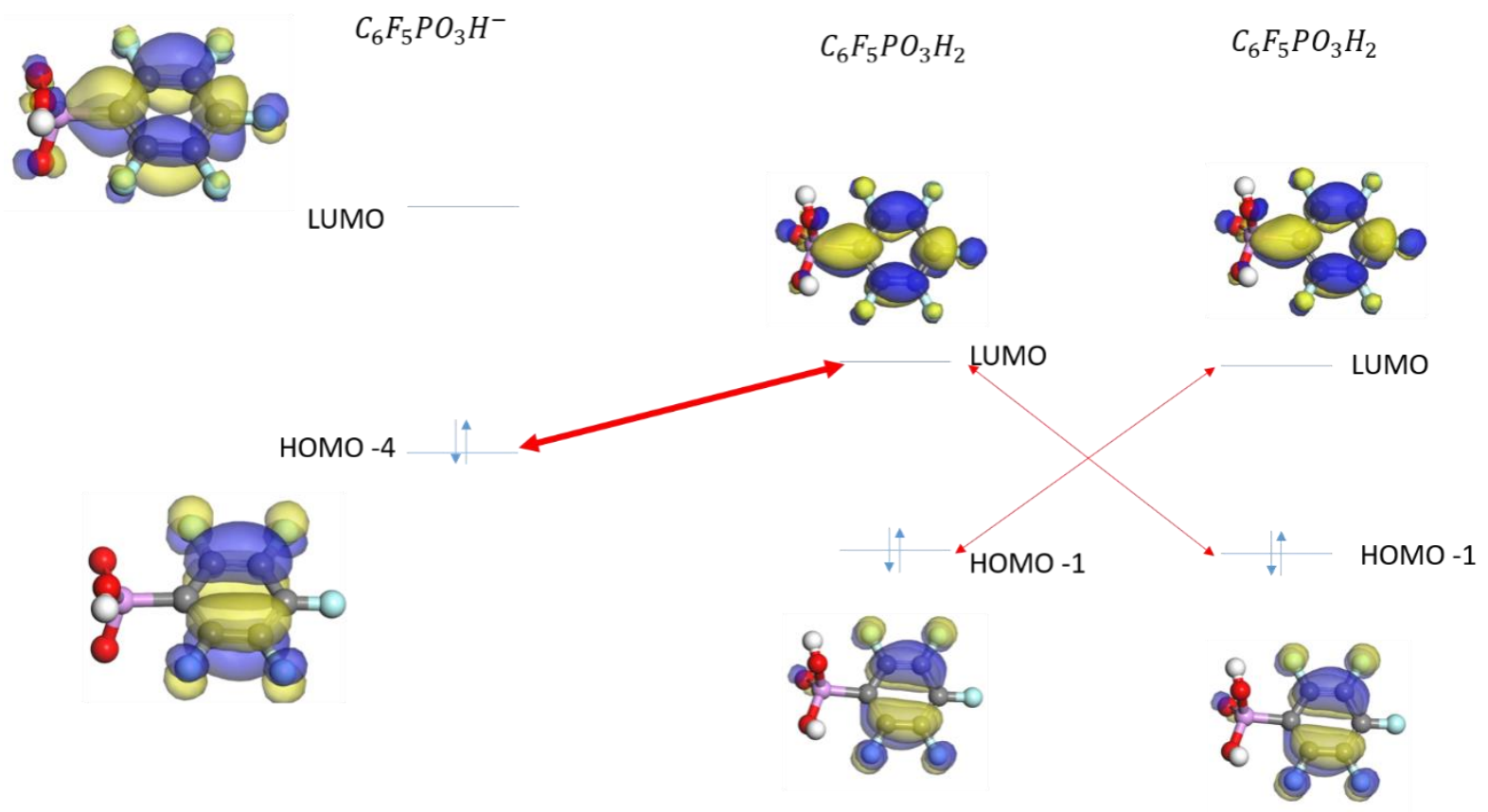

Scheme 2. Molecular orbital diagram showing the interactions between $\mathrm{C}_{6} \mathrm{~F}_{5} \mathrm{PO}_{3} \mathrm{H}^{-}$and $\mathrm{C}_{6} \mathrm{~F}_{5} \mathrm{PO}_{3} \mathrm{H}_{2}$ fragments.

In summary, subtle structural changes have a strong influence on the ionization of pentafluorophenylphosphonic acid and modify its $\mathrm{p} K_{\mathrm{a}}$ value. Indeed, polymorphism turns $\mathrm{C}_{6} \mathrm{~F}_{5} \mathrm{PO}_{3} \mathrm{H}_{2}$ into a stronger acid than water in the $\mathbf{H}_{3} \mathrm{O}^{+}$form. This situation is a consequence of efficient charge reorganization with proton transfer and is linked with a strengthening of intermolecular interactions. The ionization cost induced by protonation of water by the acid is compensated by the more favorable stacking of the $\mathrm{C}_{6} \mathrm{~F}_{5}$ moieties made possible by a better electronic delocalization. Thus, this family of fluorinated compounds may show interesting prospects as molecular organic semiconductors, with their delocalization properties controlled by polymorphism or by exchange of the protons with other cations. Interestingly, this dichotomy in the arrangement of the $\mathrm{C}_{6} \mathrm{~F}_{5}$ groups is observed exclusively in the structures of 4.4. $\mathrm{H}_{2} \mathrm{O}$ and $4.4^{-} . \mathrm{H}_{3} \mathrm{O}^{+}$. 


\section{DISCUSSION}

Unlike guanidinium sulfonate systems in which guanidinium cations are essential to promote the crystallization of the sulfonate anions with a layered arrangement, the construction from pentafluorophenylphosphonic acid $\mathbf{4}$ of layered architectures with alternating polar and nonpolar domains is not contingent on the presence of a structuring cation. In this respect, this acid is clearly a unique building block. Furthermore, it has the amazing ability to cocrystallize with neutral or cationic species, yielding polar regions where only neutral $\mathbf{4}$, or only $\mathbf{4}^{-}$, or mixtures of $\mathbf{4}$ and $\mathbf{4}^{-}$species coexist. This leads to many different structures that are organized by ionic and H-bonding interactions depending on the protonation state of the $\mathrm{PO}_{3}$ moieties. Furthermore, as shown computationally, the polar and non-polar regions are interdependent, as ionized $\mathrm{PO}_{3}{ }^{-}$moieties induce electron donation to the aromatic rings they are connected to, while $\mathrm{PO}_{3} \mathrm{H}$ groups are associated with electron-accepting phenyl rings. As a result, a change in the protonation state of the phosphonate groups in the polar region modifies the interactions between aromatic rings in the non-polar region, thereby inducing

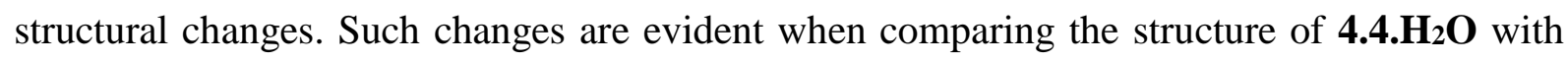
that of its $\mathbf{4 . 4}^{-} \cdot \mathbf{H}_{3} \mathrm{O}^{+}$polymorph. This structural versatility suggests that a large variety of assemblies based on 4 should be accessible, the present work reporting on just a few of them. In addition, the electronic structure of 4-based crystals can be tuned to incorporate purely donor, purely acceptor, or mixed donor/acceptor aromatic rings, giving rise to electron localization/delocalization phenomena. This makes these materials potentially useful for certain types of technological applications. Especially, derivatives of $\mathbf{4}$ could be of interest in the field of molecular electronics, as shown in the theoretical section. Some of the crystals exhibit electron delocalization and probably electron conduction throughout the non-polar domains, thus doping could be achieved by modifying the ionization of $\mathbf{4}$. Finally, 4-based materials could also be suitable for molecular recognition through a modification of the ionic and hydrogen bond networks in the polar regions, causing measurable changes in the electronic properties of the non-polar domains. Compound $\mathbf{4}$ is a new brick for a new class of hydrogen-bonded organic frameworks (HOFs) featuring the coupling between an ionic state in the polar region and an electronic one in the non-polar region. 


\section{CONCLUSION}

In conclusion, the solid-state structures of pentafluorophenylphosphonic acid and its salts are organized primarily by hydrogen bonding. The chief hydrogen bonding interactions are $\mathrm{O} / \mathrm{N}$ $\mathrm{H} \cdots \mathrm{O}$ interactions, but $\mathrm{C}-\mathrm{H} \cdots \mathrm{O}$ contacts are also important in stabilizing structures that contain organic cations. Interactions involving perfluorophenyl groups are central as well, and

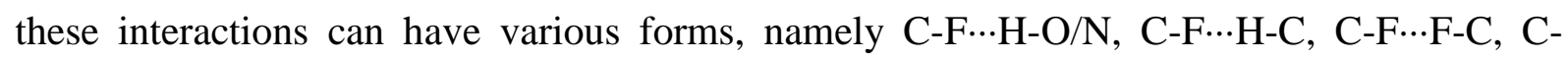
$\mathrm{F} \cdots \pi_{\mathrm{F}}$, and occasionally $\pi_{\mathrm{F}} \cdots \pi_{\mathrm{F}}$ contacts. Although the energies of these interactions are low in comparison with $\mathrm{O} / \mathrm{N}-\mathrm{H} \cdots \mathrm{O}$ contacts, their large number undoubtedly helps increasing the stability of the architectures by enhancing cohesion in the non-polar regions. Thus, novel architectures differing significantly from those prepared from phenylphosphonic acid are sometimes obtained. Furthermore, perfluoroaryl-based interactions are sufficiently flexible to allow changes in the organization of the aromatic groups in response to changes (ionization) occurring in the polar regions, as observed in the structures of 4.4. $\mathrm{H}_{2} \mathrm{O}$ and 4.4 $^{-} . \mathrm{H}_{3} \mathrm{O}^{+}$. This situation is quite unusual and may be regarded as some kind of acidity-modulated polymorphism. Clearly, the use of perfluorophenyl moieties is an asset in crystal engineering and supramolecular chemistry studies due to the plasticity of this grouping.

The size of included species (cation or neutral molecule) is important as well, and this situation is reminiscent of that observed in guanidinium sulfonates. With small cations or water molecules, bilayer stacking is possible because of the compact size of the cementing agent and the ability to form multiple hydrogen bonds with nearby phosphonate groups in the polar region. With bulky cations, bilayer stacking is unfavorable because the hydrogen-bond network in the polar region would be loose, and the separation distance between phosphonate layers would be quite large. Instead, single-layer stacking is observed. Such an arrangement creates void spaces near the pentafluorophenyl groups where the bulky cation can nest. In addition, this arrangement takes advantage of the numerous hydrogen bonds between the methyl groups of the cation and the perfluorophenyl moieties located nearby. Ultimately, one can surmise that, with very bulky cations, the layered arrangement will be disrupted and reduced dimensionality will result (columns or discrete assemblies will be produced instead of sheets). Such a situation has been observed previously for the hydrogenated counterparts, namely 1,4-diazabicyclo(2.2.2)octane bis(phenylphosphonic acid), ${ }^{10}$ dicyclohexylammonium hydrogen phenylphosphonate, ${ }^{9}$ diisopropylammonium hydrogen phenylphosphonate, ${ }^{8}$ and (triphenylmethyl)ammonium hydrogen phenylphosphonate. ${ }^{6}$ 
In addition, assemblies with compact non-polar regions are obtained that show no or prohibitively small void spaces to accommodate solvent molecules, in sharp contrast with guanidinium sulfonates. According to PLATON analyses,${ }^{61}$ none of the structures described herein contain residual solvent accessible voids. Thus, it is no surprise to find that it is impossible to incorporate halides, oxo anions, carbon tetrachloride, or benzene molecules in them. If such an endeavor could be achieved, it would certainly lead to complete structural rearrangement to compensate for the large energy cost it would entail.

A lot remains to be done with $\mathbf{4}$ and its derivatives in terms of crystal engineering studies. Especially, we have tried to co-crystallize phosphonate $\mathbf{2}$ with halide anions and benzene molecules, but there again multi-component crystals could not be obtained. Perhaps the replacement of the ethyl groups of $\mathbf{2}$ with substituents known to promote crystallization such as phenyl and $t$-butyl groups will give better results. Furthermore, work is planned to prepare metal complexes with $\mathbf{4}$ to see how the structures of these complexes compare with those of the phenylphosphonate analogues. Various tests will then be conducted on these complexes to see if the absence of groups capable of hydrogen bonding allows for the existence of arene-perfluoroarene, anion- $\pi$, and lone pair- $\pi$ interactions, and if these architectures are capable of including solvent molecules. Last, of special note is the fact that the para position of the perfluorophenyl ring is activated, ${ }^{18}$ so it is possible to replace the fluorine atom borne by that carbon by other groups, which makes easy derivatization of $\mathbf{4}$ or complexed 4 possible. 


\section{ASSOCIATED CONTENT}

\section{Supporting Information}

The Supporting Information is available free of charge at https://pubs.acs.org/doi/10.1021/acs.cgd.xxxxxxx.

OLEX2 drawings showing the contents of the asymmetric units with atom labeling schemes, tables of distances and angles for intermolecular hydrogen-bonding interactions and short contacts, projected density of state on the carbon atoms of the aromatic ring for the $\mathbf{H}_{2} \mathbf{O}$ and $\mathbf{H}_{3} \mathbf{O}^{+}$phases, Fukui functions ( $f+$ and $f-$ ) associated respectively with electrons (in the conduction band) or holes (in the valence band) for the $\mathbf{H}_{3} \mathrm{O}^{+}$and $\mathbf{H}_{2} \mathbf{O}$ phases (PDF). CIF files of computed structures.

\section{Accession Codes}

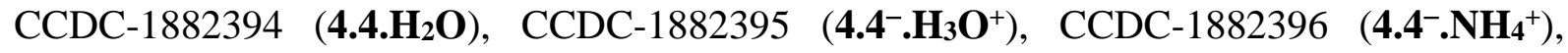

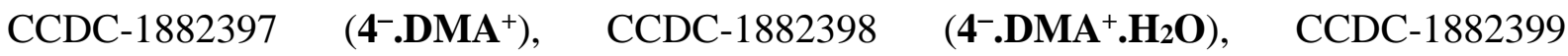

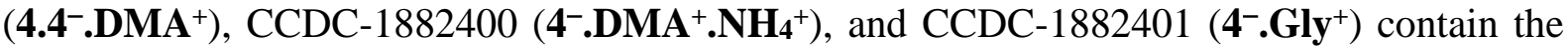
supplementary crystallographic data for this paper. These data can be obtained free of charge via www.ccdc.cam.ac.uk/data_request/cif, or by emailing data_request@ccdc.cam.ac.uk, or by contacting The Cambridge Crystallographic Data Centre, 12 Union Road, Cambridge CB2 1EZ, UK; fax: +44 1223336033. 


\section{ACKNOWLEDGMENTS}

The computational work described in this study was performed using HPC resources from GENCI-CINES (Grant No. 2019-A0060910369). 


\section{REFERENCES}

(1) Clearfield, A.; Demadis, K. Metal Phosphonate Chemistry: From Synthesis To Applications; RSC Publishing: Cambridge, UK, 2012.

(2) Weakley, T. J. R. Benzenephosphonic Acid. Acta Crystallogr., Sect. B 1976, $32,2889-2890$.

(3) Mahmoudkhani, A. H.; Langer, V. Phenylphosphonic acid as a building block for two-dimensional hydrogen-bonded supramolecular arrays. J. Mol. Struct. 2002, 609, $97-$ 108.

(4) Rao, K. P.; Vidyasagar, K. Syntheses, Structure and Intercalation Properties of Low-Dimensional Phenylphosphonates, $\mathrm{A}\left(\mathrm{HO}_{3} \mathrm{PC}_{6} \mathrm{H}_{5}\right)\left(\mathrm{H}_{2} \mathrm{O}_{3} \mathrm{PC}_{6} \mathrm{H}_{5}\right)\left(\mathrm{A}=\right.$ Alkali Metal, $\mathrm{NH}_{4}$ and Tl). Eur. J. Inorg. Chem. 2005, 4936-4943.

(5) Lin, Z.; Lei, X.-Q.; Bai, S.-D.; Ng, S. W. Ammonium benzenephosphonate. Acta Crystallogr., Sect. E 2008, 64, o1607.

(6) Yuge, T.; Kai, N.; Hisaki, I.; Miyata, M.; Norimitsu, T. Topologically Different Two Pseudo-decahedral Hydrogen-bond Networks Composed of Triphenylmethylammonium Phosphonates. Chem. Lett. 2007, 36, 1390-1391.

(7) Beckmann, J.; Dakternieks, D.; Duthie, A. Dimethylammonium phenylphosphonate-2(phenylphosphonic acid). Appl. Organomet. Chem. 2003, 17, 817-818.

(8) Sarr, M.; Boye, M. S.; Diasse-Sarr, A.; Grosjean, A.; Guionneau, P. Diisopropylammonium hydrogen phenylphosphonate. Acta Crystallogr., Sect. E 2012, 68, o3078.

(9) Diop, T.; Diop, L.; Maris, T.; Stoeckli-Evans, H. Dicyclohexylammonium hydrogen phenylphosphonate. Acta Crystallogr., Sect. E 2012, 68, o1432.

(10) Ferguson, G.; Glidewell, C.; Gregson, R. M.; Meehan, P. R. Chain, Sheet and Framework Structures in the Adducts of Phenylphosphonic Acid with 4,4'-Bipyridyl (1/1), Piperazine (2/1) and 1,4-Diazabicyclo[2.2.2]octane (2/1). Acta Crystallogr., Sect. B 1998, 54, 129-138.

(11) Fuller, J.; Heimer, N. E. Substituted imidazolium phenylphosphonate salts for nonlinear optical applications. J. Chem. Crystallogr. 1995, 25, 129-136.

(12) Abu-Salem, Q.; Sweidan, K.; Mallah, E.; Joshi, R.; Mubarak, M. S.; Steinmann, M.; Voelter, W. Hydrogen-Bonded Phosphorous Acids. Synthesis and Structure of Imidazolium-Containing Salts of Hydrogenphosphonate and Phenylphosphonate. Jordan J. Chem. 2011, 6, 113-121.

(13) Singh, U. P.; Kashyap, S.; Butcher, R. J.; Singh, H. J.; Mishra, B. K. Effect of electron donating substituents on supramolecular structure of salts having phenylphosphonic acid and pyrazoles. Struct. Chem. 2011, 22, 931-941.

(14) Singh, U. P.; Narang, S. A supramolecular approach towards the construction of molecular salts using phosphonic acid and pyrazole. CrystEngComm 2014, 16, 7777-7789.

(15) Weakley, T. J. R. The Crystal Structures of Guanidinium Phosphonate Acetone (1/1) and Guanidinium Phenylphosphonate - Water (1/2). J. Chem. Soc. Pak. 1980, $2,145-150$.

(16) Latham, K.; Downs, J. E.; Rix, C. J.; White, J. M. Interactions of guanidinium with benzene-sulphonic, -phosphonic and -arsonic acids and several of their nitro-derivatives. J. Mol. Struct. 2011, 987, 74-85.

(17) Gregson, R. M.; Glidewell, C.; Ferguson, G.; Lough, A. J. meso5,5,7,12,12,14-Hexamethyl-1,4,8,11-tetraazacyclotetradecane as a building block in supramolecular chemistry; salts formed with 2,2'-biphenol, 4,4'-biphenol, 4,4'-thiodiphenol, 4,4'-sulfonyldiphenol, 3- and 4-hydroxybenzoic acids, 3,5-dihydroxybenzoic acid and 
phenylphosphonic acid; supramolecular structures in zero, one, two and three dimensions. Acta Crystallogr., Sect. B 2000, 56, 39-57.

(18) Alter, C.; Neumann, B.; Stammler, H.-G.; Hoge, B. Bis(diethylamino)pentafluorophenylphosphane as Valuable Precursor for the Design of Tetrafluorophenylphosphanes, Tetrafluorophenylphosphinic and -phosphonic Acids. Eur. J. Inorg. Chem. 2018, 867-875.

(19) Panini, P.; Chopra, D. Understanding of Noncovalent Interactions Involving Organic Fluorine. Lect. Notes Chem. 2015, 87, 37-67.

(20) Russell, V. A.; Ward, M. D. Molecular Crystals with Dimensionally Controlled Hydrogen-Bonded Nanostructures. Chem. Mater. 1996, 8, 1654-1666.

(21) Dubey, R.; Pavan, M. S.; Desiraju, G. R. Structural landscape of benzoic acid: using experimental crystal structures of fluorobenzoic acids as a probe. Chem. Commun. 2012, 48, 9020-9022.

(22) Li, H.; Ratcliff, E. L.; Sigdel, A. K.; Giordano, A. J.; Marder, S. R.; Berry, J. J.; Brédas, J.-L. Modification of the Gallium-Doped Zinc Oxide Surface with Self-Assembled Monolayers of Phosphonic Acids: A Joint Theoretical and Experimental Study. Adv. Funct. Mater. 2014, 24, 3593-3603.

(23) Sang, L.; Mudalige, A.; Sigdel, A. K.; Giordano, A. J.; Marder, S. R.; Berry, J. J.; Pemberton, J. E. PM-IRRAS Determination of Molecular Orientation of Phosphonic Acid Self-Assembled Monolayers on Indium Zinc Oxide. Langmuir 2015, 31, 5603-5613.

(24) Patrick, C. R.; Prosser, G. S. A Molecular Complex of Benzene and Hexafluorobenzene. Nature 1960, 187, 1021.

(25) Meyer, E. A.; Castellano, R. K.; Diederich, F. Interactions with Aromatic Rings in Chemical and Biological Recognition. Angew. Chem. Int. Ed. 2003, 42, 1210-1250.

(26) Reichenbächer, K.; Süss, H. I.; Hulliger, J. Fluorine in crystal engineering-"the little atom that could". Chem. Soc. Rev. 2005, 34, 22-30.

(27) Salonen, L. M.; Ellermann, M.; Diederich, F. Aromatic Rings in Chemical and Biological Recognition: Energetics and Structures. Angew. Chem. Int. Ed. 2011, 50, 48084842 .

(28) Quiñonero, D.; Garau, C.; Rotger, C.; Frontera, A.; Ballester, P.; Costa, A.; Deyà, P. M. Anion- $\pi$ interactions: do they exist? Angew. Chem. Int. Ed. 2002, 41, 3389-3392.

(29) Schottel, B. L.; Chifotides, H. T.; Dunbar, K. R. Anion- $\pi$ interactions. Chem. Soc. Rev. 2008, 37, 68-83.

(30) Robertazzi, A.; Krull, F.; Knapp, E.-W.; Gamez, P. Recent advances in anion- $\pi$ interactions. CrystEngComm 2011, 13, 3293-3300.

(31) Gale, P. A.; Busschaert, N.; Haynes, C. J. E.; Karagiannidis, L. E.; Kirby, I. L. Anion receptor chemistry: highlights from 2011 and 2012. Chem. Soc. Rev. 2014, 43, $205-$ 241.

(32) Giese, M.; Albrecht, M.; Rissanen, K. Anion- $\pi$ Interactions with Fluoroarenes. Chem. Rev. 2015, 115, 8867-8895.

(33) Giese, M.; Albrecht, M.; Rissanen, K. Experimental investigation of anion- $\pi$ interactions - applications and biochemical relevance. Chem. Commun. 2016, 52, 1778-1795.

(34) Bauzá, A.; Mooibroek, T. J.; Frontera, A. Towards design strategies for anion$\pi$ interactions in crystal engineering. CrystEngComm 2016, 18, 10-23.

(35) Wang, H.; Wang, W.; Jin, W. J. $\sigma$-Hole Bond vs $\pi$-Hole Bond: A Comparison Based on Halogen Bond. Chem. Rev. 2016, 116, 5072-5104.

(36) Egli, M.; Sarkhel, S. Lone Pair-Aromatic Interactions: To Stabilize or Not to Stabilize. Acc. Chem. Res. 2007, 40, 197-205.

(37) Mooibroek, T. J.; Gamez, P.; Reedijk, J. Lone pair- $\pi$ interactions: a new supramolecular bond? CrystEngComm 2008, 10, 1501-1515. 
(38) Neel, A. J.; Hilton, M. J.; Sigman, M. S.; Toste, F. D. Exploiting non-covalent $\pi$ interactions for catalyst design. Nature 2017, 543, 637-646.

(39) Russell, V. A.; Etter, M. C.; Ward, M. D. Layered Materials by Molecular Design: Structural Enforcement by Hydrogen Bonding in Guanidinium Alkane- and Arenesulfonates. J. Am. Chem. Soc. 1994, 116, 1941-1952.

(40) Russell, V. A.; Etter, M. C.; Ward, M. D. Guanidinium Para-Substituted Benzenesulfonates: Competitive Hydrogen Bonding in Layered Structures and the Design of Nonlinear Optical Materials. Chem. Mater. 1994, 6, 1206-1217.

(41) Russell, V. A.; Ward, M. D. Solid-state structure of a layered hydrogen-bonded salt: guanidinium 5-benzoyl-4-hydroxy-2-methoxybenzenesulfonate methanol solvate. Acta Crystallogr., Sect. B 1996, 52, 209-214.

(42) Russell, V. A.; Ward, M. D. Two-dimensional hydrogen-bonded assemblies: the influence of sterics and competitive hydrogen bonding on the structures of guanidinium arenesulfonate networks. J. Mater. Chem. 1997, 7, 1123-1133.

(43) Burke, N. J.; Burrows, A. D.; Mahon, M. F.; Warren, J. E. Incorporation of dyes into hydrogen-bond networks: The structures and properties of guanidinium sulfonate derivatives containing ethyl orange and 4-aminoazobenzene-4'-sulfonate. Cryst. Growth Des. 2006, 6, 546-554.

(44) Horner, M. J.; Holman, K. T.; Ward, M. D. Lamellae-nanotube isomerism in hydrogen-bonded host frameworks. Angew. Chem. Int. Ed. 2001, 40, 4045-4048.

(45) Ward, M. D. Design of crystalline molecular networks with charge-assisted hydrogen bonds. Chem. Commun. 2005, 5838-5842.

(46) Horner, M. J.; Holman, K. T.; Ward, M. D. Architectural Diversity and Elastic Networks in Hydrogen-Bonded Host Frameworks: From Molecular Jaws to Cylinders. J. Am. Chem. Soc. 2007, 129, 14640-14660.

(47) It is worth noting that the proton conductivity of anhydrous $\mathbf{4}$ has just been reported. See: Alter, C.; Wiesemann, M.; Neumann, B.; Stammler, H.-G.; Hoge, B. Tetrafluoroaryl Phosphonic Acid Functionalized Polyphosphazenes - Synthesis, Characterization, and Evaluation of Proton Conductivity. Eur. J. Inorg. Chem. 2020, 44014408.

(48) Sopkova-de Oliveira Santos, J.; Montouillout, V.; Fayon, F.; Fernandez, C.; Delain-Bioton, L.; Villemin, D.; Jaffrès, P.-A. Assembly of benzene-1,3,5tris(methylenephosphonic acid) and guanidinium salt: Single crystal-X-ray characterization and ${ }^{31} \mathrm{P}$ solid state NMR investigations. New J. Chem. 2004, 28, 1244-1249.

(49) Plabst, M.; Stock, N.; Bein, T. Hydrogen-Bonded Networks of Ammonium Bis- and Tetrakisphosphonates-Synthesis, High-Throughput Screening and Structural Trends. Cryst. Growth Des. 2009, 9, 5049-5060.

(50) Maiti, B.; Schubert, A.; Sarkar, S.; Bhandari, S.; Wang, K.; Li, Z.; Geva, E.; Twieg, R. J.; Dunietz, B. D. Enhancing charge mobilities in organic semiconductors by selective fluorination: a design approach based on a quantum mechanical perspective. Chem. Sci. 2017, 8, 6947-6953.

(51) Maiti, B.; Wang, K.; Bhandari, S.; Bunge, S. D.; Twieg, R. J.; Dunietz, B. D. Enhancing charge mobilities in selectively fluorinated oligophenyl organic semiconductors: a design approach based on experimental and computational perspectives. J. Mater. Chem. C 2019, 7, 3881-3888.

(52) Cagardová, D.; Matúška, J.; Michalík, M.; Poliak, P.; Lukeš, V. Theoretical comparative study of promising semiconducting aromatic molecules and their fluorinated counterparts. Synth. Met. 2020, 260, 116263.

(53) Namestnikov, V. I.; Trishin, Yu. G.; Bel'skii, V. K. Synthesis of substituted 5,6,7,8-tetrafluoro-1,4-dihydrobenzo[e]-1,2,4-diazaphosphorin by the reaction of diethyl 
pentafluorophenylphosphonite with C-(p-nitrophenyl)-N-phenylnitrilimine. Russ. J. Gen. Chem. 1998, 68, 1334-1335.

(54) Burton, D. J.; Flynn, R. M. A Facile Synthesis of Trifluoromethane- and Pentafluorobenzenephosphonates. Synthesis 1979, 615.

(55) Nair, H. K.; Burton, D. J. Facile Synthesis of Fluorinated Phosphonates via Photochemical and Thermal Reactions. J. Am. Chem. Soc. 1997, 119, 9137-9143.

(56) Furin, G. G.; Terent'eva, T. V.; Rezvukhin, A. I.; Yakobson, G. G. Aromatic fluoro derivatives. XI. Polyfluorinated phenylphosphonium ions. Zh. Obshch. Khim. 1975, 45, 1473-1479.

(57) Furin, G. G.; Krupoder, S. A.; Rezvukhin, A. I.; Kilina, T. M.; Yakobson, G. G. Aromatic fluoroderivatives. XCV. The investigation of the behaviour of the polyfluoroaromatic compounds containing group VA elements in acid media. J. Fluorine Chem. 1983, 22, 345-375.

(58) Sheldrick, G. M. A short history of SHELX. Acta Crystallogr., Sect. A 2008, $64,112-122$.

(59) Altomare, A.; Cascarano, G.; Giacovazzo, C.; Guagliardi, A. Completion and Refinement of Crystal Structures with SIR92. J. Appl. Crystallogr. 1993, 26, 343-350.

(60) Sheldrick, G. M. Crystal structure refinement with SHELXL. Acta Crystallogr., Sect. C 2015, 71, 3-8.

(61) Spek, A. L. Single-crystal structure validation with the program PLATON. $J$. Appl. Crystallogr. 2003, 36, 7-13.

(62) Dolomanov, O. V.; Bourhis, L. J.; Gildea, R. J.; Howard, J. A. K.; Puschmann, H. OLEX2: a complete structure solution, refinement and analysis program. J. Appl. Crystallogr. 2009, 42, 339-341.

(63) Grimme, S.; Ehrlich, S.; Goerigk, L. Effect of the damping function in dispersion corrected density functional theory. J. Comput. Chem. 2011, 32, 1456-1465.

(64) Blöchl, P. E. Projector augmented-wave method. Phys. Rev. B 1994, 50, 17953-17979.

(65) Kresse, G.; Joubert, D. From ultrasoft pseudopotentials to the projector augmented-wave method. Phys. Rev. B 1999, 59, 1758-1775.

(66) Kresse, G.; Hafner, J. Ab initio molecular-dynamics simulation of the liquidmetal-amorphous-semiconductor transition in germanium. Phys. Rev. B 1994, 49, 1425114269.

(67) Kresse, G.; Furthmüller, J. Efficiency of ab-initio total energy calculations for metals and semiconductors using a plane-wave basis set. Comput. Mater. Sci. 1996, 6, 15-50.

(68) Akhmetova, I.; Beyer, S.; Schutjajew, K.; Tichter, T.; Wilke, M.; Prinz, C.; Martins, I. C. B.; Al-Sabbagh, D.; Roth, C.; Emmerling, F. Cadmium benzylphosphonates the close relationship between structure and properties. CrystEngComm 2019, 21, 5958-5964.

(69) Pavan, M. S.; Durga Prasad, K.; Guru Row, T. N. Halogen bonding in fluorine: experimental charge density study on intermolecular F $\cdots \mathrm{F}$ and $\mathrm{F} \cdots \mathrm{S}$ donor-acceptor contacts. Chem. Commun. 2013, 49, 7558-7560.

(70) Mukherjee, A.; Tothadi, S.; Desiraju, G. R. Halogen Bonds in Crystal Engineering: Like Hydrogen Bonds yet Different. Acc. Chem. Res. 2014, 47, 2514-2524.

(71) Yamamura, M.; Ikuma, S.; Nabeshima, T. Herringbone structures of 2,7dihalogenated acridine tailored by halogen-halogen interactions. J. Mol. Struct. 2015, 1093, 59-64.

(72) Prasanna, M. D.; Guru Row, T. N. C-halogen $\cdots \pi$ interactions and their influence on molecular conformation and crystal packing: a database study. Cryst. Eng. 2000, $3,135-154$. 
(73) Vasylyeva, V.; Merz, K. Crystal architecture of the low melting nitrogen heterocycles tetrafluoropyrimidine and trifluorotriazine. Z. Kristallogr. - Cryst. Mater. 2014, 229, 603-608.

(74) Shishkin, O. V.; Merz, K.; Vasylyeva, V.; Zubatyuk, R. I. Isotypic Transformation Principle in Molecular Crystals. Analysis of Supramolecular Architecture of Fluorinated Benzenes and Pyridines. Cryst. Growth Des. 2018, 18, 4445-4448.

(75) Eppel, S.; Fridman, N.; Frey, G. Amide-Templated Iodoplumbates: Extending Lead-Iodide Based Hybrid Semiconductors. Cryst. Growth Des. 2015, 15, 4363-4371.

(76) Das, D.; Banerjee, R.; Mondal, R.; Howard, J. A. K.; Boese, R.; Desiraju, G. R. Synthon evolution and unit cell evolution during crystallization. A study of symmetryindependent molecules ( $\left.\mathrm{Z}^{\prime}>1\right)$ in crystals of some hydroxy compounds. Chem. Commun. 2006, 555-557.

(77) Gdaniec, M. On the polymorphs of pentafluorophenol and its $2: 1$ co-crystal with pentafluoroaniline. CrystEngComm 2007, 9, 286-288.

(78) Kirchner, M. T.; Bläser, D.; Boese, R.; Desiraju, G. R. Additive induced polymorphism. The pentafluorophenol-pentafluoroaniline system. CrystEngComm 2009, 11, 229-231.

(79) Głowiak, T.; Szemik, A. W. Crystal structure and spectroscopic properties of glycinium monophenylphosphate. J. Crystallogr. Spectrosc. Res. 1986, 16, 79-89.

(80) Głowiak, T.; Wnęk, I. Crystal and molecular structure of glycinium diphenylphosphate. J. Crystallogr. Spectrosc. Res. 1985, 15, 157-171.

(81) Thulasidhass, R.; Mohana Rao, J. K. The crystal structure of Glycine orthophosphate. Curr. Sci. 1979, 48, 626-627.

(82) Averbuch-Pouchot, M. T.; Durif, A.; Guitel, J. C. Structures of Glycine Monophosphate and Glycine cyclo-Triphosphate. Acta Crystallogr., Sect. C 1988, 44, 99-102.

(83) Averbuch-Pouchot, M.-T. Structures of Glycinium Phosphite and Glycylglycinium Phosphite. Acta Crystallogr., Sect. C 1993, 49, 815-818.

(84) Baran, J.; Łukaszewicz, K.; Pietraszko, A.; Śledź, M. Structural investigations of the ferroelectric glycinium hydrogenphosphite (GPI) and its deuterated analogue (DGPI) I. X-ray diffraction studies of the crystal structure of paraelectric and ferroelectric phases. $J$. Mol. Struct. 2002, 611, 155-168.

(85) Shikanai, F.; Komukae, M.; Czapla, Z.; Osaka, T. Crystal Structure of $\mathrm{NH}_{3} \mathrm{CH}_{2} \mathrm{COOHH}_{2} \mathrm{PO}_{3}$ in the Ferroelectric Phase. J. Phys. Soc. Jpn. 2002, 71, 498-503.

(86) Lapshin, A. E.; Smolin, Yu. I.; Pankova, G. A. Crystal structure of glycine phosphite $\mathrm{C}_{2} \mathrm{H}_{5} \mathrm{NO}_{2} \cdot \mathrm{H}_{3} \mathrm{PO}_{3}$. J. Struct. Chem. 2005, 46, 315-319.

(87) Duarte Rodrigues, A.; Fahsi, K.; Dumail, X.; Masquelez, N.; van der Lee, A.; Mallet-Ladeira, S.; Sibille, R.; Filhol, J.-S.; Dutremez, S. G. Joint Experimental and Computational Investigation of the Flexibility of a Diacetylene-Based Mixed-Linker MOF: Revealing the Existence of Two Low-Temperature Phase Transitions and the Presence of Colossal Positive and Giant Negative Thermal Expansions. Chem. Eur. J. 2018, 24, 15861605.

(88) Parr, R. G.; Yang, W. Density Functional Approach to the Frontier-Electron Theory of Chemical Reactivity. J. Am. Chem. Soc. 1984, 106, 4049-4050.

(89) Filhol, J.-S.; Doublet, M.-L. Conceptual Surface Electrochemistry and New Redox Descriptors. J. Phys. Chem. C 2014, 118, 19023-19031. 


\section{LEGENDS}

Scheme 1. Synthesis of pentafluorophenylphosphonic acid (4).

Scheme 2. Molecular orbital diagram showing the interactions between $\mathrm{C}_{6} \mathrm{~F}_{5} \mathrm{PO}_{3} \mathrm{H}^{-}$and $\mathrm{C}_{6} \mathrm{~F}_{5} \mathrm{PO}_{3} \mathrm{H}_{2}$ fragments.

Figure 1. Unit cell of 4.4. $\mathrm{H}_{2} \mathrm{O}$ viewed along $a$ showing a bilayer stacking motif.

Figure 2. View along $a$ of $\mathbf{4 . 4}^{-} . \mathbf{H}_{3} \mathrm{O}^{+}$showing a bilayer stacking motif.

Figure 3. View of anhydrous $\mathrm{C}_{6} \mathrm{~F}_{5} \mathrm{PO}_{3} \mathrm{H}_{2}$ along $a$ showing a layered $\mathrm{A}-\mathrm{B}-\mathrm{A}-\mathrm{B}$ arrangement. ${ }^{18}$

Figure 4. View along $a$ showing the single-layer stacking motif present in $\mathrm{C}_{6} \mathrm{H}_{5} \mathrm{PO}_{3} \mathrm{H}_{2}{ }^{3}$

Figure 5. View along $a$ of $\mathbf{4 . 4}^{-} \cdot \mathbf{N H}_{4}{ }^{+}$showing a bilayer stacking motif.

Figure 6. View along $c$ of $\mathbf{4}^{-}$.DMA ${ }^{+}$showing a single-layer stacking motif.

Figure 7. View along $a$ of $\mathbf{4}^{-} . \mathbf{D M A} \mathbf{A}^{+} \cdot \mathbf{H}_{2} \mathbf{O}$ showing a single-layer stacking motif.

Figure 8. View along $b$ of $\mathbf{4 . 4}^{-}$.DMA ${ }^{+}$showing a single-layer stacking motif.

Figure 9. View along $c$ of $\mathbf{4}^{-}$.DMA ${ }^{+} . \mathbf{N H}_{4}{ }^{+}$showing a single-layer stacking motif.

Figure 10. View along $b$ of $\mathbf{4}^{-}$.Gly ${ }^{+}$showing a single-layer stacking motif.

Figure 11. Organization of the $\mathrm{C}_{6} \mathrm{~F}_{5}$ moieties in the computed $\mathrm{H}_{2} \mathrm{O}$ (A) and $\mathrm{H}_{3} \mathrm{O}^{+}$(B) polymorphs. Rows of $\mathrm{C}_{6} \mathrm{~F}_{5}$ moieties with a same orientation are colored in blue or yellow.

Figure 12. Charge density variation upon ionization of half of the $\mathrm{C}_{6} \mathrm{~F}_{5} \mathrm{PO}_{3} \mathrm{H}_{2}$ entities into $\mathrm{C}_{6} \mathrm{~F}_{5} \mathrm{PO}_{3} \mathrm{H}^{-}$and $\mathrm{H}_{3} \mathrm{O}^{+}$. Top line: transformation of the experimental $\mathbf{H}_{2} \mathbf{O}$ phase into $\mathrm{H}_{3} \mathrm{O}^{+}$(hypo.). Bottom line: ionization of $\mathrm{H}_{2} \mathrm{O}$ (hypo.) into the experimental $\mathrm{H}_{3} \mathrm{O}^{+}$phase. Left 
column: yellow isosurfaces show the localization of electron deficient areas. Right column: blue isosurfaces reproduce an increase in electron density. Ionization induces the formation of intermolecular bonds that generate either a dimer (red ellipse) or a polymer (red wavy line). 
SUBJECTS: Pentafluorophenylphosphonic acid, Molecular crystal, Crystal structure, 2D layered arrangement, Polymorphism, DFT-D3 calculations 
For Table of Contents Use Only

\section{Pentafluorophenylphosphonic Acid as a New Building Block for Molecular Crystal Fabrication}

Sylvain G. Dutremez,* Xavier Dumail, Sonia Mallet-Ladeira, Arie van der Lee, Dominique Granier, Nathalie Masquelez, and Jean-Sébastien Filhol

\section{Graphic}
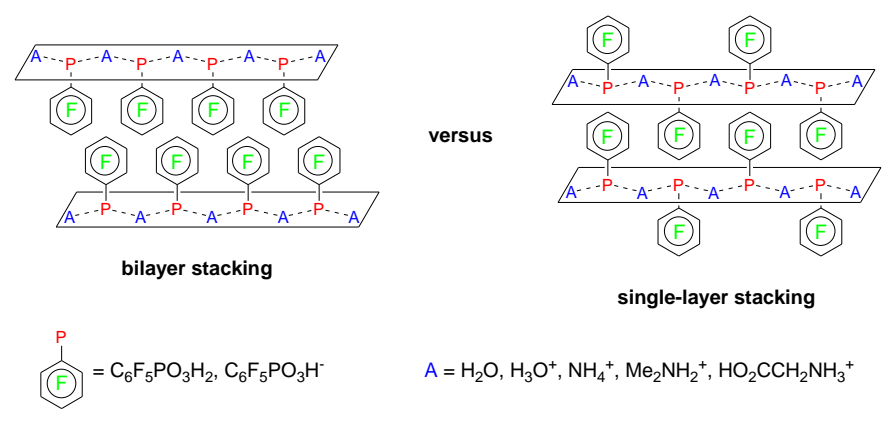

$\mathrm{A}=\mathrm{H}_{2} \mathrm{O}, \mathrm{H}_{3} \mathrm{O}^{+}, \mathrm{NH}_{4}^{+}, \mathrm{Me}_{2} \mathrm{NH}_{2}^{+}, \mathrm{HO}_{2} \mathrm{CCH}_{2} \mathrm{NH}_{3}^{+}$

\section{Synopsis}

Molecular crystals have been prepared from pentafluorophenylphosphonic acid and characterized by single-crystal X-ray diffraction and computational methods. All of these assemblies crystallize with a 2D layered arrangement. As in the case of guanidinium sulfonates, two structural types have been recognized depending on the size of the included species, a single-layer stacking motif and a bilayer stacking motif. 